\title{
THE JUST ALLOCATION OF CLIMATE BURDENS
}

\author{
by
}

\section{Ewan Kingston}

A thesis submitted to the Victoria University of Wellington in fulfilment of the requirements for the degree of Master of Arts in Philosophy

Victoria University of Wellington 
The Just Allocation of Climate Burdens

(C) Ewan Kingston 2012. All rights reserved 


\section{Acknowledgements}

I could not have completed this thesis without help coming from many quarters. Ramon Das provided a wealth of insight and expertise and a contagious enthusiasm for philosophy and international affairs. Simon Keller deserves thanks for his helpful suggestions and critical feedback, and for organising a very rewarding Workshop on Climate Change and Philosophy. I wish to thank the attendees of that workshop, as well as fellow students at Victoria University of Wellington who gave critical comments and worthwhile suggestions on my work. I especially want to thank Steven Riley for sharing his encyclopaedic knowledge of political philosophy and Dan Weijers for his generous engagement, as well as John Mathewson, David Gilbert and Felice Marshall. Luc Bovens, Darrel Moellendorf and Axel Gosseries went well beyond the call of duty in responding to my queries about their work. David Frame, Jonathon Boston and Ralph Chapman kindly shared their extensive expertise with this student from outside their disciplines. Tikitu De Jager and Helen Kingston devoted themselves to proofreading with great results. I wish to thank Sam Gleisner, Sophie Cradwick, Lisa Cunnigham and Daniel Simpson-Beck for their friendship and practical support. Finally I acknowledge from my heart the kind and patient support given to me by Lillian Fougere and by Helen, Derry and Jenni Kingston over the past year. 
The Just Allocation of Climate Burdens 


\section{Abstract}

Human-induced climate change threatens the lives and livelihoods of vulnerable people. Preventing the worst effects of climate change and compensating those who will suffer are tasks that should be taken up by individuals, firms and states, tasks that constitute a burden. In this thesis I suggest the use of particular principles for justly allocating this "climate burden". I first defend my use of an orthodox ethical approach from Dale Jamieson's challenge that the ethics of climate change must be revisionary. I also reply to Luc Bovens' Lockean argument that a history of high emitting justifies giving past polluters more rights to emit. Then, I propose a two-track theory under which the climate burden is divided in two. These two different parts are allocated by a contribution-based "polluter pays" principle and by an "ability to pay" principle. The "fault burden" is the burden from greenhouse gas emissions produced since it became reasonable to suppose that such emissions were harmful, except for the emissions from the very poor, which are not included. The fault burden should be allocated to those who have contributed to it, in proportion to their contribution. The "no fault burden" is the remaining portion. The no-fault burden should be allocated by an "ability to pay" principle which requires all parties (except for the very poor) to shoulder burdens that constitute an equal drop in whatever goods we deem most relevant. Finally I defend the two track theory from the claim that a "beneficiary pays" principle better allocates the burden caused by past emissions. 


\section{CONTENTS}

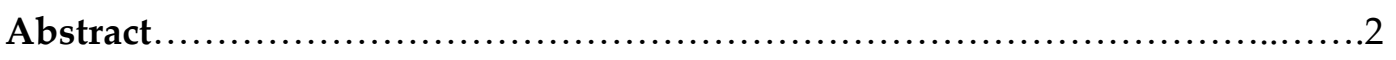

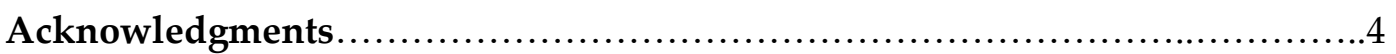

\section{Chapter 1 - Introduction}

1.1 Context_____ 7

1.2 The Just Allocation of Climate Burdens__ 13

\section{Chapter 2 - Must Climate Ethics Be Revisionary?}

2.1 Orthodoxy or Revisionism?_____ 17

2.2 Jamieson's Argument____ 19

2.2.1 Moral Responsibility?......................................................20

2.2.2 Political Responsibility?....................................................24

2.3 A Reply to Jamieson's Argument____ 27

2.3.1 Principles of Burden Sharing.......................................27

2.3.2 Delineating Groups........................................................29

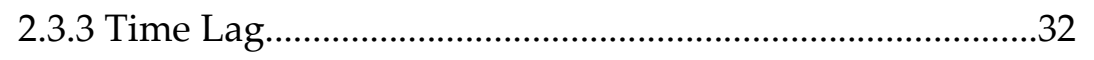

2.3.4 Complexity of Cause.............................................................35

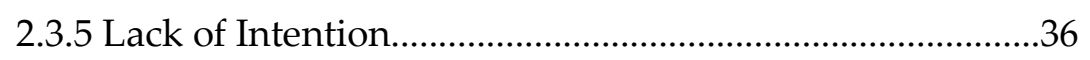

2.3.6 Non-existent Harm?..............................................................37

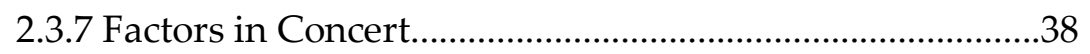

2.4 Towards Orthodoxy___ 40

2.5 Conclusion____ 42

\section{Chapter 3 - Against Grandfathering Emissions Rights}

3.1. The Argument for Grandfathering

3.1.1 Grandfathering..................................................................43

3.1.2 Bovens' Argument...............................................................

3.1.3 Lockean Emissions Rights? ..................................................48

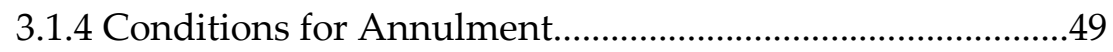

3.2 Challenging the Lockean Approach____ 53

3.2.1 A Worry from Climate Scientists.............................................53

3.2.2. Worries from Contractarians and Welfarists........................54

3.2.3 Worries for Pluralists and Libertarians...................................57

3.3 The Internal Critique Reconsidered 58 


\section{Chapter 4 - The Two-Track Theory and its Application}

4.1 Theory 64

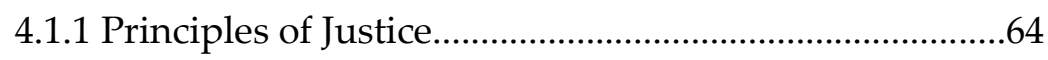

4.1.2 Polluter Pays.......................................................................66

4.1.3 Historical Emissions and Excusable Ignorance..............67

4.1.4 When Should Polluter Pays Start to Apply?....................73

4.1.5 Further Exemptions - Poverty-Related Emissions.........78

4.1.6 Ability to Pay.......................................................................81

4.2 Application 86

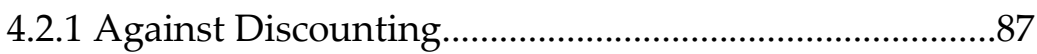

4.2.2 Emissions Allocation - Equal Per Capita?.......................89

4.2.3 Which Agent?...............................................................91

4.2.4 An Alternative Practical Framework...............................93

4.3 Conclusion 95

\section{Chapter 5 - Beneficiary Pays?}

5.1. The "Beneficiary Pays" idea 96

5.2 Which Principle? 98

5.2.1 BIP - Benefitting from injustice...........................................98

5.2.2 Against BIP in Application to Climate Harms.................100

5.2.3 Bell's Framework..........................................................101

5.2.4 An Unjust Distribution?.................................................104

5.3 BHP - Benefitting from Harm___ 108

5.3.1 Against the BHP Principle.................................................108

5.3.2 Gosseries' Argument and a Reply.....................................110

5.4 Postscript: The Limited Responsibility of Beneficiaries____ 112

Chapter 6 - Conclusion 115 


\section{1 \\ Introduction}

Climate change...is simply the greatest collective challenge we face as a human family. - UN Secretary General Ban-Ki Moon (2009: line 42).

\subsection{CONTEXT}

We are changing the world's climate, ${ }^{1}$ and very many people will be affected. Extreme weather events, the decrease in arctic sea ice, ocean acidification, flooding from early snowmelt, changes to the natural ranges and growing seasons of many species and a rise in average sea level of $2 \mathrm{~mm}$ per year have all been linked to the rise in temperature of $0.7^{\circ} \mathrm{C}$ since the pre-industrial era (Solomon et al. 2007: 36, 48; Parry et al. 2007: 28). While the last report of the Intergovernmental Panel on

\footnotetext{
${ }^{1} \mathrm{I}$ am assuming that most of the climate change that is occurring is due to human activity. This assumption is well supported by the position of the Intergovernmental Panel on Climate Change (Solomon et al. 2007) and the opinion of the vast majority of climate experts. A survey by Peter Doran and Maggie Kendall-Zimmerman found $82 \%$ of earth scientists responding were in agreement with the statement that "human activity is a significant contributing factor in changing mean global temperatures" (Doran \& Kendall-Zimmerman 2009: 22-23). This number rose to $97.4 \%$ when the sample was restricted specifically to climate experts. The authors of the survey conclude that "the debate on the authenticity of global warming and the role played by human activity is largely non-existent among those who understand the nuances and scientific basis of long-term climate processes" (Doran \& Kendall-Zimmerman 2009: 23).
} 
Climate Change (IPCC) considered the current effect of climate change on human health to be "small" (Parry et al. 2007: 43), other studies suggest that the death toll from climate change is currently hundreds of thousands each year, particularly due to the increased range of malaria-bearing mosquitoes (McMichael et al. 2005). ${ }^{2}$

Whatever the effects of climate change are now, they are likely to be much more severe in the future, with the IPCC projecting that unmitigated climate change would cause widespread negative impacts on almost every feature of the natural world we rely on: freshwater systems, food, fibre and wood production, ecosystems, and sea level (Parry et al. 2007: 35-47). Nicholas Stern (2007: 139) predicts unchecked climate change would cause annual damages equal to several percent of world GDP by 2100.

Worst-case scenarios have reinforcing feedbacks (such as the release of methane from melting permafrost or the seafloor, the drying and burning of rainforests, or reduction in the shininess of the earth due to melting ice) pushing the world into "runaway" climate change where these natural warming factors add to the effect of anthropogenic greenhouse gases (Hansen et al. 2007) and cause global temperatures to rise by even more than the IPCC's upper bound of $6.4^{\circ} \mathrm{C}$ by 2100 (Parry et al. 2007: 70). Because of the possibility of such feedbacks, catastrophic climate change, causing warming of $10^{\circ} \mathrm{C}$ or even up to $20^{\circ} \mathrm{C}$, cannot be ruled out (Weitzman 2009). A temperature rise above $10^{\circ} \mathrm{C}$ would probably result in the melting of Antarctica (Weitzman 2009), which would raise sea levels by 70 metres (Poore et al. 2000). A temperature rise above $12^{\circ} \mathrm{C}$ would render the regions that are home to most of the world's people uninhabitable due to mammalian inability

\footnotetext{
2 The World Health Organization estimates that 166000 people die per year due to the contribution of human-induced climate change on malaria, diarrhoea and malnutrition and cardiovascular disease (McMichael et al. 2005: 1606). The Global Humanitarian Foundation puts the death toll at 315000 per year, with 300 million having their livelihoods "compromised temporarily or permanently by climate change" (Global Humanitarian Forum 2009: 9).
} 
to tolerate wet-bulb temperatures (temperatures adjusted for the cooling effect of evaporation) above 35 degrees (Sherwood and Huber 2010).

Even if the temperature rise from climate change is restricted to the $1.1-6.4^{\circ} \mathrm{C}$ range by 2100, the victims of climate change will be huge numbers of the world's most vulnerable people. Not only do the severely poor lack the resources to cope with the increased threats to their lives and livelihoods from climate change, but regions that will be strongly affected (Sub-Saharan Africa, South and Southeast Asia, Latin America, small island states) contain high proportions of very poor people (Global Humanitarian Forum (GHF) 2009: 15). Climate change presents us with three distinct tasks or duties (Caney 2009a). Some climate change should be dealt with by mitigation: restricting greenhouse gas emissions and possibly removing greenhouse gases from the atmosphere. What climate change cannot be prevented should be met with adaptation: increasing communities' resilience in vulnerable areas and, where necessary, assisting migration. Finally, those who suffer harms from climate change may need to receive compensation from the parties responsible. Determining the appropriate mix of adaptation, mitigation and compensation is beyond the scope of this thesis (although I argue in Chapter Four that we cannot discharge our duties by bearing just the compensation task). In this thesis I only assume that some mitigation must be undertaken. The combined tasks of preventing the worst effects of climate change through mitigation and adaptation, along with compensating those who suffer nonetheless, is what I will call "the climate burden".

For the most part, countries agree that much of the climate burden needs to be shouldered by us now. Representatives of 193 countries meeting at the $15^{\text {th }}$ Conference of Parties (COP-15) to the United Nations Framework Convention on Climate Change (UNFCCC) recognised a shared goal to "stabilize greenhouse gas concentration in the atmosphere at a level that would prevent dangerous anthropogenic interference with the climate system... recognizing the scientific 
view that the increase in global temperature should be below 2 degrees Celsius"3 (UNFCCC 2009). The Green Climate Fund was proposed at the same meeting, with rich countries pledging 100 billion US dollars per year ${ }^{4}$ to poorer countries for climate change adaptation and mitigation (UNFCCC 2009). Against this background of agreement about the need for us collectively to shoulder the climate burden now, a thorny question arises: who in particular should bear how much of the burden?

The first agreement on climate change stated that different countries should protect the climate system "on the basis of equity and in accordance with their common but differentiated responsibilities and respective capabilities", a principle that has been emphasised many times since (UNFCCC 1992: Article 3.2; 2009: principle 1). Yet what this principle must mean in practice is not clear, especially as rapidly developing countries are in the process of increasing both their responsibility for the climate burden and their capability to bear it. The aforementioned summit in Copenhagen was widely seen as a vital chance to solve the political problem of climate change, ${ }^{5}$ but fell short of a solution. Countries made pledges of emissions reductions that were thoroughly insufficient to meet the goal of restricting warming to 2 degrees (United Nations Environment Program 2011: 8), and failed to agree on a legal instrument to replace the Kyoto Protocol which might hold countries to their pledges. Two years later, the main outcome of the Seventeenth Conference of Parties (COP-17) in Durban was

\footnotetext{
${ }^{3}$ The text is ambiguous as to whether the permitted 2 degrees rise is to be measured against current temperatures or pre-industrial temperatures. The latter would mean the goal is limiting the rise to a much more demanding 1.3 degrees above current temperatures. Boston (2011) argues that even 2 degrees of warming above pre-industrial temperatures is likely to constitute dangerous anthropogenic climate change.

${ }^{4}$ For comparison, the OECD spent around 130 billion USD in 2010 on development aid. (OECD 2011)

${ }^{5} \mathrm{Ban} \mathrm{Ki}$ Moon referred to Copenhagen as a "once in a generation chance... to put in place a climate change agreement that all nations can embrace" (Ki-moon, 2009). For a typical example of the media's focus on such an event see Ferguson (2009).
} 
essentially to delay a decision on how the climate burden should be borne until 2020 (UNFCCC 2011b).

Representatives of rapidly developing countries such as China and India have stated that their countries are doing more than their fair share. At COP-17, Indian Minister of Environment Affairs Jayanthi Natarajan said: “We have shown more flexibility than virtually any other country. The centrepiece of a climate change agreement is and has to be equity, and the equity of burden-sharing cannot be shifted... Does climate change mean you give up on equity?" (Natarajan 2011: 21:59). The Chinese delegate Xie Zhenhua made a similar appeal to equity: "We should look at not what is said but what is done. Some countries have made commitments but are not meeting them. We are doing whatever we should do. We are doing things you are not doing....we are taking actions. We want to see your actions" (Xie 2011: 49:00). On the other hand, Todd Stern, Chief Climate Negotiator for the USA, sees the current regime as too lenient on rapidly growing emitters:

For the past 20 years, there has been a kind of firewall between developed and developing countries, most vividly embodied by the Kyoto Protocol, where all real obligations for reducing emissions apply to developed countries. If that ever made sense, it sure doesn't make sense now at a time when China is already far larger than the United States in emissions and will be more than twice our size in this decade, and where nearly all the global growth in emissions going forward will come from developing countries (T. Stern 2011: para. 3).

The position of any country in international negotiations is influenced (to a varying extent) by the beliefs of that country's citizens. And many citizens of rich countries believe that the kinds of domestic institutions which are necessary for their country to tackle the climate tasks are unfair. When a carbon tax was proposed in Australia, it met with vehement opposition, with 58\% of people 
polled opposing the tax, and only 34\% supporting (Benson 2011). In New Zealand, proposals that would see farmers bear some of the cost of their substantial greenhouse gas emissions are highly controversial (BBC News 2003). Corporations, too, appeal to the unfairness of burden-sharing. For example, in July 2011 a coalition of US airlines (unsuccessfully) sued the EU over its scheme to pass some of the costs of aviation emissions on to airlines flying to and from Europe (Harrison 2011).

A consequence of the controversy about who should bear the burdens is that little progress has been made towards undertaking the climate tasks. One analysis shows that even if countries stick to their pledged emissions of greenhouse gases, the world still faces a warming of $3.5^{\circ} \mathrm{C}$ above pre-industrial levels (Höhne et al. 2011). The Montreal Protocol, intended primarily to halt the destruction of the ozone layer, has had a "side effect" of reducing the greenhouse effect possibly five times greater than the agreement intended to reduce the greenhouse effect: the Kyoto Protocol (Karoly 2011: 20:36). As far as adaptation and compensation goes, the money that was pledged at Copenhagen to developing countries has been only slowly forthcoming and has often taken the form of existing aid repackaged as climate assistance (Cuming 2011).

Philosophers may have been slow to turn to questions of climate justice, ${ }^{6}$ but recently the subject has been gaining more attention. In 2011 alone an edited book (Arnold 2011) and two journal special issues ${ }^{7}$ were devoted to the ethics of climate change. Denis Arnold has suggested that we are now seeing the "second generation" of literature on climate ethics (Arnold 2011: 1), in which the claims of

\footnotetext{
'In 2004 Stephen Gardiner's review found that "very few moral philosophers have written on climate change" (Gardiner 2004: 555). Notable exceptions were Shue (1993, 1999), Traxler (2002), Singer (2004) and Broome (1992).

7These were the Critical Review of International Social and Political Philosophy 14 (2) "Special issue: Climate Change and Liberal Priorities", and The Monist, 94(3) "Morality and Climate Change". The Royal Institute of Philosophy Supplement, Vol. 69 "Ethics and the Environment" was also dominated by papers on climate change.
} 
first-generation literature are engaged with and responded to. We are starting to see detailed exploration of nuanced questions, including whether the individual actions that contribute to climate change are morally wrong (Hiller 2011; Nolt 2011; Sinnott-Armstrong 2010), whether trading emissions permits is morally permissible (Caney and Hepburn 2011; Page 2011b), and the appropriate level of warming we should aim to prevent (R. Miller 2010: 109-15).

The question I want to address in this thesis, central to the main conflict in the political sphere, is: who should bear what portion of the climate burden?

\subsection{THE JUST ALLOCATION OF CLIMATE BURDENS}

In this thesis I develop a two-track approach to dealing with the burdens of climate change, involving a "polluter pays" principle and an "ability to pay" principle. Because I approach the question of allocation as a problem of applied ethics I must face the challenge that climate change is too far removed from paradigm ethical problems to be dealt with using only orthodox ethical concepts. This idea has been best articulated by Dale Jamieson (2010). In Chapter Two I respond to his argument that the responsibility to bear the climate change burden is highly irregular and thus cannot be understood without accepting a duty of respect for nature. In response I argue that, while climate change involves several special features (such as a complex causal pathway, a time lag between cause and harm, and a diverse group of perpetrators) they are not enough, neither alone nor in concert, to render climate change significantly non-paradigm. In fact, principles of justice play a key role in apportioning orthodox moral responsibility among the diverse range of possible duty bearers.

I assume that the principles that determine the just allocation of climate burdens need not be limited to allocating burdens among countries. Individuals and 
corporations have great influence on the eventual positions of states, and these parties appeal to claims about justice when they are asked to bear a portion of the climate burden. Furthermore, for some particular climate tasks or sub-tasks (such as the restriction of greenhouse gas emissions), applying the principles at the level of the corporation may be the most effective. For this reason, I will depart from much philosophical work (a notable exception is the work of Simon Caney (2005, 2009b, 2010, 2011)), and consider the just allocation problem as potentially applying to many different types of actor - including firms, individuals or countries. I will use the catch-all term 'party' to refer to such potential bearers of burdens.

The primary principle I propose for distributing the climate burden amongst parties is a "polluter pays" principle, by which emitters should bear the burdens of their own emitting (unless they are very poor). Opposing such a principle is the idea that we should "grandfather" emissions rights. This would mean that past heavy polluters should bear burdens in less than direct proportion to their current emissions. Luc Bovens suggests that we should apply a moderate kind of grandfathering on moral grounds, because past emitters have acquired rights to emit through historical appropriation. I argue that the kind of Lockean argument Bovens makes may be inappropriate to apply to the novel case of distribution of rights to emit greenhouse gases. Even if it is appropriate, the long-standing violation of the Lockean proviso and the Lockean no-waste condition should, by Bovens' own lights, annihilate such rights.

Chapter Four develops the two-track approach I advocate. An important step, I argue, is the separation of what I term the "fault" portion of the climate burden (which should be subject to a "polluter pays" principle) from the "no-fault" portion (which should be subject to an "ability to pay" principle). Part of the nofault burden comes from past emissions produced under ignorance of their harmful effects. The other part of the no-fault burden comes from the emissions 
produced by the global poor, who are unable to bear the burdens of their own emissions without suffering harm of a similar scale to that which the climate tasks are intended to prevent. The no-fault burden is significant, forming roughly half the total climate burden. I argue that it should be allocated by an "ability to pay" principle, which asks parties, except those suffering from severe poverty, to each bear a similar burden. Due to parties' different ability to pay, this will translate to burdens that are roughly proportionate to such ability. At the end of Chapter Four I argue against equal per capita emissions rights as a way of implementing the "polluter pays" principle, and turn to an alternative, auction-based scheme for applying the two-track approach.

The idea that those who have benefitted from climate change should pay for its effects is the main alternative to using an ability to pay principle to allocate the nofault burden. I turn to the two forms this idea can take in Chapter Five, and argue that, whichever form it takes, it is inferior to the ability-based principle for allocating the no-fault burden. In its most plausible form, it states that the beneficiaries of injustice have a special responsibility to the victims of the injustice, but this form, I argue, is inapplicable to climate change (because no injustice created the no-fault burden). If, on the other hand, those who have benefitted from merely harmful activity should pay, this would place duties on the current beneficiaries of past emissions, but this seems to be an implausible form of the "beneficiary pays" principle and I develop counterexamples to it. Finally, I describe some special circumstances under which the idea that beneficiaries of harmful activity should pay may be applicable.

Allocating the burden of climate change justly is a difficult problem, but it is solvable without positing unconventional duties such as a duty of respect for nature. Especially important is the recognition of two very different portions of the burden - the fault and the no-fault portions. A contribution-based principle 
should allocate the fault burden, and an ability-based principle the no-fault burden. 


\section{2}

\section{Must Climate Ethics Be Revisionary?}

Yes, global warming is bad, but it doesn't make us feel nauseated or angry or disgraced, and thus we don't feel compelled to rail against it as we do against other momentous threats to our species, such as flag burning. The fact is that if climate change were caused by gay sex, or by the practice of eating kittens, millions of protesters would be massing in the streets - Daniel Gilbert (2006: para. 15)

\subsection{ORTHODOXY OR REVISIONISM?}

This thesis makes use of orthodox methods. It uses familiar ethical tools, including concepts of responsibilities, rights, interests, harms, and theories of distributive justice, to analyse a problem related to global climate change. Further, it is anthropocentric; it treats these concepts and theories as applying to humans, and does not posit any special duties or responsibilities toward nature directly. 
There are those who believe that particular features of climate change mean that conventional ethical theories are ill-equipped to deal with climate-related problems, and that our ethical concepts may need to be revised. Let us call this belief the "irregularity thesis". Support for it comes most obviously from those committed to bio-centrism (the view that all life is morally considerable) or ecocentrism (the view that ecosystems or the earth itself are morally valuable). From such nature-centred views, one could argue that, because climate change will have even greater impacts on non-human animals and ecosystems than it will on humans, a focus on the harms to or rights of humans will skew our ethical reasoning. ${ }^{8}$ I will not attempt a rebuttal of such views here; this thesis will simply assume an anthropocentric perspective. Nonetheless, those convinced by naturecentric views and their importance in the question of allocation of climate burdens may still find this work valuable. Given that many figures in the current political debate also take an anthropocentric view, nature-centred thinkers may well wish to accept initial anthropocentric moves for the sake of argument, in order to explore broadly acceptable conclusions about the nature of responsibilities or duties of particular parties. ${ }^{9}$

Aside from the standpoint of nature-centrism, there are at least two other arguments put forth for treating climate ethics as highly unorthodox. One I will call the "modern complexity thesis", and deal with only briefly. Robin Attfield affirms the modern complexity thesis, claiming that the "scope and content of ethics" must be "reconceived" because widespread industrialisation and globalisation has "significantly changed the range of foreseeable impacts of human actions and policies" (Attfield 2009: 225; see also Parfit 1984: 86 for a similar point). Rather than a genuine argument for the insufficiency of

\footnotetext{
${ }^{8}$ But see Palmer (2011) for the complications involved with this view.

${ }_{9}^{9}$ Perhaps, as Bryan Norton (1994) suggests, the practical conclusions recommended in this case will be similar no matter what view of the moral standing of non-humans one takes. See Norton (1994), especially Chapter 10. See also Palmer (2011).
} 
conventional morality for addressing inherently modern problems, the modern complexity argument seems to be no more than an account of how such insufficiency could come about. It is true that conventional moral theories were for the most part developed during a time when the range of an act or policy's foreseeable impacts were predominantly local, but this does not entail that the theories must be insufficient to deal with the more extensive impacts of actions (such as emitting greenhouse gases) that we see today.

There is a more formidable way in which an argument for the irregularity thesis could progress. It could argue for a set of paradigm cases that our ethical concepts apply to, and show how climate change differs significantly from such cases in ways that make it impossible or very difficult for the concepts to apply without revision. If climate change does differ in such ways then we have reason to believe that orthodox ethical theory is under-powered and inappropriate when it comes to explaining our duties with regard to climate change.

\subsection{JAMIESON'S ARGUMENT}

Dale Jamieson (2010; 2007) makes such an argument. He claims that our responsibility to act on climate change cannot be adequately explained in purely prudential, moral or political terms, and this exhausts the way standard moral theories can account for such responsibility. ${ }^{10}$ Jamieson's conclusion is not that our collective responsibility to deal with climate change is weak or non-urgent, but rather that this responsibility arises from a duty (compatible with

\footnotetext{
${ }^{10}$ Although Jamieson says little to define responsibility, he does say something to characterise it. By practical responsibility, Jamieson refers to what we are "responsible for doing". I might have a responsibility to get to work on time, or to call my girlfriend, or to donate to an earthquake appeal. Practical responsibility can be plural: "one act can discharge multiple responsibilities" (2010: 433) and layered: "agents can have practical responsibilities at the different levels of social organization at which they are causally efficacious" (2010: 433).
} 
anthropocentrism) of respect for nature. Jamieson makes a tripartite classification of responsibility into moral, political and prudential responsibility. For Jamieson, prudential responsibility "centres on responsibilities one has to oneself" (Jamieson 2010: 432 $)^{11}$. In its paradigm case, it involves a single agent acting on the basis of her own self-interest. Ethical responsibility, comprised of "moral" and "political" responsibility, concerns our responsibilities to others (433). I will not say much about Jamieson's claim that climate change offers us a non-paradigm case of prudential responsibility, since discharging our duties to ourselves is not the main goal of a just allocation of climate burdens. Rather I will present Jamieson's arguments that climate change strays significantly from conventional standards of moral and political responsibility. I then reply to these arguments in Section 2.3.

\subsubsection{Moral Responsibility?}

According to Jamieson one of the central ways in which an agent acquires moral responsibility is by directly causing identifiable, intentional harm locally. An example of this is an agent "Jack" stealing a bicycle from a victim "Jill", which Jamieson calls "Example 1" (436). We can imagine a case differing from the paradigm case of Example 1 along one or more relevant dimensions. Jamieson writes:

Consider some further examples. In Example 2, Jack is part of an unacquainted group of strangers, each of which, acting independently, takes one part of Jill's bike, resulting in the bike's disappearance. In Example 3, Jack takes one part from each of a large number of bikes, one of which belongs to Jill. In Example 4, Jack and Jill live on different continents, and the loss of Jill's bike is the consequence of a causal chain that begins with Jack ordering a used bike at a shop. In Example 5,

\footnotetext{
${ }^{11}$ Direct quotes from this work will be referred to solely by page number for the rest of this chapter.
} 
Jack lives many centuries before Jill, and consumes materials that are essential to bike manufacturing; as a result, it will not be possible for Jill to have a bicycle. While it may still seem that moral considerations are at stake in each of these cases, this is less clear than in Example 1, the paradigm case with which we began. The view that morality is involved is weaker still, perhaps disappearing altogether for some people, if we vary the case on all these dimensions at once. Consider Example 6: acting independently, Jack and a large number of unacquainted people set in motion a chain of events that causes a large number of future people who will live in another part of the world from ever having bikes. (Jamieson 2010: 436 and a similar passage in Jamieson 2007: 476-477 )

Jamieson claims that our sense that Jack has an urgent duty to remedy the harm he is linked to diminishes, and perhaps disappears, as we descend from Examples 2 through 6. Yet, Jamieson argues, it is Example 6 that is most similar to the case of climate change, which suggests that if we feel that the problems of climate change do generate urgent duties, these arise from a source other than orthodox morality.

At this point it will be fruitful to explore the similarities between climate change and Jamieson's Examples 2 through 6, to see just what features are supposed to make the case of climate change irregular in the same way that Example 6 is. I will present a list of five different features of climate change that I take Jamieson to be stressing as the features that make both Examples 2-6 and climate change irregular. They can be found by examining the range of examples and seeing which feature or features of climate change each example stresses.

In Example 6, Jack is part of a large, unacquainted group of strangers. Similarly, Jamieson suggests, the group that is causing climate change is very large indeed, and does not form a distinct, organised collective. It is hard even to identify a group of unorganised perpetrators, for the world does not divide neatly into those who emit greenhouse gases and those who don't. Even if a group of perpetrators could be identified, Jamieson might argue, differences within the group are 
significant. Some emitters have died, while others are currently alive. Some produced emissions lacking knowledge of their harmful effects; others did so with comprehensive knowledge of such effects. Some emitters may be in circumstances (high latitudes, low access to alternative energy sources) where they need more emissions to meet their basic needs, others in circumstances where they need less. Some emitters find themselves embedded in societies that have become dependent on dirty technology, others do not. These differences, Jamieson might argue, compound the vague boundaries of the group and make it difficult for orthodox approaches to attribute moral responsibility to the group or its members.

The dispersed and diverse group that causes climate change, Jamieson argues, makes climate change more irregular than Example 1, but it is far from the only difference that Jamieson's Examples 2-6 highlight. In Example 6 and the bridging case of Example 5, Jack will harm future people. This is mirrored in the case of climate change, Jamieson points out, because climate change is a "lagged" problem (Gardiner 2006: 402). Some of the carbon dioxide we emit now will warm the earth for centuries to come. Prominent damage assessments put most of the worst effects of climate change after 2100 (N. H. Stern 2007: 55-84). To further complicate matters, future generations may be far better off than we are due to continued economic growth (Mendelsohn 2006).

A third potentially irregular feature of climate change that Jamieson's passage above emphasises is that, as in Examples 4, 5 and 6, the connections that link individuals' actions to the eventual harm are via a long "chain of events". To begin with, it is not the emissions we create or even the rise in global average temperature we are indirectly causing that harms people, but rather the systemic effects of temperature rise on the natural environment that do. Further, many acts of emitting cannot be linked to a single actor. An example would be the embedded emissions created by the manufacture of (say) a lounge suite I purchase. I am not producing the emissions in this case, but merely adding to the demand for such 
products. The manufacturer who has emitted greenhouse gases in making the lounge suite may or may not have been subject to regulations on energy efficiency set by a state, which is now involved in the causal chain, along with the manufacturers and suppliers of the glues, fabrics and wood used in the lounge suite's construction.

Fourth, Jamieson's Examples 5 and 6 are supposed to highlight the difference that lack of intention to harm can make. In these examples, Jack lacks the intention to harm, and intention to harm is also absent in the case of climate change. Past emitters did not intend or even foresee the harm that would occur from their emissions of greenhouse gases. Even now, when we know that driving cars or using fossil-fuel generated electricity contributes to the greenhouse effect, it is strange to say that a person intends to cause the hurricanes, drought or sea-level rise that will harm future people when she drives her car or runs a bath.

The fifth supposedly irregular feature of climate change that Jamieson's examples remind us of is that the effect of the emissions from small-scale parties such as individuals (or small corporations) is each a tiny contribution to a problem that emerges only through the aggregation of a multitude of such contributions. Jamieson's Example 2 has Jack taking only "one part" of Jill's bike, and the harm of the lost bike only arises when a large number of other people do the same (436). Walter Sinnott-Armstrong pushes this idea more forcefully. He argues that the effect caused by an individual's act of emitting is non-existent, because it is only an infinitesimal part of an effect that only causes harm when it passes a threshold. One Sunday drive (say) does not release enough $\mathrm{CO}_{2}$ to raise the temperature of the globe by any amount at all. Even if it did raise the temperature infinitesimally, it is systemic climate change that causes the harm to people, not gradual change, 
and "no storms or floods or droughts or heat waves can be traced to my individual act of driving" (Sinnott-Armstrong 2010: 336). ${ }^{12}$

We understand conventional moral responsibility and feel it most urgently, Jamieson argues, when we consider an individual causing harm to another individual, intentionally, directly, immediately and locally. The harm from climate change, like the harm in Examples 2 through 6, varies from this paradigm in many dimensions: the lack of an individual perpetrator and intention to harm, the causal complexity, and the distance in time and space between the perpetrators and the victims. Thus climate change, according to Jamieson, is far enough from the paradigm of moral responsibility that orthodox ethical approaches fail to gain traction.

\subsubsection{Political Responsibility?}

I have presented and developed Jamieson's argument that climate change is far removed from paradigmatic moral problems involving direct harm, so moral responsibility of this type may be hard to trace using an orthodox approach. But Jamieson also recognises that individual moral responsibility for direct harms does not exhaust the types of ethical responsibility. He refers to a different kind of ethical responsibility: "political responsibility" (438). While Jamieson admits political responsibility plays some role in the ethics of climate change, he argues that the problem of climate change is sufficiently non-paradigm that orthodox approaches to delineating political responsibility will be inadequate to explain our

\footnotetext{
12 There is a philosophical response with a famous pedigree that suggests itself here, but it is unclear whether it is capable of helping those proposing an orthodox approach to climate change . Famously, Parfit has argued that it is a "mistake of moral mathematics" to assume that an act's morally relevant effects need be traceable to that act's particular effects, especially if that act belongs to a set of harmful acts (Parfit 1984: 67-83). But importantly, Parfit sees his argument as being revisionary, and makes the same kind of historical apology for our moral conventions (or rather "mistakes") as does Attfield.
} 
duties on climate change. His conclusion is that "the problems that climate change presents us with stray from the paradigm of global justice" (439) and thus the claim that climate change involves a strong instance of political responsibility must be revisionary.

Jamieson provides no definition for either "political responsibility" or "global justice", but does provide an example of a paradigm problem of global justice, presumably one that results in clear political responsibility. Such a paradigm problem is "a country unjustly invading another country" (439). The case for political responsibility "becomes stronger" when we consider the plight of particular countries that will suffer the most from climate change: Bangladesh and small island states, for example (438).

Yet, Jamieson argues, while some countries may be clear losers from climate change, climate change differs from paradigm problems of global justice in "several important respects" (439). One respect Jamieson explicitly mentions is the geographically and politically dispersed nature of the perpetrators and victims of climate change: "[s]ince the atmosphere does not attend to national boundaries and a molecule of carbon has the same effect on climate wherever it is emitted, climate change is largely caused by rich people, wherever they live, and is suffered by poor people, wherever they live" (439). He cites the high numbers (in absolute terms) of car owners in relatively poor countries such as India and China, and the disproportionate suffering of the poor in rich countries (such as in the USA when Hurricane Katrina struck) as examples of this. On Jamieson's view, the groups of perpetrators and of victims of climate change cross national boundaries, are vague and ill-defined, and perhaps are not even collectives at all. As well as the dispersed nature of perpetrators and victims, the other features which make moral responsibility problematic might also affect our attribution of political responsibility, especially the time lag and the lack of intention of perpetrators. The responsibility of current states for past transgressions is a controversial topic (cf. 
D. Miller 2004; Posner and Weisbach 2010: 115), and unintended harmful consequences of state actions also do not neatly invite attributions of political responsibility for those harms.

Jamieson's argument is that climate change strays from the paradigms of political and moral responsibility to such an extent that we cannot understand our obligations without providing a revisionary analysis. It is not a conventional political problem primarily because the persons that are most responsible for climate change are scattered among the globe and belong to different political units. Climate change is not a conventional moral problem because it differs from the paradigm case of direct, local harm on many dimensions. Thus he concludes by affirming the irregularity thesis - that climate change is a case that requires our concept of ethical responsibility to be "revised" or "extended" (Jamieson 2010: 439).

Jamieson's revisionary response to the irregularity thesis is to draw on what he claims is an "under-theorised and [under]-defended" duty of respect for nature (443). According to Jamieson, this need not be based on a "morally extravagant view such as biocentrism or ecocentrism" (443). ${ }^{13}$ That we have some duty to respect nature may be plausible. But the question of allocating the burdens of climate change is difficult enough as it is, and we should be wary of building any analysis of climate justice on such contestable and unexplored territory as a duty of respect for nature (whether such a duty is compatible with anthropocentrism or not). As indicated earlier, I wish to develop an account of the ethics of climate change that draws on principles of justice that lie within the realm of orthodox ethics, principles that have been discussed in general terms outside of the environmental context (Butt 2007; D. Miller 2001). Consideration of central ethical

\footnotetext{
${ }^{13}$ Jamieson gives four arguably anthropocentric reasons (apart from the motivation due to the moral urgency of climate change despite its irregularity) why we might have a general duty to respect nature. But my purpose here is not to investigate the grounds for a duty of respect for nature, but to reply to the idea that climate ethics must be revisionary.
} 
concepts such as individuals' vital interests and moral responsibilities play central roles in my argument. The strategy of this thesis is thus to apply orthodox ideas about ethical responsibility to climate change, not to revise them. The next section will present a case that such a strategy can be sufficient to answer the question of the just allocation of climate burdens.

\subsection{A REPLY TO JAMIESON'S ARGUMENT}

We have seen Jamieson's argument for the irregularity thesis, and that he suggests our urgent duty to act on climate change should be derived in part from a duty to respect nature. We need not accept either conclusion. I believe Jamieson gives too little attention to orthodox principles that attempt to share responsibility justly for urgent moral tasks. Here in Section 2.3, I will propose that principles of burdensharing can dissolve some of the particular difficulties that climate change poses to orthodox ethics, and that those which remain are not significant enough to require a revisionary approach. Finally, in Section 2.4, I will point out some features of the burden-sharing approach which make it more rather than less urgent for parties to bear their portion of the climate burden.

\subsubsection{Principles of Burden-sharing}

A way forward against Jamieson's argument for the irregularity thesis involves two steps. The first is to treat the importance of dealing with the climate burden as a brute fact (after all, a situation in which the poor of the tropics have their lives and livelihoods devastated by anthropogenic climate change caused generations 
earlier seems in urgent need of rectification). ${ }^{14}$ The second is to propose a principle (or more plausibly, principles) that can transform the urgent duty of humanity in general to meet the climate burden into more clearly delineated ethical responsibilities of specific parties.

Human induced climate change presents us with an unacceptable situation. If climate change is not mitigated, people's vital interests will be adversely affected by extreme weather, sea level rise and disruption to ecosystems (Parry et al. 2007: 28). Thus their vital interests should be protected through the tasks of mitigation and adaptation. Furthermore if we do not mitigate climate change, we risk truly catastrophic or runaway climate change that would severely threaten the ability of civilisation to survive at all (Hansen et al. 2007; Sherwood and Huber 2010; Weitzman 2009). For us to let people (albeit indirectly) harm other people in the ways described above without attempting intervention would be morally unacceptable. Perhaps exactly who should take up how much of the climate burden and why is not immediately obvious. We can however turn to principles of burden-sharing to answer these questions. I will develop arguments for particular principles of burden-sharing later in this thesis, but what I want to argue now is that we can use such principles to explain the urgency of our ethical responsibility to deal with climate change without a revisionary approach.

Burden-sharing to remedy an unacceptable situation is not an unorthodox or irregular proposal. Such distribution of "remedial responsibility" might occur when we consider any case where a situation requires urgent remedy: for example, when we consider who had responsibility to aid the Iraqi children harmed by economic sanctions on Iraq (D. Miller 2001: 453ff). Singer (2004) uses the more prosaic example of finding the bathroom sink blocked by hair; again, the situation demands remedy, and we can plausibly turn to principles to decide who

\footnotetext{
${ }^{14}$ Note that Jamieson also helps himself to the notion that the need to remedy climate change is urgent in his argument for a duty of respect for nature.
} 
should clean it up. In these cases our model might be similar to the apportioning of legal liability, (but not strict liability, as I will argue in Chapter Four) rather than moral culpability. ${ }^{15}$ Assigning legal liability and remedial responsibility both involve distributing burdens rather than punishment, and share a purpose: to ensure that the victims do not bear the entire burden themselves. In this thesis I take it that burden-sharing principles can apportion moral responsibility to the parties involved in climate change.

\subsubsection{Delineating Groups}

The problem of allocating the climate burden would stray far from orthodoxy if we could not identify who should bear the burdens. So a key role for principles of burden-sharing is to delineate the parties involved more clearly. It does not matter if there is some vagueness regarding the size and shape of the initial collective amongst which we are distributing responsibility. All that is needed to start applying the principles of burden-sharing is a rough idea of who could bear responsibility. The broad notion that some collective of humans is responsible for a particular problem is enough to begin such an application; principles of burdensharing will bring the parties who actually bear specific responsibility into clearer focus.

\footnotetext{
${ }^{15}$ Jamieson briefly responds to the idea that responsibilities to deal with climate change are best understood as the acceptance of fault liability (where negligence is needed to apportion burdens). His argument is that it is hard to see climate change being a case of individual negligence when there is widespread distrust of climate science. People, he argues, are not acting negligently if they don't believe their behaviour is contributing to any harm. Furthermore, this false belief is not the fault of individuals, but the fault of a faulty science education system and the pronouncements of public figures. This issue becomes somewhat tricky, but against Jamieson I would argue that negligence is a good way to characterise the emitting of collectives of high emitters today. Perhaps in some countries, where awareness of the effects of greenhouse gas emissions is not widespread, this once again shifts a climate task to broader collectives to ensure that science education is adequate, but the overall analogy with liability is not seriously threatened.
} 
To take an example, we might begin with the vague notion that "some of us" are practically responsible for the high rates of rheumatic fever in New Zealand. As more about the problem is learnt, certain groups or individuals may be identified by a principle based on contribution to the problem. Perhaps particular parenting practices are the cause, perhaps there is some individual spreading the related bacteria, perhaps it is due to our poor insulation, which is partly the fault of the Department of Building and Housing. Or maybe the causes are too diffuse and a capacity-based "ability to pay" approach is most just. In any case, some groups will be determined by the application of the relevant principles. The group or groups now delineated may still have unclear boundaries, but we face such problems of vague borders in most problems of applied ethics, and climate change should not be deemed any less orthodox for that reason. Fundamentally the amorphous nature of the collective before the application of distributive principles is not enough to render problems like these unprecedented, or even significantly non-paradigm.

How might groups be picked out by principles in the case of climate change? Recall the problem that the group of emitters was diverse and did not form a political unit. We can however, through a contribution-based or "polluter pays" principle, link the proportion a party emits with the responsibility to bear a proportion of the burden. Jamieson recognises that "a molecule of carbon has the same effect on climate wherever it is emitted". This fact about the insensitivity of circumstance to the effect of acts of emitting allows, at least in theory, a clear relationship to be drawn between proportionate emissions and proportionate responsibility. If you and I are the only emitters of greenhouse gases and my emissions came to three tonnes of $\mathrm{CO}_{2}$ last year and yours one tonne, it is plausible to suggest I am responsible for $75 \%$ of the climate change caused by that year's emissions. Of course once we introduce multiple types of actors (corporations, states, individuals) and consideration of the epistemic and socio- 
economic situations of different emitters across time and space, the allocation of proportionate responsibility for the climate change burden will become much more complex. I will explore these issues in Chapter Four. But it is important to note for now that the direct link between each additional unit of greenhouse gas emitted and the increase in risk makes proportionate responsibility applicable to climate change.

At this point, it is worth noting that if we can determine, even approximately ${ }^{16}$, the relative shares of the climate burden for different parties, we gain a level of precision that increases the ethical force of the responsibility to bear such burdens. Often, the level of causal responsibility for an unfortunate event will be impossible to appropriately quantify. For example, it is unclear how much responsibility I bear when I serve a drunk patron (whom I suspect to be somewhat likely to drive home) who then kills someone in a road accident. Perhaps legal procedure might assign some exact percentage of proportionate responsibility, but very often it is hard to express the moral responsibility in any more precise way than saying I have "some" responsibility, or perhaps a "major" or "minor" responsibility. In the case of climate change, however, the scientifically demonstrable graduated effect of a multitude of small contributions allows us, at least in theory, to specify the relative responsibility of each contributor. Likewise, if parties' relative ability to pay was the measure by which responsibility should be distributed, the degree of precision available in measuring this ability may again render climate change more tractable as an ethical problem compared to many smaller-scale cases of burden-sharing.

\footnotetext{
${ }^{16}$ In some cases it may be difficult to judge the amount of greenhouse gas emissions any particular actor is responsible for, as I noted in sub-section 2.2.4. Still, the "carbon footprint" of activities as diverse as sending a text message to buying a new car has been estimated with some accuracy (Berners-Lee 2011). Alternatively, a global economic instrument (such as an auction-based scheme of emissions restriction that requires firms to purchase permits in order to remove fossil fuels from the ground) could allow all emitters to bear costs in rough proportion to their use of fossil fuels. See Chapter Four for a description of such a scheme.
} 
Once we have dealt with the difficulty of identifying duty bearers by proposing principles that will be able to apportion responsibility on the basis of, for example, parties' causal contribution or ability to pay, I suggest that the other apparently special features of the case of climate change become amenable to orthodox ethical analysis as well. The other features that Jamieson raised were the complexity of the cause, the lack of intention to harm, the temporal lag between the cause and the harm, and the infinitesimal nature of the contribution that a single individual makes. I will argue that, if proportionate responsibility can be distributed, none of these other features undermine the idea that such responsibility to bear the climate burden is an instance of orthodox ethical responsibility

\subsubsection{Time Lag}

Jamieson suggests that the responsibility to deal with climate change is irregular because the ill effects occur in the future. In his Example 5 he asks us to consider a case in which the agent, Jack, lives "many centuries before Jill, and consumes materials that are essential to bike manufacturing; as a result, it will not be possible for Jill to have a bicycle" (436). In this, and in Example 6 (in which future people are prevented from having bikes by Jack and a group of strangers) our sense of the urgency of Jack's duty is diminished, compared to Example 1, in which Jack harms Jill immediately. This may be so, but here two factors may be confounding our judgement: the type of harm that the future people are suffering and the precision with which we can trace the cause of the harms. In examples 5 and 6, we only know that Jack indirectly deprives someone of resources, rather than contributes to threats to her vital interests or her life. Responsibility for these latter, more serious types of harms may be insensitive to time lags. As Stephen Gardiner (2011) points out, someone who places a time bomb under an elementary school is clearly culpable whether the detonation is set for 100 seconds or 100 years. 
If we see climate change as jeopardising the basic interests of future people (whomever they turn out to be) such jeopardy can be caused inter-generationally (Caney 2009b). A typically consequentialist approach to the problem, involving a commitment to impartiality, is even less likely to discount harms simply because they are in the future (Broome 1992: 92-108).

Additionally, in Examples 5 and 6, the degree of confidence with which we can say that the perpetrators will actually cause harms is low. It seems plausible for the perpetrators in such cases to argue that we cannot know that people will be prevented from having bicycles due to their consuming materials essential to bike manufacturing, because the requirements of future people for specific resources are so hard to predict. Linking future climate-related harms to present emissions is different in this regard. We know that greenhouse gases cause global warming, and we know, or can find out, the approximate relative contributions to global warming from many parties. While we cannot predict any particular future harm, we can be fairly certain that serious harms will be caused by increasing the concentration of greenhouse gases in the atmosphere. Thus climate change presents more of a paradigm moral problem than Examples 5 and 6, despite the harms being located in the future.

There is one aspect to the time-lag involved in climate change that does raise problems for the distribution of climate burdens. The different levels of knowledge about the effects of greenhouse gases (call these the "epistemic conditions") of parties who emitted in different eras suggest that apportioning responsibility cannot be a simple matter of assessing contributions to the problem and assigning burdens accordingly. I will return to this problem especially in Chapters Four and Five, and I will touch on what may be the best strategy for dealing with it only briefly below. 
The different epistemic conditions of parties in different eras may just mean that a singular principle of justice will not adequately distribute the burdens of emissions. There are different portions of emissions (for instance, the portion emitted under excusable ignorance, and the portion emitted once the science of climate change was well-accepted) and the climate burden is constituted out of those different portions. But there seems to be no reason why we cannot use different principles of justice to allocate these different portions of the climate burden. We can imagine instances in which we might use several principles to distribute a burden fairly at smaller scales. Thomas Pogge describes an illuminating example of burden-sharing: imagine you have gone on a vacation in a developing country, and with four others have organized a beach party with fireworks. You ran the bar for your own account and made a tidy sum. The fireworks display, however, destroyed a boat - a very poor local family's only means of income. Legal authorities are not getting involved; the responsibility involved is a moral one. Pogge concludes that each of you has a responsibility to pay one-fifth of the cost of a new boat. But if the situation changes and several of your collaborators won't pay, it seems plausible that you have the responsibility to provide the remaining funds, because you have benefitted directly from the beach party (Pogge 2005). Here we have a two-track approach involving a contributionbased principle and a "beneficiary pays" principle. You are meeting a special portion of the burden, that created by your friend's refusal to pay, and the twotrack approach lets that portion be distributed fairly. The moral obligation seems to be standard enough, without a revision of moral responsibility.

Similarly we can use multiple principles to distribute the costs of climate change. I am not here arguing for a particular combination of principles (I do so in Chapter Four) or suggesting a close correlation between the example of the beach party and climate ethics. All I want to show is that variation in the epistemic circumstances of contributors from different eras could be dealt with by the application of multiple principles for the portions of the burden that originated at 
different times. This does not require revision of the concept of ethical responsibility.

\subsubsection{Complexity of Cause}

Recall that Jamieson suggested that the complexity of the causal pathway makes it difficult to assign responsibility to individuals for a share of the climate burden. This is mirrored in Jamieson's Example 6 with its reference to a "chain of events" that causes a large number of future people to suffer deprivation.

In response, it is worth noting that many of the causal pathways involved in climate change are made up of only a few steps. States might decide whether or not to apply restrictions to greenhouse gas emissions and large corporations whether to concentrate investments in clean or dirty energy. Individuals might choose to take or refrain from actions with a large carbon footprint such as building a house or taking a job that requires commuting daily. By some of these acts, such parties can be causally linked to climate change relatively directly through the associated increase in greenhouse gas emissions.

More fundamentally, however, a complex chain of events, where the victim is indeterminate and far removed from the agent, need not mean that the sense of moral responsibility placed on the perpetrator be watered down at all. John Nolt (2011) gives the example of someone making sexist or racist comments. In this case, the potential victims of bigoted talk are those who would be harmed through the complex causal mechanisms of the fostering of prejudicial attitudes in oneself and others. These attitudes in turn affect people's actions which can cause tangible harm. Bigoted talk merely increases the possibility that a distant individual will be harmed through a complex causal chain, involving the actions of other agents. Nevertheless, if we are convinced that bigoted talk raises the probability of harm, 
we may have no qualms about saying that for this reason, the person who is talking unfairly has a clear moral responsibility to stop.

The challenge of climate change is not irregular due to the complexity of its cause - some of the causal chains are not very complex, and the causal chains that are complex need not undermine the apportioning of responsibility.

\subsubsection{Lack of Intention}

In Example 5, Jack harms Jill with no ill intent - he merely "consumes materials that are essential for bicycle manufacturing" (436). Plausibly, the suggestion is that we see Jack's duty (if it exists at all) as non-urgent because he does not intend to harm Jill - merely going about his business, he causes harm. Lack of intention to harm is present in the climate change case as well - our daily activities that consume greenhouse gases are not intended to cause harm. But this should not stop us attributing responsibility using principles of burden-sharing. As with the

problem of time-lag, the scale of the harm that will be caused and the confidence with which we can trace the harm to our collective activity of creating greenhouse gases make the apportioning of responsibility via conventional means more apt. If it were made clearer in Example 5 and Example 6 that the parties knew of their effects on the future victims, and such effects were not denying future persons bicycles, but seriously endangering their lives and livelihoods, I think their duties to undertake the remedial tasks associated with their activities would become much more urgent. Lack of intention does not render climate change highly irregular. 


\subsubsection{Non-existent Harm?}

Finally, we must deal with the challenge that individuals' single acts cause no harm in the case of climate change, and that this makes assigning responsibility to individuals difficult. We saw the claim that single acts of individuals cause no harm is most forcefully made by Walter Sinnott-Armstrong (2010), who argues that, because climate change is an issue of thresholds, and individual contributions are miniscule, individual contributions cause no harm. But that claim is controversial, especially if we see acts that raise the probability of great harm as harmful themselves. John Nolt draws an interesting analogy:

Even one Sunday afternoon drive (like one cigarette) slightly increases the probability of harm, and the number of people and animals in the world during the centuries in which the emissions from the drive will persist in the atmosphere is (like the number of potential mutation sites in the individual strands of DNA in our lungs) vast (Nolt 2011: 65).

Following Nolt, we could argue that an individual's acts of emitting could easily be judged as harmful, if harm can be understood in a probabilistic sense.

But even if it were true that the actions of individuals cause no harm, this need not stop us allocating responsibility to individuals in proportion to their contribution to the problem. For, under a contribution-based principle, it would be an individual's share of the climate burden that they are asked to meet, rather than responsibility for the particular harm that individual caused. Perhaps it is hard to attribute any harm to the actions of particular individuals, but it is not hard to show that someone who lives a highly consumptive lifestyle contributes more to the overall climate burden than one living in austerity. More obviously, we need 
not show that individuals have caused harm in order to allocate responsibility to them by an ability-based principle.

\subsubsection{Factors in Concert}

The problem of climate change involves a range of features: infinitesimal harms from individual contributors, temporal, geographic and political diversity among contributors to the climate burden, the lack of intention of the contributors and the fact that the harms from climate change are (mainly) in the future. We have dealt with each of these factors in turn and rejected the idea that they require us to take a revisionary approach to climate ethics. We still need to assess the idea that while none of these factors alone is sufficient to make sharing the climate burden nonparadigmatic, they do so in concert.

Here the supporter of the irregularity thesis needs to make a strong case. After all, if none of the special features of climate change threaten the burden-sharing approach, why should they somehow acquire the power to do so when considered together? A supporter of the irregularity argument might respond that generally the effect of several types of variation from the paradigm of a singular agent directly harming a singular victim does dilute our intuition of responsibility. This is why Jamieson uses Example 6 to prove his point:

Example 6: acting independently, Jack and a large number of unacquainted people set in motion a chain of events that causes a large number of future people who will live in another part of the world from ever having bikes (436).

Considering such an example, even if they rejected the idea that any one of the non-standard features we have identified significantly reduces Jack's moral responsibility, many people would judge that Jack is not even partly morally responsible for the harm to the victims. Perhaps there is a compounding effect 
here that stems from the combination of several unusual features. But is Example 6 really closely analogous to climate change? If it were, we would expect other small-scale analogies that attempt to model the moral implications of climate change to also render responsibility problematic.

First let us consider the disanalogies between Example 6 and the case of climate change. Two of them we have already seen: climate change, but not the loss of bicycles, will threaten lives directly, and we have more certainty about the causal chain that connects the eventual harm to the acts undertaken today. Consider also that the victims of climate change are not only in the future (see Section 1.1) and not only in "another part of the world" (436), since the impacts from climate change will be felt in almost every country.

Stephen Gardiner reconstructs what I believe is a more accurate small-scale analogy of climate change. Imagine a group of wealthy people who collectively put on fireworks displays that consistently threaten people living in poorer neighbourhoods (Gardiner 2011) ${ }^{17}$. Perhaps (to reflect the time lag in climate change) the threat from the fireworks could be that they are of a special type that not only cause some damage now, but also emit harmful radiation that will affect fetuses in that area for years to come. ${ }^{18}$ Now few, I imagine, will be willing to say that the application of orthodox, anthropocentric moral responsibility to those putting on the fireworks displays is undermined by the multiple differences between the firework example and a simple example of direct, immediate harm. If the argument for the combined effect of the specific complications in the case of climate change rests on thought experiments such as Example 6, and a more analogous example finds much less of a combined effect, the argument suffers considerably. So it would be wrong to suggest that responsibility cannot cleanly

\footnotetext{
${ }^{17}$ The fact that Pogge and Gardiner both make use of fireworks displays in their examples seems to be a simple coincidence.

${ }^{18}$ This addition of the lag element is my own. Gardiner discusses lag separately from his example.
} 
apply due to the specific combination of complexities in the case of climate change.

\subsection{TOWARDS ORTHODOXY}

Some of the characteristics of the climate change burden serve to make ethical responsibility for it not less but more orthodox. I have already mentioned that the precision involved in determining proportionate burdens increases the force of the responsibility to bear those burdens. There are two more considerations that make the allocation of the climate change burden more orthodox.

First, climate change plausibly poses a question of the distribution of only burdens, rather than the more familiar question of the distribution of benefits and burdens of social institutions. To what extent (if at all) there should be a deliberate redistribution of the benefits of different parties' economic activity is controversial, but apportioning responsibility for the burdens of climate change need not face this controversy. Climate change involves a great deal of harm, and this harm can be increased or decreased depending on the activity of currently alive people. If a state of affairs is created in which people have their basic interests jeopardised through climate change, this involves the type of crossing of a person's boundaries that even hard-line libertarians could appreciate. What a successful set of distributive principles attempts to do is to apportion remedial responsibility for bearing the burden to ensure this harm is avoided or reduced to a morally acceptable level. This fact alone means that the question of distribution of burdens is less like the controversial question of how the fruits of society's labours should be divided, and more an urgent moral question of distributing responsibility to remedy serious harm. 
Second, we have been considering climate change as a distribution of responsibility to remedy harm, which has similarities with the allocation of legal liability. But this model may be somewhat misleading in the case of the distribution of climate burdens, because it may bring to mind cases with less sense of urgency than the task of the distribution of the burdens of climate change. If I am involved in a three-party collision destroying one party's vehicle, there is some sense of urgency in apportioning the blame. But the urgency is not very strong. Say that the forensic work that entails apportioning responsibility takes many years, and yet comes up with an answer that I am at fault, and I pay compensation to you (that includes the opportunity cost of what you could have done with the capital). Here it seems that my responsibility to you is at least partially met. In contrast, due to the lagged nature of the climate change problem, apportioning burden-shares for the climate tasks is almost entirely a forward looking project. Any delay in apportioning burden shares does not just delay injustice; it is likely to directly increase it, for two reasons. First, any delay will mean many of those who had duties ascribed to them will pass away without discharging them, leaving more burdens to be divided by a secondary principle amongst those who otherwise would not have borne primary responsibility for the burden. ${ }^{19}$ Second, delay in bearing the specific burdens of adaptation and mitigation will increase the burden on those who are least responsible for bearing it - the victims of physical climate change - due to the increased harms from extreme weather and other ill effects of under-mitigated climate change.

\footnotetext{
${ }^{19}$ This ignores the possibility that current generations should bear none of the burden of climate change. No philosophers I know of defend such a view, but see Mendelsohn (2006) for an example of one economist's defence of something like it.
} 


\subsection{CONCLUSION}

To find a just allocation of the climate change burden, we need not revise our moral concepts. No aspect of climate change is ethically irregular in itself, even in just the weak sense that it is unprecedented. Perhaps climate change is unusual in that it combines several features that involve moral complexity into one problem. But this need not make the sharing of the climate burden an ethically deviant problem that requires a revisionary approach. Rather it just calls for more care when applying the principles that apportion responsibility to various parties. Furthermore, climate change involves some features that cause it to lie closer to the paradigm of an urgent, orthodox ethical challenge than other examples of burden-sharing do. 
3

\title{
Against Grandfathering Emissions Rights
}

\author{
"The atmosphere is not a perfume, it has no taste of the distillation, it is \\ odorless, it is for my mouth forever..." Walt Whitman, Song of Myself (1999 [1888]: \\ Book 3, verse 2)
}

\subsection{THE ARGUMENT FOR GRANDFATHERING}

\subsubsection{Grandfathering}

To grant greater rights to emit greenhouse gases to those parties who have emitted more in the past is known in the context of climate change negotiations as "grandfathering" ${ }^{20}$ If such an approach were justified, it would seriously affect

\footnotetext{
${ }^{20}$ The etymology of the term 'grandfathering' is interesting. According to the Oxford English Dictionary, the term is derived from the "grandfather clauses" of late $19^{\text {th }}$ century southern states. These clauses exempted voters from the otherwise quite stringent laws that restricted
} 
our assessment of the allocation of climate burdens. Most obviously, it would influence the emissions entitlements that parties should be granted, with past high emitters receiving more permits to emit than my two-track approach would otherwise allocate to them. Changing the pattern of emissions entitlements to account for high historical use could also modify how a "polluter pays" principle apportions parties' shares of the other climate tasks of adaptation and compensation, by creating a variable baseline against which parties should be judged to be contributing to the problem. (That is to say, grandfathering might allow past high emitters a certain level of historically justified emissions before they are judged to be polluting and thus receive shares of the burden under "polluter pays".)

Grandfathering is common in the world of climate policy. It is a feature of the Kyoto Protocol, under which emissions entitlements for the high-emitting Annex One countries are expressed as a proportionate reduction from their 1990 emissions (UNFCCC 2011a). The USA, which remains outside the Protocol, and Canada, which recently left it, are also asserting their right to continue emitting at a high level (The Guardian 2011). By merely offering pledges on a voluntary basis to slightly reduce their emissions compared to 1990, these two countries are asserting the right to continue emitting at approximately the levels set by their past high use. Grandfathering could also be applied to a distribution of emissions entitlements at the level of the firm or the individual. ${ }^{21}$ For example, under a firm-

suffrage, as long as their grandfather had possessed the right to vote. The grandfather clauses were intended to allow illiterate and thus potentially disenfranchised whites the vote, without allowing illiterate blacks the same right. See also Van Deusen (1936).

${ }^{21}$ The Lockean argument for grandfathering we will focus on is somewhat typical of the climate ethics literature in that finding the correct distribution of emissions rights among countries is taken as the key problem. In order to reply to this argument I will follow this convention in this chapter, although I think that countries may well not be the appropriate entities to receive emissions entitlements in the first place. However, the flaws in the Lockean argument for grandfathering emissions rights to historically high-emitting countries are general; they would equally trouble Lockean arguments for grandfathering in other schemes where the subjects are not countries but firms or individuals. 
based scheme, companies could be granted rights to emit based on their relative share of past emissions, instead of having to purchase them, as was done in the first phase of the European Union Emissions Trading Scheme (Pew Center on Global Climate Change 2005). Under a personal carbon allowance scheme, again, individuals with a history of high emissions could be granted more entitlements to emit.

It is important to note that this particular pattern of distribution can be argued for from different backgrounds. There certainly is a pragmatic argument for supporting an international agreement which allows past heavy emitters greater entitlements than the more recent emitters; it is probably true that in order to reach an international agreement on climate change, concessions to these disproportionately powerful past heavy emitters must be made. But judging that a prudent contract with a known bully might involve grave concessions to him is not the same thing as claiming he has a moral reason to demand those concessions. As Caney forcefully points out, the fact that grandfathering might be necessary for an international agreement to be formed might be a moral reason for those desperate for such an agreement to support a grandfathering proposal, but cannot be cited as a moral reason in favour of grandfathering by the heavy emitters themselves (Caney 2009a).

Luc Bovens, a supporter of moderate grandfathering, admits that the "Realpolitikstyle concessions" of those willing to compromise with powerful forces do nothing to establish the correct course of action in the moral sense (Bovens 2011: $143)^{22}$. Bovens instead tries to defend moderate grandfathering on moral grounds. His reasoning is that there is some force to the claim that historically high emitters have harmlessly appropriated some of a common resource at an early stage, before the limits to the atmosphere's ability to absorb greenhouse gases safely was threatened. Because this argument for grandfathering builds on John Locke's

\footnotetext{
${ }^{22}$ This work will subsequently be referred to simply by page number in this chapter.
} 
account of just appropriation of commonly held resources (Locke 1956 [1689]), one might suspect the argument would only appeal to those who are convinced of that account's correctness. But Bovens defence of grandfathering is heavily qualified. His argument is merely that there is "some appeal" to the Lockean story about the conditions under which resources that are held in common can be privately appropriated (129). By contrast, Bovens also recognises an "external critique", noting that other considerations than Lockean property rights, such as sufficentarian, egalitarian or utilitarian concerns, might be relevant to determining the fair holdings of resources today (136). His practical conclusion is modest: grandfathered entitlements provide a "starting point" that should guide our thinking in the distribution of emissions entitlements (142). Yet, although we should "move away" from the starting point of grandfathering with "haste and determination" (142), Bovens ultimately claims that we should assign "initially unashamedly unequal emissions rights" (144) to historically high emitters, rights which are based on a "moral ground" - the on-going (if limited) recognition of rights gained in an earlier period (134). ${ }^{23}$

Modest as it is, it is nonetheless a moral defence of grandfathering. And as such, it stands against the tide in climate ethics. Philosophical discussions of emissions entitlements usually focus on such proposals as the equal per capita approach, and question whether this scheme, already much harder on historical heavy emitters than the status quo, still would grant over-generous entitlements to

\footnotetext{
${ }^{23}$ One weakness of Bovens' argument as he presents it is that it assumes our options for distributing emissions entitlements as roughly two: grandfathering to some extent, or an equal shares approach where the rights to emit are divided equally among the parties. This obscures the fact that a more sophisticated proposal for dividing emissions entitlements, such as the auction-and-dividend approach we will investigate in Chapter Four, might be more plausible than either grandfathering or equal shares. Of course, a grandfathering aspect could be brought into auction-and-dividend, but to determine whether it should, we are still no longer adjudicating between a simple egalitarian division and one that incorporates grandfathering. Thus, Bovens' reliance on the grandfathering/equal shares dichotomy might make his case seem stronger than it is, and I will try to represent Bovens argument as best I can without this dichotomy.
} 
historical high emitters (D. Miller 2008; Neumayer 2000; Singer 2004). Some also wonder if the equal per-capita approach protects the historically low-emitting global poor enough (Caney 2009a; Gosseries 2005; R. Miller 2010; Shue 1993). Simon Caney is perhaps the most vocal in rejecting grandfathering, claiming that it "rewards people in accordance with their contribution to the creation of a problem", a characteristic which is "clearly perverse"(Caney 2011: 88). Bovens' argument is both nuanced and controversial, and it will be worth investigating it in some detail.

\subsubsection{Bovens' Argument.}

The Lockean paradigm of just acquisition of land is represented by Bovens in a vignette I will refer to as Homesteading: ${ }^{24}$

Let there be a commons that is genuinely unmanaged and unproductive. Some people decide to fence in part of the commons to work the land. Suppose that every such act of homesteading is such that some are better off and nobody is worse off, where such welfare evaluations are understood in terms of reasonable preferences. This is the Lockean enough-and-as-good condition which Nozick dubs "the Lockean proviso". Now some may decide to homestead larger plots, some smaller plots, all dependent on their needs and aspirations in life. Some people may choose not to homestead, since they would not derive any joy from such enterprise and they prefer to work for wages by selling their labor to homesteaders. But nobody is allowed to homestead a plot of land that is larger than what he or she can reasonably put to good use. That is the Lockean no-waste condition. Let us suppose that this homesteading constrained by both Lockean

\footnotetext{
${ }^{24}$ Bovens does refer to Homesteading as a 'popularised' version of the Lockean account of just appropriation. (129). Yet he gives no clearer exposition of just what the "right-libertarian intuition for property rights in land" (129) actually consists of. In what follows, I will take Bovens' presentation of Homesteading to function as a paradigm case illustrating how rights to resources could be gained in a Lockean way.
} 
conditions goes on for a while. At some point it becomes clear that further homesteading would no longer satisfy the enough-and-as-good condition. The practice of homesteading is then stopped. The outcome of this process is that some people own smaller plots of land, some own larger plots of land and some own no land whatsoever. But this does not make the procedure of allocating land or the resulting allocation unfair (128).

The next step of Bovens' argument involves extending the Lockean story about land to another commonly held resource: the ability of the Earth's atmosphere to absorb greenhouse gases without serious harm. The aptness of the application of the Lockean account to the atmosphere and the possible annulment of rights when the recognition of the violation of the Lockean proviso is delayed will concern us in Section 3.2 and Section 3.3 respectively.

\subsubsection{Lockean Emissions Rights?}

The atmosphere's ability to absorb anthropogenic greenhouse gases without causing unacceptable climate change, we have learnt in the last few decades, can be seen as an important resource. (For ease of expression, I will call this resource the "atmospheric sink"). Plausibly, the atmospheric sink was (at least at one point in time) a resource in the global commons, much like land once was, in Homesteading, a resource in a nascent society's commons.

Bovens' Lockean account of the fair appropriation of the atmospheric sink is this: at one time in the past, use of the atmospheric sink did not violate the Lockean proviso; when the first "little puff of GHGs [greenhouse gases]" was emitted from "the first steam engine in England" the commons was still able to be used without making anyone worse off (132). Bovens says very little about the no-waste condition besides noting that it was not violated. Presumably though, we should 
judge that the vast resource that was the atmosphere's ability to absorb greenhouse gases safely was not being squandered in these early days, but used to benefit people through the greatly increased opportunities for transport, heating, electricity generation and manufacturing goods.

While the Lockean proviso was not violated until some time after the first industrial use of the atmospheric sink, Bovens rightly recognises that it must have been violated much earlier than the time at which we discovered that continual greenhouse gas emissions would seriously harm future people. We can identify an early period, before the Lockean proviso was violated; and an interim period, during which parties "illicitly" appropriated the atmospheric sink without knowing they were violating the Lockean Proviso (133). Now we are in a late period, which may have begun somewhere between 1970 and 199025, in which our recognition of the limits of the atmospheric sink means we can see that further appropriations violate the Lockean proviso. Again, all that is needed to motivate moderate grandfathering is that at least some rights to the atmospheric sink were gained during the early period. It is those legitimate appropriations that could form the basis of the limited claim for heavy emitters to a greater use of the atmospheric sink now.

\subsubsection{Conditions for Annulment}

The lag between the Lockean proviso being violated and our knowledge that it has been violated raises a problem for those supportive of Lockean rights. During the interim period, when we did not know the proviso was being violated, massive amounts of greenhouse gases were added to the atmosphere, meaning that rights to the moderate flows of emissions that would have legitimately passed

\footnotetext{
${ }^{25}$ I will explore the issue of what was known when about harmful climate change in Chapter Four.
} 
the Lockean proviso in the early period can no longer do so now. In such a case where the correct stopping point for appropriation has been overshot, what should happen to the rights gained legitimately before the Lockean proviso was violated?

Bovens does not think the legitimacy of property rights depends on the consequent distribution of resources continually satisfying the Lockean proviso, and this is a plausible enough view. ${ }^{26}$ However, he does see the continuing legitimacy of rights that were gained in an early period of appropriation as contingent on the holders of those rights satisfying at least one of the two Lockean conditions. If such a test fails, Bovens claims, we can make an "internal critique" of the Lockean approach, so called because the rights gained through appropriation can be challenged with reference to the same conditions that justified the rights in the first place.

To explain how, he introduces a thought experiment adapted from Robert Nozick that he calls Nozick's Well.

Suppose that a number of people have drilled wells (or, in Nozick's terms, water holes). The enough-and-as-good condition was satisfied; they have appropriated these wells and are selling the water in a competitive market. (Nozick does not include Locke's no-waste condition.) Now conditions change and all wells run dry except for one. The owner of this well now has a monopoly position and can extract monopoly prices. Nozick suggests that this might be permissible if the situation came about due to this person's good stewardship (and, presumably, the

\footnotetext{
${ }^{26}$ In support of this, Bovens gives the example of an orchardist appropriating a piece of waste land that was "an eyesore to the neighbouring community" (137). At the time, no-one lost out from the orchardist's acquisition, so the Lockean proviso was not violated. But once the orchard has been established, the community might well benefit if the orchard was returned to them. There is no longer "enough and as good" of the newly improved land to go around. Bovens asserts that even if continued private possession of the orchard does violate the Lockean proviso, to judge that it should therefore be reclaimed by the public seems wrong.
} 
poor stewardship of others) rather than just luck. But it is not permissible if it came about due to desertification and the simple good luck that this person owns a well in the only location where there is still water to be tapped. (137)

Bovens posits that, while continued ownership does not require strict ongoing applications of the original Lockean conditions, massive violations can annul property rights. But he also notes that the situation is somewhat more complicated, as considering Nozick's Well suggests that we should see an interaction between the two conditions. Once the Lockean proviso is comprehensively violated, a small violation of the no-waste condition is enough to annul previously held property rights. Likewise, once the no-waste condition is comprehensively violated, a minor violation of the Lockean proviso also would annul such rights. For example, in a situation where housing is very scarce, leaving a building unoccupied for even a short period of time may justify squatters taking possession of it, or at least gaining use rights over it. Likewise, a very small benefit to others (such as being able to save a minute by crossing someone's land) might be enough to over-ride property rights and create a rightof-way when land has been unoccupied - and thus wasted - for a significant period of time. The interaction between the two conditions can also have the effect of maintaining private property rights: extraordinary stewardship can count for the preservation of some property rights even when the Lockean Proviso is strongly violated, as Bovens suggests would be the case with the prudent owner in Nozick's well. Returning to the atmospheric sink, the point Bovens emphasises is that, even though the Lockean proviso is now comprehensively violated, the nowaste condition has been (relatively speaking) respected by historical heavy emitters. This means the Lockean claim of historical heavy emitters to more of the atmospheric sink should bear some weight, and count against an immediate redistribution of emissions entitlements. 
Bovens defends this claim of good stewardship of the atmospheric sink by emphasising the poor stewardship of developing countries. The developed world, admittedly, has used the atmospheric sink for luxuries as well as necessities, but the developing world has not been a good steward of their portion of the atmospheric sink, holding a "poor performance in GHG emissions per unit of GDP” (143). Relatively speaking then, developed countries have not violated the no-waste condition, meaning that their past appropriation of a common resource still provides a reason why some of the differences in emissions that exist between developed and developing countries should remain.

According to Bovens, if we do not think that appropriation of common land that hurt no-one was unjust, we have a reason to support the property rights in the atmospheric sink gained before the Lockean proviso. Although there are good reasons to now reduce the gap in emissions between developed and developing countries, there are also moral reasons, especially from a sophisticated Lockean perspective, to respect the patterns of use that create this gap, in the same way that we might respect historically-generated property rights in other domains. The fair distribution of climate change burdens involves a "balancing" (143) of reasons for and against grandfathering, with the result being moderate grandfathering.

This ends my exposition of Bovens' argument. In the next section, I will first present general worries from several perspectives about the move from accepting Lockean rights in the case of land to affirming that such rights exist in the case of the atmospheric sink. Finally I will put these worries aside, and show that, even if we grant that Lockean approaches could make sense in the case of the atmosphere, the very caveats that Bovens recognises should apply in cases of postappropriation violation of the Lockean proviso undermine the case for moderate grandfathering. 


\subsection{CHALLENGING THE LOCKEAN APPROACH}

\subsubsection{A Worry from Climate Scientists}

One complaint which is worth considering is that Bovens is wrong to treat the atmospheric sink as a resource system like land that can provide a constant service. Since $\mathrm{CO}_{2}$, the most important greenhouse gas, has a complex lifetime (some $\mathrm{CO}_{2}$ emitted now will persist in the atmosphere for centuries) the total amount of $\mathrm{CO}_{2}$ that can be emitted in the next few centuries without causing dangerous climate change is finite. One might say that the world has a 'global carbon budget' of a trillion, or maybe 750 billion tonnes of carbon, after which our emissions should cease completely (Shue 2011; Allen et al. 2009). The atmospheric sink, for $\mathrm{CO}_{2}$ at least, is now a depletable resource, not a productive system - more like rations on a lifeboat than like commonly held land - and this alone is enough to undermine the analogy with Homesteading.

Likewise, Lockean approaches could equally apply to finite resources. I might be justified in claiming sand from a beach, not because the amount I claim will be replenished quickly, but because I leave such a vast amount there that no-one can complain there is not enough left for them. Bovens' argument for grandfathering emissions rights could still hold even if the rights that are to be now distributed are not rights to continue to use a natural service at a given level, but entitlements to consume an unequal share of a finite resource.

In any case, there is good reason to believe that around the time of the industrial revolution, when Bovens' Lockean rights were being gained, the atmosphere was still a resource system with the potential to provide a constant service of absorption of $\mathrm{CO}_{2}$ (as it still does in the case of short-lived greenhouse gases). As long as $\mathrm{CO}_{2}$ has a finite lifetime (even if this is long and complex) there is some 
amount of $\mathrm{CO}_{2}$ that can be emitted continuously without the net effects on anyone being negative. Admittedly, since this amount must not make others worse off, taking into account the persistence of $\mathrm{CO}_{2}$, it will be quite a low amount. Recognising the long lifetime of $\mathrm{CO}_{2}$ shortens the 'early' period of acquisition, pushing back in time the moment at which early industrialists violated the Lockean proviso, but it does not undermine the analogy with Homesteading. The atmospheric sink was once a resource system that provided a steady flow of a good available for use, just as land does in Homesteading.

In the rest of Section 3.2 I will suggest that we should be concerned by the application of the Lockean framework to the atmospheric sink because the features that ground Homesteading's appeal may not be present in the case of the atmospheric sink. Unpacking the appeal of Homesteading is deep and difficult territory, however, and what follows can only be a sketch of some concerns. Those unconvinced by such a sketch will find more reasons to deny grandfathering in Section 3.3.

\subsubsection{Worries from Contractarians and Welfarists}

Despite having an essential Lockean element, Bovens tries to make his argument ecumenical by not requiring us to be committed Lockeans about property rights, but only to accept that there is something appealing about the Lockean story he

tells in Homesteading. This appeal can then be balanced against what he calls the "external critique" of his Lockean view of appropriation - the critique that broadly welfare-based considerations matter more than rights gained through historic use.

So the background to Bovens' argument for moderate grandfathering seems to be a kind of ethical pluralism, in which concern for historically generated rights and concern for the welfare of current people provide competing reasons for action - 
competing reasons that require balancing. Yet it should be obvious that such pluralism need not be the only framework by which we view the apparent conflict between our intuitions about Homesteading on the one hand and our commitment to the concerns of the external critique on the other.

One possibility is that, instead of Lockean rights providing reasons which support private property by themselves, they instead only gain their power from a tacit contract between relevant parties at the time. It is interesting that in Bovens' presentation of Homesteading, people "choose" not to homestead and "prefer" to work for wages, which could be prompting our intuitions about the importance of a tacit acceptance of a bargain or contract.

Alternatively, it could be that any appeal we see in the story of Homesteading arises just because we recognise that granting of rights on historical grounds is instrumentally valuable to the promotion of those broader welfare-based or other humanitarian concerns that Bovens sees as fundamentally opposing the Lockean allocation. For instance, we might only commend the pattern of property allocation in Homesteading because human welfare is best served by accommodating our particular psychological biases towards having domain over the tangible parts of the common land we have become involved with, where this doesn't obviously harm others. Or we could commend it because endorsing a general programme of quasi-Lockean land rights is the best way to promote the most efficient use of the resources (because in granting continued property rights we encourage good stewardship, investment and prudence (Hardin 1968), and first use is as good a criterion as any by which to allocate such rights).

These accounts shows that it is possible for us to be quasi-Lockean, fully affirming that past appropriation of land gives rise to rights (subject to the Lockean proviso) but only because of deeper considerations of the importance of welfare or tacit contracts. But the question of grandfathering concerns the just allocation of rights 
to a type of resource we have only just discovered - the atmospheric sink. From the contractarian and welfare-centred points of view we have been considering, it may be desirable to allocate rights to this resource by some quite different principle from that by which we allocate land. The goals of satisfying psychological needs for territory and promoting efficient use do not seem to translate easily to the atmospheric sink. If we have a deep need to stake out parts of the atmosphere, it's essentially non-excludable nature means this need should probably be curbed, rather than indulged. As for efficiency, granting greater rights to the atmospheric sink to those who have used more of it seems to reward inefficiency rather than efficiency. We will return to the latter point in Section 3.3 27. As for the contractarian position, the idea of even a tacit contract being formed between early major and minor emitters while they were so ignorant of the nature of the resource they had been using is bizarre.

If we were to judge that the Lockean allocation pattern we found appealing in Homesteading was fundamentally grounded in deeper considerations of welfare or a social contract, Bovens' argument for grandfathering emissions rights would be unconvincing. In the case of the atmospheric sink those considerations either count against grandfathering or cannot apply to it, so there would seem to be no reason to grant any weight to the historical appropriation of the sink.

\footnotetext{
${ }^{27}$ One welfare-based pragmatic argument for grandfathering might be that heavy historical emitters should be allowed more emissions entitlements because such parties are so dependent on high emissions industries that restricting their emissions would be devastating. This is easily met, though: it seems fair to allow some kind of trading of emissions rights in order to allow those privileged yet highly dependent on greenhouse gas emissions to legitimately purchase surplus entitlements from those less developed nations that will not use their full entitlement (Page, 2011b, Caney and Hepburn 2011). Allowing the developed nations to have more entitlement to emit once they have paid for such rights in no way justifies giving heavy emitters more emissions rights to begin with.
} 


\subsubsection{Worries for Pluralists and Libertarians}

Of course, those who subscribe to libertarianism will see instrumental justifications of the kinds of rights gained in the appropriation of common land as missing the point. Some pluralists also might see Lockean rights as providing reasons in themselves to respect property. For both groups, the attractiveness of Lockean rights in Homesteading is genuine: the account illustrates a way in which individuals can actually gain rights over land through their activity on it. These views face a different worry: that the likely accounts of how people gain rights over the land in Homesteading are either too wide in their scope to be plausible generally, or too narrow to apply to the atmospheric sink.

Perhaps it is that individuals simply had some effect on land in Homesteading, without necessarily intending to, that gives them title to it. But this seems wrong. For it is surely not the case that we have ongoing claim to every part of nature's services that we have some effect on, subject to the Lockean conditions. If we did allow rights to be claimed simply by the habitual, unintentional affecting of any dimension of the world that does not presently leave others worse off or involve significant waste, rights of this kind would have a scope so wide as to be absurd. I might now be gaining ongoing rights to the ability of the Earth's crust to support my weight, the ability of the atmosphere to absorb the heat from my computer, and so on ad absurdum. We should be very wary of such a proliferation of rights.

The other alternative, that one condition of gaining Lockean rights is that one does intend to work the particular resource one gains title over, also seems to run into difficulty in the context of climate change. The homesteaders in Bovens' story certainly intended to interact with the land, but it would be controversial to say that early industrialists intended to use the atmospheric sink; they had no idea it existed, or at best, considered it to be limitless. It is far from clear that we intend to 
use unknown resources, or resources we judge to be practically limitless like the ability of the Earth's crust to support our bodyweight.

That said, the philosophy of intention is complex, and a sophisticated Lockean account might be able to respond to such worries. Equally, an argument for moderate grandfathering in the case of the atmosphere might be able to proceed on contractarian or welfare-based grounds. But more work needs to be done for the Lockean approach to answer the worries above.

However, in the remainder of this chapter I shall assess Bovens' defence of moderate grandfathering assuming, for the sake of argument, that an application of the Lockean account to the appropriation of the atmospheric sink is apt. In doing so, it seems that the caveats that Bovens himself suggests for when property rights in general should be annulled (the "internal critique") still lead us away from even moderate grandfathering.

\subsection{THE INTERNAL CRITIQUE RECONSIDERED.}

Recall that the internal critique revolved around the interaction of two considerations. When there are serious violations of the Lockean proviso, only good stewardship (i.e. respecting the no-waste condition) can prevent previously obtained rights being annulled. Likewise, when persons are wasting a resource, even a minor violation of the Lockean proviso could be enough to remove historically acquired rights. But, according to Bovens, "[i]f the no-waste condition is strongly respected, then the violation of the enough-and-as-good condition by itself is not enough to revoke my property rights" (140). In the case of climate change, Bovens believes, the no-waste condition has been respected by historical high emitters: their "good stewardship" (142) prevents their violation of the Lockean proviso removing the rights they had gained in the early period. The 
whole case for moderate grandfathering of emissions entitlements therefore rests on the strength of the claim that some (or perhaps most) historic emitters have been good stewards.

Bovens' only defence of this claim of good stewardship is to point out that developed countries and developing countries have both wasted the service of the atmospheric sink: the developed world through "inefficient and frivolous consumption", the developing world through "the use of dirty industries and hence its poor performance in GHG emissions per unit of GDP" (143). But even if Bovens' claim about the developing world wasting the atmospheric sink is true, it is insufficient to justify even limited grandfathering. Remember from Nozick's well that a serious violation of the enough-and-as-good condition was sufficient to justify the redistribution of water unless good stewardship has been shown. All that Bovens has done is claim that developed countries have been at least as bad stewards of the atmospheric sink as developing countries have been. But by Bovens' own theory developed countries need to have done better than that. As it stands, according to Bovens, all have violated both the Lockean proviso and the no-waste condition, so none of the parties are entitled to the atmospheric sink by dint of historic appropriation.

Could we go further than Bovens, and claim that the developing world's "use of dirty industries and hence its poor performance in GHG emissions per unit of GDP" (143) shows worse stewardship than the developed world's love affair with SUVs and long-chaul flights? I doubt it. First it is a gross oversimplification to say that the developing world has a poor performance in greenhouse gas emissions per unit of GDP. It is true that India and China have some of the highest of these figures, but countries such as Mozambique, Gabon and Zambia are among the twenty cleanest countries when $\mathrm{CO}_{2}$ emissions from fossil fuel consumption are measured per unit of GDP (International Energy Agency (IEA) 2011: 94). 
If we compare $\mathrm{CO}_{2}$ emissions from fossil fuel combustion with GDP measured by purchasing power parity, ${ }^{28}$ there is even less support for Bovens' claims about waste. 43 of the cleanest 50 countries on this metric are developing countries. Heavy past emitters tend to rank poorly. An EU average would come 61st, USA comes 97th, and Australia 109th out of 141 major countries (IEA 2011: 94). ${ }^{29}$

But there is a deeper problem: reaping more economic benefits from a resource simply does not represent good stewardship. It is true that getting more benefits from a given amount of pollution is a valuable goal, but this fact is orthogonal to our purposes here, which is to determine the degree to which different parties have violated the no-waste condition.

The idea that good stewardship involves getting the most economic value out of the resource or service one has appropriated is odd, and its strangeness can be seen when we translate it to other cases. Take the case of commercial fisheries, for instance, which Bovens believes is another common resource in which historical rights are (and should be) respected. ${ }^{30}$ The value that one extracts from fish, once it is harvested, is not really relevant to stewardship per se. Whether I choose to sell my fish at a good price or give it away is irrelevant to whether or not I have been a good steward of my quota (or the fish stocks generally). Likewise with land.

\footnotetext{
${ }^{28}$ Purchasing power parity seems to be a better measurement of efficient use here, for it is not the nominal value of benefits gained, but their actual value that matters.

${ }^{29}$ Interestingly, if a low ratio of tangible benefits per unit of greenhouse gas emitted indicates wastage of the atmospheric sink, this would, on the face of it, undermine Bovens' assumption that early emitters did not violate the no-waste condition. For they used vastly dirtier technologies than the coal power plants of India and China today, such as coal fired steam engines, that would take much more of the atmospheric sink to deliver the same tangible results as the dirtiest technology would today. Perhaps some relative measure of waste could be used to excuse early emitters, but in that case, one might suggest that developing countries, due to their differing circumstances, be given the same kind of leniency, and judged better stewards than developed countries.

${ }^{30}$ Bovens cites EU fisheries policy in this respect, which grants quotas to countries on the basis of their relative past use of the resource. In New Zealand waters, rights are distributed to firms in a similar way.
} 
Whether a homesteader in Homesteading invests their agricultural surplus well and becomes rich or spends it frivolously and continues to toil by the sweat of their brow seems to be irrelevant to whether or not they satisfy the no-waste condition.

We should reject the ratio of economic benefits to emissions level as a metric of stewardship. ${ }^{31}$ We need to investigate more deeply what stewardship might mean. To do so, let us consider the measures of stewardship in Bovens' own examples. There are two main threads. In Homesteading and his general discussion of property rights in land and buildings the key criterion was that appropriators be "capable of working or willing to work or manage" the land or space that the agents enclose (138). Appropriators must be ready to capture the flow they get from their portion of the resource system - their land. By this criterion, all countries would have been good stewards of the atmospheric sink, since all countries have used the flows from their initial appropriation of the atmospheric sink during the early phase (and much more). But to apply the no-waste condition in this way to the atmospheric sink is laughable. If good stewardship means anything here, it means not using the flows from the stock you have previously appropriated.

How is the no-waste or stewardship condition meant to be interpreted in the case of Nozick's Well? Here, according to Bovens, it means something quite different. Two main ways wells could survive, let us say, are either by restrictions on their use, or by improving the system in other ways (covering them so water does not evaporate). ${ }^{32}$ But historic high emitters have done none of these things. They have not rationed the use of the atmospheric sink. As to improvement, the minor

\footnotetext{
${ }^{32}$ Why would Bovens interpret the no-waste condition so differently between Homesteading and Nozick's Well? Perhaps because land is excludable in a special way. Once you have annexed common land, and excluded others from investing in it, it seems plausible to ask that you use it in order to maintain your claim to it. But it is impossible to exclude others from the atmospheric sink, and so claiming more than one can use is not physically possible, so stewardship must mean something different here.
} 
improvements some may have made to the atmospheric ability to absorb greenhouse gases through afforestation have been swamped by their rapacious use of it in terms of emissions. Even when one includes carbon captured by their $20^{\text {th }}$ century increase in forest cover, Annex 1 countries (roughly the group of heavy historical emitters) have taken roughly $70 \%$ of the total portion of the atmospheric sink claimed by people since 1750, despite forming just a small fraction of the world's population (Dellink and Den Elzen 2009).

Overall, when we examine the distribution of emissions entitlements using Bovens' own theory of what justifies respecting Lockean rights post conditionviolation, it seems that developed countries have been poor stewards of the atmospheric sink. Given they also would violate the Lockean proviso by continuing to use the atmospheric sink at previous levels, any historically-based claim they might have had to the atmospheric sink should be annulled.

\subsection{CONCLUSION}

Bovens provides us with a unique, Lockean attempt at justifying what has been, and will probably continue to be, political reality: those who have used the atmosphere's ability to absorb greenhouse gases the most in the past are given the most entitlements to continue to use it. However appealing the Lockean framework is for land, I think there are significant worries about applying it to the atmospheric sink. But even if one thinks that the Lockean story about appropriation could be applied in principle to the atmospheric sink, it should not lead us to support grandfathering. Bovens own plausible emphasis on the importance of owners continually satisfying at least one of the conditions of appropriation undermines the claim of the developed world to their high level of emissions. They have neither left as much and as good for others nor been good 
stewards. Bovens' argument fails, and we must measure entitlements to emit, and contributions to the problem of global warming, without reference to rights supposedly gained through historical patterns of emissions.

At the political level, the failure of Bovens' attempt to justify grandfathering on moral grounds is of great importance. As mentioned before, there have been few if any scholarly attempts to justify grandfathering morally, yet it is a concept that remains at the heart of international climate policy. The Kyoto protocol embodies a kind of grandfathering, and those historic heavy emitters who refuse to sign it or pull out to accept only relatively lenient voluntary targets to reduce emissions seem to be claiming to have a right to continue emitting at higher levels than other countries, with no moral justification. Grandfathering will still shape domestic climate change policy as well. In the emissions trading schemes such as those of New Zealand and the EU, many firms with historical high emissions are granted their allocations of emissions entitlements for free (Climate Change Information New Zealand 2011; European Comission 2008). Presumably because of the influence that heavy emitters hold, grandfathering emissions rights is seen as an acceptable practice. In the political world, past emissions are seen to justify, rather than undermine claims for disproportionately high emissions now. As a new legal agreement on climate change to replace the Kyoto Protocol is negotiated over the coming decade, it will be interesting to see if any moral case could be made to justify such a practice. If not, and if the new agreement allows current emissions to be significantly determined by past emissions, it would be another deeply regrettable case of injustice in international affairs. 


\section{4}

\section{The Two-Track Theory and its}

\section{Application}

"It appears that we must settle for a pluralist approach to distributing responsibilities." David Miller (2001: 468)

"Climate change is a very unusual ethical challenge because it's so completely measurable" - George Marshall (cited in Harding 2011: para. 102)

\subsection{THEORY}

\subsubsection{Principles of Justice}


In Chapter Two we recognised that principles of burden-sharing are needed to help decide who is responsible for remedying the harms due to climate change. In Chapter Three we rejected the principle that initial use of the atmospheric sink provides a reason to grant historical heavy emitters more rights to emit now. We still face the morally urgent tasks that make up the climate burden: tasks of mitigation, adaptation and compensation. Therefore, we need to find acceptable principles of justice in this domain, to guide us in choosing who should bear how much of the overall climate burden. In this chapter I develop a two-principle theory for allocating climate burdens, inspired by Simon Caney $(2005,2010)^{33}$. I divide the burden of climate change into the part that should be allocated by a plausible "polluter pays" principle (the "fault burden") and the part which should not (the "no-fault burden"). ${ }^{34}$. The no-fault burden is that part caused by the emissions created by the very poor and the emissions created under conditions of excusable ignorance. I defend the claim that a date in the range of 1970 to 1990 will best demarcate the end of conditions of excusable ignorance and I sketch the relative sizes of the two parts of the climate burden. Finally I develop an "ability to pay" principle and briefly discuss the practical import of my two-track theory.

\footnotetext{
${ }^{33}$ My two-track theory follows Caney's in its basic structure, with the division of the burden into two parts, and the use of a poverty sensitive "polluter pays" principle and an "ability to pay" principle to allocate the fault and no-fault parts respectively. It differs from Caney's in its recognition that emissions produced under ignorance should not form part of the fault burden, its rationale for the poverty sensitive clause of the "polluter pays" principle, and its assertion that the "ability to pay" principle does not need to be justified by the fact that those able to pay have benefitted from climate change. These differences will be explained more fully in what follows.

${ }^{34}$ The "fault" and "no-fault" labels play a similar role in work by Shue (1993), but I do not rely on his analysis. Caney refers to the burden from emissions that cannot be assigned by a "polluter pays" principle as "the remainder" (2010: 213ff). Such terminology suggests that this portion of the total climate change burden is rather minor. As we will see, burdens from such emissions are plausibly of the same magnitude as the burdens that can be allocated by a "polluter pays" principle. Calling them fault and no-fault makes no assumptions about the importance or magnitude of either set of burdens.
} 


\subsubsection{Polluter Pays}

Here is a principle for allocating the climate burden:

Polluter Pays: Parties should bear the climate burden in proportion to their contribution to its cause.

As stated, this principle is vague. It is unclear, for instance whether an individual has contributed to the cause of climate change if her emissions were low enough to be sustainable had all others kept to such a level. Partly because of the difficulties in defining what a sustainable level is (or might have been), and partly because others actually have not kept to a sustainable level, I will treat all current emissions as contributions under the "polluter pays" principle. ${ }^{35}$

Polluter Pays (Total) - (PPT): Parties should bear the climate burden in proportion to their contribution to its cause, where contribution is measured by the total amount of greenhouse gas emissions created by that party.

Why should we accept PPT or something like it? First, it matches the intuitions we have about small-scale examples: we hold a litterer, not someone else, responsible for rubbish she leaves in the street. This intuitive appeal may be grounded by the general idea that morality requires holding people accountable for the effects of their actions (Caney 2009c: 177). Second, reference to the "polluter pays" principle already features strongly in the political domain, having been recommended by the Organization for Economic Co-operation and Development (OECD), the

\footnotetext{
${ }^{35}$ Additionally, if we reject the notion that emissions should be allocated on an equal per capita basis (see section 4.2.2), much of the motivation for defining pollution as that over a sustainable level is lost.
} 
European Union (EU), and the Commission on Global Governance (Comission on Global Governance 1995: 212; EU 2004; OECD 1974: 12-13, 18-19). Third, a "polluter pays" principle penalises and thus aims to deter people from performing the activity we wish to reduce (polluting) without directly deterring them from other possibly valuable activities. Finally the "polluter pays" idea provides firm ground on which to answer the challenge we investigated in Chapter Two, that climate ethics must be revisionary. By linking responsibility for harm directly to the performers of harmful action we remain in the familiar ethical realm of harmers and the harmed.

\subsubsection{Historical Emissions and Excusable Ignorance}

The "polluter pays" principle appears well suited to distribute the burdens from current emissions. If a firm is burning large amounts of coal today, it makes sense to attach the responsibility of dealing with the climate burden created by the coalburning to that firm. But the burdens of climate change arise from historical as well as current emissions. The huge quantity of greenhouse gases emitted between the beginning of the industrial revolution and the present is the main cause of the changes in climate occurring now, and will be the cause of the changes to come. ${ }^{36}$

Many have argued that the parties who created such historical emissions should bear responsibility for their effects. One example is the following statement by 41 developing countries to the UN general assembly:

\footnotetext{
${ }^{36}$ Scientific evidence suggests that around $50 \%$ of the $\mathrm{CO}_{2}$ emitted a century ago is still in the atmosphere, contributing to global warming now. $20 \%$ of any $\mathrm{CO}_{2}$ that has been emitted will persist in the atmosphere for millennia. See Meehl et al (2007: 824). Furthermore, even once $\mathrm{CO}_{2}$ has dissipated, much of the warming it produced remains in the climate system. For these reasons, we should treat historical emissions seriously.
} 
Responsibility for the emissions of greenhouse gases should be viewed both in historical and cumulative terms, and in terms of current emissions. On the basis of the concept of equity, those developed countries who have contaminated most must contribute more" (Ministerial Conference on Environment and Development 1991: 4 (section II.12) [italics mine]).

In the lead-up to the creation of the Kyoto Protocol, Brazil formally suggested that countries should face emissions restrictions in proportion to their historical emissions since 1840 (Brazilian Delegation to the UNFCCC 1997). This stands in strong contrast to the Protocol that was eventually adopted, under which historical emissions before 1990 do not count against the quotas of countries today. ${ }^{37}$

Developing countries have continued to stress the importance of historical emissions. Take, for example, the following statement from Pablo Solon, Bolivia's ambassador to the UN.

[Industrialised countries] have used up two thirds of the atmospheric space, depriving us of the necessary space for our development and provoking a climate crisis of huge proportions. It is entirely unjustifiable that countries like Bolivia are now forced to pay for the crisis. This creates a huge draw on our limited resources to protect our people from a crisis created by the rich and their over-consumption (quoted in Buxton 2009: para 3-4).

\begin{abstract}
Although distributing these historical burdens according to a polluter pays principle is a popular idea, it has problems. Many of the individuals and collectives that emitted heavily in the past no longer exist. ${ }^{38}$ Granted, most of the

\footnotetext{
${ }^{37}$ Arguably, an acknowledgement of historical responsibility may still be behind the Kyoto Protocol's division between Annex 1 countries (who are assigned burdens) and non-Annex 1 countries (who are assigned none).

${ }^{38}$ Recall from Chapter One the main types of actors that could be judged capable of possessing duties regarding climate change: states, firms, institutions and individuals.
} 
historical heavy emitting states such as the UK, the USA and Germany still exist, but the notion that current individuals should be liable for the responsibilities generated by their forebears is controversial. ${ }^{39}$ Fortunately, we can avoid this controversy, for we should not assign responsibility via a "polluter pays" principle for those emissions created before scientists suspected anthropogenic global warming was possible.

Call this the "excusable ignorance" defence of historical emitters. The fact that an agent had no way of being aware of the harmful effects of her action provides a good reason to excuse her from responsibility for those effects. Emissions released before scientists suspected anthropogenic global warming was possible (call these "emissions under ignorance") were created by polluters who were excusably ignorant that greenhouse gases could be so harmful. Therefore we should respond to parties' excusable ignorance about the effects of emitting greenhouse gases by exempting them from responsibility for their emissions under ignorance (cf. Page 2008; Singer 2004: 34).

To be plausible, the excusable ignorance defence must overcome two major objections: the objection from benefits and the objection from strict liability. The objection from benefits argues that, since currently extant parties have benefitted from their own historical polluting, it is fair to ask them to pay for all their emissions, even those produced under ignorance (at least until the costs they are asked to bear match the benefits they have gained). I put aside this objection

Around half of the $\mathrm{CO}_{2}$ emissions since 1750 have been released by individuals who are now dead. ( $\mathrm{CO}_{2}$ data from Houghton (2008) and Boden et al (2011), world population data from United States Census Bureau (2012) except for 1947-1942, 1922-1907 from Wolfram Alpha (2012); 1927-37 from League of Nations (cited in Manning (2008)). Calculations available in Kingston (2012)). As to other types of actor, most firms from the historical period will have also disappeared - one estimate has the average "life-expectancy" of a corporation as "well below 20 years", with only a very few passing 40 or 50 years (de Geus: 52-53).

${ }^{39}$ For an argument that, at least in the case of climate change, members of collectives should not directly bear the burdens created by their forebears, see Caney (2006). For a general defence of the transferability of historical responsibility of collectives, see Miller (2004). 
for now; I address it in Chapter Five. The objection from strict liability states that in certain situations, we are perfectly willing to demand that agents be morally responsible for the effects of their actions, regardless of their ignorance (at the time) of the consequences of those actions. The historical release of greenhouse gases by those ignorant of its effects, according to this objection, should be one of these cases (Gardiner 2004; Neumayer 2000; Shue 1999).

Strict liability seems to be overly harsh on those who cause unexpected harm. If my spitting an orange pip off the side of a mountain path happens to cause a rockslide below, we would not ordinarily judge that I was morally responsible for the harm the rockslide causes (D. Miller 2004). Why should the case of the unexpected harm caused by early emitters be any different? Shue suggests that a commitment to equal dignity can justify applying strict liability here:

If there were an inequality between two groups of people such that members of the first group could create problems and then expect members of the second group to deal with the problems, that inequality would be incompatible with equal respect and equal dignity. For the members of the second group would in fact be functioning as servants for the first group. If I said to you, 'I broke it, but I want you to clean it up', then I would be your master and you would be my servant. If I thought that you should do my bidding, I could hardly respect you as my equal (Shue 1999: 535).

Shue is right that expecting others to deal with the problems one creates is a selfserving attitude normally incompatible with a principle of equal dignity. But it is a mistake to characterise the excusable ignorance defence as a straightforward instance of such an attitude. In Shue's characterisation, the first group rejects strict liability but also demands that the second group bear all the burdens. There are better alternatives. As I will argue later in this chapter, the burdens from excusably ignorant historical emitters (regardless of whether those emitters are 
still around) should be assigned by a secondary principle of justice, an abilitybased principle. Other elements are also missing from Shue's characterisation. The passage of time between a breakage and the clean-up effort is insufficient on its own to remove the obligation of someone who breaks something, but surely is a mitigating factor. Further, Shue's focus on historical emitters "creating problems" and the metaphor of a breakage creates associations with negligence, for habitual activity that causes problems like breakages very often is negligent behaviour. And negligent behaviour certainly can carry strong moral responsibility for any ill effects. But historical emitters were not negligent. ${ }^{40}$ Taking all these differences into account gives us a picture rather different from Shue's. Instead of saying "I broke it, but I want you to clean it up", currently alive parties who caused historical emissions under ignorance are saying: “I broke the atmosphere's ability to absorb greenhouse gases safely, in ignorance of its value, without acting negligently, many decades ago. Given that we now have differing abilities to clean up, we should contribute to the clean-up effort in accordance with our abilities. Any breaking of the atmosphere's ability to absorb greenhouse gases after the time I became aware of its value I will certainly clean up myself." This is radically different from the pronouncement of a master to a servant, and is compatible with a commitment to equal dignity.

Supporters of strict liability in the case of climate change sometimes point to legal precedent. Under many legal systems, strict liability applies to a range of activities in both civil and criminal law: inherently dangerous activities, driving, and the

\footnotetext{
${ }^{40} \mathrm{Negligence} \mathrm{is} \mathrm{often} \mathrm{defined} \mathrm{as} \mathrm{not} \mathrm{taking} \mathrm{reasonable} \mathrm{care.} \mathrm{If} \mathrm{early} \mathrm{emitters} \mathrm{did} \mathrm{not} \mathrm{know} \mathrm{of}$ climate harms, reasonable care would not require them to abstain from emitting. An opponent might be tempted to cast the whole project of resource-intensive industrialisation as negligent, once the associated general harms to the environment had become obvious. But the harms of industrial activity that were evident in the early $20^{\text {th }}$ century were typically area-limited effects such habitat destruction and local air pollution. The publication of Rachel Carson's Silent Spring (1962) is typically regarded as the first recognition of global effects of pollutants emitted locally. Further, one could charge that to cautiously reduce resource-intensive industrialisation would also be negligent because it is not taking reasonable care of the material needs of people at the time.
} 
sale of products that harm consumers ${ }^{41}$. For these activities, actors are often held legally responsible for serious harm caused by their actions even if they were taking reasonable care not to cause harm. More specifically, there is precedent for the use of strict liability in environmental law, both internationally and in the US (Boyle 1990, 2005; Gardiner 2004; Klass 2004).

But as Bell (2011b) points out, the application of strict liability within environmental law is usually reserved for those committing dangerous or unusual activities. For example, in United States environmental law, activities that are "a matter of common usage" are not subject to strict liability (Restatement (Third) of Torts, (cited in Klass 2004: 918)). Burning coal and oil has been a matter of common usage - the very reason why global warming is a problem now. Appeals to legal precedent are insufficient to ground the objection from strict liability.

The excusable ignorance defence can survive the objection from strict liability, and (I argue in Chapter 5) the objection from benefits. However, it does require some clarification with respect to the question of ignorance. In particular, if it is possible for emitters to be excusably ignorant, at what point do emissions become the responsibility of the emitter? We also face a question of historical fact: when did this change occur? This is not the place to settle the question of historical fact, but I will touch on it while I treat the question of clarification, and thus present an upper and a lower date, before which emissions of greenhouse gases should be judged as being produced under excusable ignorance.

\footnotetext{
${ }^{41}$ Perhaps one could argue that strict liability should apply to oil and coal companies because their products turned out to be harmful. But this would be controversial, not least because applying strict liability in the case of harmful products was a legal move intended to reduce the difficulty of winning cases where negligence was very hard to prove. For an example of contemporary reluctance to accept strict liability see Hart (1968: 20) who notes that strict liability has been "admitted as an exception to the general rule, with the sense that an important principle has been sacrificed to secure a higher measure of conformity and conviction of offenders".
} 


\subsubsection{When Should Polluter Pays Start to Apply?}

The theoretical possibility that the world's climate might change due to human activity was proposed as early as 1896 - should this be the date at which excusable ignorance should cease to exempt parties from Polluter Pays? At the other extreme, human-induced climate change is denied even today by a majority of US residents (Yale Project on Climate Change Communication 2011). Could people still be excusably ignorant of the harms of greenhouse gas emissions? We need a standard by which to judge what constitutes excusable ignorance.

Peter Singer (2004: 34) suggests that a legitimate standard for the end of excusable ignorance is when "solid evidence" of the hazards of $\mathrm{CO}_{2}$ emissions emerged in the scientific community (according to him, this was around 1990). Excusable ignorance existed, according to Singer, while agents polluted when they "could not know" (italics mine) of the limits of the capacity of the atmosphere to absorb gases. ${ }^{42}$

Paul Baer (2008) remains undecided on the issue, but suggests that a different standard for judging excusable ignorance might be justified. He counts some events much earlier than 1990 as possibly relevant to the removal of the excusable ignorance exemption. These include the threat of anthropogenic global warming being recognised by the US Johnson Administration in the 1960's, by some universities in the 1940's, and by Svante Arrhenius in 1896. Such dates might indeed be relevant if the suspicion of a scientific minority, rather the knowledge of a majority, was the crucial element in removing the excusable ignorance exemption for historical emissions.

\footnotetext{
${ }^{42}$ Edward Page (2008: 560) also mentions the "widespread ignorance" of "the nature and scale of global climate change" until the 1990's as a relevant mitigating factor in polluters' liability.
} 
I propose that, generally, once it is reasonable for an agent to suppose that her action has the potential to cause systemic harm, she is morally responsible for the effects of that action. This conjecture seems particularly plausible where the harm is due to fall on especially vulnerable people (cf. Barry 2005), as is the case with climate change. A distinction is necessary here. I have not said that agents at the time of suspicion should have begun to act cautiously, ${ }^{43}$ rather, that this is the point at which moral liability should start to be applicable. The latter is surely what we are interested in when we consider whether historical emissions should be exempt from a "polluter pays" principle.

The difference is worth stressing, and can be seen more clearly if we place ourselves in the position of the actors in question. Some scientists suspect that increased levels of extra-high and extra-low frequency electromagnetic radiation from wireless phones and power lines will harm us (Draper et al. 2005; Hardell et al. 2009), although the evidence is far from strong (Maslanyj et al. 2010), while the benefits of technologies that cause increased electromagnetic radiation are large. Asking those agents responsible for increasing the amount of such radiation (telecommunication and electricity companies, as well as the consumers creating demand for the technology) to desist from their activities in the name of caution would be rash. On the other hand, asking such agents to take responsibility for any eventual systemic harm from the large increase in electromagnetic radiation might be fair. Many instances of increased electromagnetic radiation will present benefits great enough that agents will be willing to take the risk and continue to produce and develop and use the radiation-emitting technology, as long as the payoff is worth the risk. On the other hand, stressing actors' liability for potential harm at the stage of mere suspicion does discourage profligate and unnecessary

\footnotetext{
${ }^{43}$ This extreme view would be justified by a precautionary principle strong enough to render any action which we were not convinced of the safety of as unadvisable. But any precautionary principle this strong would prohibit any novel activity, including regulation of the dangerous activity, as regulation poses its own risks. Hence Cass Sunstein's accusation that precautionary principles are incoherent. Sunstein (2005: Chapter 1).
} 
alteration of the environment - massive electromagnetic radiation to please one or two people, for instance.

Now we can add an excusable ignorance clause to Polluter Pays (Total):

Ignorance-Sensitive Polluter Pays (ISPP): Parties should bear the climate burden in proportion to their (total) contribution to its cause, not counting emissions produced before it was reasonable to suppose they had the potential of systemic harmful consequences.

Even armed with ISPP, choosing any single date before which emissions can be judged to be emissions under ignorance would be a highly complex undertaking. Scientific suspicion about each of the different greenhouse gases arose at different times. Even if we focus on suspicion about the harmfulness of $\mathrm{CO}_{2}$, impediments (such as language barriers and fragmented scientific communities) could have excusably slowed dissemination of the scientific community's suspicion. Finally, to suggest a single date as a threshold for responsibility might make our theorising easily applicable, but is unrealistic. In a world of gradations and complexity, it is nonsense to think that all agents suddenly acquired full responsibility for their emissions on January 1, 2000, 1990 or 1950.

It will be impossible to be completely faithful to the gradual and uneven emergence of relevant suspicion when we put a principle like ISPP into practice, but in the spirit of pragmatism we can examine the question of which emissions were emissions under ignorance. It was not reasonable to suppose that human emissions of $\mathrm{CO}_{2}$ had significant harmful effects simply from the publication of Arrhenius' ideas on the possibility of human induced global warming (Arrhenius 1896). Arrhenius was no Cassandra - he was mainly concerned with the possibility that natural variations in $\mathrm{CO}_{2}$ explained the procession of ice ages and interglacial periods. He believed it would take thousands of years, rather than 
decades, before the increase in $\mathrm{CO}_{2}$ from fossil fuel combustion would cause substantive warming. Moreover, his models were derided as overly simplistic by contemporaries (Weart 2011b). It was 1960 before measurements (taken from atop Hawaiian mountains to avoid local distortions) could detect that atmospheric $\mathrm{CO}_{2}$ was steadily increasing (Weart 2011a). Before then, to be suspicious of $\mathrm{CO}_{2}$, scientists would need to believe two unlikely facts: that human emissions could cause $\mathrm{CO}_{2}$ to rise, and that this rise would be enough to warm the earth. However, I depart from Page and Singer's assessment, noted earlier, by suggesting 1970 as a key date. In 1970 major scientific meetings were held addressing "possible impacts of man's activities on the regional and global climate" (Massachusetts Institute of Technology (MIT) 1970: 1). The conclusion of climate scientists at such meetings was that more study was urgently needed, which makes it seem reasonable for people to suppose at that time that anthropogenic $\mathrm{CO}_{2}$ emissions were potentially harmful ${ }^{44}$, and so ISPP could be applicable to emissions of $\mathrm{CO}_{2}$ at that time. Certainly by 1990, at least, most individuals and collectives had ample reason to suspect that $\mathrm{CO}_{2}$ emissions carried risks of harmful climate change. Conversely, the lack of significant suspicion before 1970 should excuse all pre-1970 emissions from being allocated by a "polluter pays" principle. A compromise date between these two thresholds might be a rough approximation, or different dates for the removal of excusable ignorance could be applied to parties according to their circumstance.

\footnotetext{
${ }^{44}$ The study published after the meeting states "We have a conviction that man can influence the climate, especially if he proceeds at the present accelerating pace. We hope that the rate of progress of our understanding can match the growing urgency of taking action before some devastating forces are set in motion - forces that we are powerless to reverse" (MIT: 27). Much is often made of the fact that, through the 1970's, global cooling was apparently perceived to be as serious a risk as global warming (e.g. Holcombe 2006). However, a recent review (Peterson et al. 2008) of early climate change science has found much more evidence of scientific concern over warming rather than cooling, even in the 1970's. Even if cooling were as great a concern in the 1970's as warming was, this would render most polluters even more liable for their past emissions. For it is the same activities that were linked to global warming - the burning of fossil fuels - that were suspected to have the potential to cause global cooling.
} 
How large does this make the historical portion of the no-fault burden? It is impossible to be exact, but we can point to some key facts. Humankind has emitted roughly 2000 billion tonnes of $\mathrm{CO}_{2}$ since the industrial revolution. Around 1400 billion tonnes of this was emitted before 1990, and 900 billion tonnes of it before 1970 (Boden et al. 2011; Houghton 2008). If the date at which parties became responsible for their emissions under ISPP lies somewhere between 1970 and 1990 this means that between $44 \%$ and $67 \%$ of total $\mathrm{CO}_{2}$ emissions have been emitted by parties who were excusably ignorant..$^{45}$ Of course $\mathrm{CO}_{2}$ is not the only greenhouse gas, but the short decay times of HCFC-22 and methane mean that the warming potential from historical emissions of these gases are not as great that of $\mathrm{CO}_{2}$, so historical proportions of these gases may count for less (Meehl et al. 2007: 824-5).

In the long term, the historical portion of the no-fault burden will be comprehensively outweighed by the cumulative total of the fault burden. For now that we know about the consequences of greenhouse gas emissions, future emissions can be attributed to the emitters under ISPP. ${ }^{46}$ But the date at which this will happen is truly far off. Even in 2050 the proportion of cumulative emissions that were produced before 1970 is projected to be still a sizeable $25 \%{ }^{47}$

\footnotetext{
${ }^{45}$ Calculated using data from Houghton (2008) and Boden et al. (2011). The proportion should be reduced by a certain factor, because due to decay and concentration effects, a tonne of $\mathrm{CO}_{2}$ emitted in 1963 does not have the same warming effect as a tonne emitted in 2011. But this will probably not be a drastic reduction, as the long time scale on which the ocean absorbs and radiates heat means present and past emissions will continue to have warming effects on the rest of the earth (Solomon et al. 2007: 68). On the other hand, we also could judge (especially if we were taking a strictly individualist stance) that the no-fault burden should be increased from the ensuing fraction by a certain factor, for some of the parties who have created emissions since the threshold of ignorance was crossed have disappeared, meaning there are extra no-fault emissions - those emitted by the now-deceased even after the threshold of ignorance had been crossed.

${ }^{46}$ Even if current emitters manage to pass away without discharging their responsibilities, those who have received the benefits of those emissions should inherit their responsibility, since a "beneficiary pays" principle based on past injustice could now apply. See Chapter Five. ${ }^{47}$ Calculated with data from Boden et al. (2011) and Houghton (2008)
} 
Still, the effect of historical no-fault $\mathrm{CO}_{2}$ emissions dwarfs that of current $\mathrm{CO}_{2}$ emissions, which stand at 35 billion tonnes of $\mathrm{CO}_{2}$ annually. Were it not for the nofault emissions, the burdens of mitigation, adaptation, and compensation that parties face today would be lower. We also need to reach some agreement on how to distribute the climate burden as soon as possible. We must distribute it fairly as it stands, rather than erroneously assuming that past emissions have made little difference to our current predicament, or that soon enough they will be so insignificant that we can forget about them.

Given that excusable ignorance should exempt the part of the climate burden created before (at least) 1970 from being allocated by a "polluter pays" principle, finding the best way to allocate this burden is very important. I will try to do so later in this chapter. First, though, I will explore the other portion of the no-fault burden - that portion created by the desperately poor. ${ }^{48}$

\subsubsection{Further Exemptions - Poverty-Related Emissions.}

Very many of the world's inhabitants are desperately poor. 1.4 billion people live on less than the equivalent of \$1.25 per day ${ }^{49}$ (World Bank 2005: 67), 14\% of the world suffers systemic undernourishment (World Bank 2005: 112) and around

\footnotetext{
${ }^{48}$ Besides the climate change caused by historical emissions emitted by people who no longer exist, Caney also points out that there is quite plausibly some portion of global warming that is not caused by people - a portion caused by cyclical variation, sunspots or other natural phenomenon. Caney wants to allocate responsibility for the accompanying nonanthropogenic set of harms to some actor. This is because, he states, from the victim's point of view, it does not matter from what quarter her interests are disturbed, but rather that she should be offered protection or compensation for the disruption to her vital interests (Caney 2010). As I see it, judging naturally caused global warming as part of the no-fault burden seems to rely on significant positive rights to subsistence, life and health. To broaden the appeal of my two-track theory, I will not include naturally caused climate change as a no-fault burden. This omission might have some bearing on the appropriate magnitude of the climate tasks (which I do not discuss in this thesis) but has no bearing on the allocation of the climate burden, since it will need to be borne, whatever its size.

${ }^{49}$ The \$USD 1.25 figure refers to the equivalent in local purchasing power parity.
} 
17\% of adults cannot read and write (Central Intelligence Agency 2010: [online]). Applying the "polluter pays" principle to the greenhouse gas emissions of these already severely disadvantaged people would mean assigning an unacceptably grave burden to those with already very limited opportunities and resources.

As mentioned earlier, we have defined "contribution" in ISPP as total emissions, rather than emissions above what would be a sustainable equal per capita level. So to protect the vital interests of the very poor we must make the "polluter pays" principle itself "poverty sensitive" (Caney 2010: 218). I will formalise it thus:

Poverty and Ignorance Sensitive Polluter Pays (PISPP): Parties should bear the climate burden in proportion to their (total) contribution to its cause, not counting emissions produced before they were suspected by a significant proportion of the relevant scientific community to have the potential of systemic harmful consequences, unless doing so would seriously threaten their basic needs [or those of their members].

One might think that such an exemption from the "polluter pays" principle for the desperately poor must be motivated by an acceptance of sufficientarian or egalitarian patterns of welfare distribution, or a commitment to extensive positive rights. Caney seems to suggest this: "If one holds, as I do, that people should not fall beneath a certain standard of living then the Polluter Pays Principle should be qualified to prevent it being the case that people are made to pay for emissions needed for their fundamental survival" (Caney 2010: 213 [italics mine] ). But one need not subscribe to a particular theory of distributive justice, or hold that people should have the positive right to escape poverty, in order to accept the povertysensitivity clause. PISPP can be justified by the idea that the principles of burdensharing we take up to prevent harm to others should not cause the same degree of harm amongst the polluters we require payment from. Perhaps sufficientarianism or something similar will be needed to justify a strong reading of 'basic needs' in 
the clause above, but the poverty-sensitivity aspect itself can be justified from a (negative) rights-based framework too. If our concern to distribute the burdens of climate change is due to our desire to not let the basic rights of future people be jeopardised, ${ }^{50}$ this reason will justify exempting the emissions of the very poor from being subject to a "polluter pays" principle. To include the emissions of the very poor under such a principle would be to violate their right not to be interfered with in seeking their own basic survival. This would be a rights violation of the same magnitude that the burden-sharing has been proposed to prevent, and so the poverty sensitive clause should be added to prevent such a counter-productive result.

Ascertaining at this point the relative level of those no-fault emissions that are generated by the severely poor would be very difficult. To define exactly which emissions would be exempt under PISPP due to the poverty of the emitter depends on what we judge are "basic needs". Further, if we were to take the justification above for the principle this would lead us to consider two unclear factors. One is the extent of the harm that climate change is expected to impose on people, the other is how much of the world is so poor that they cannot be asked to bear any burdens because to do so would create the same degree of harm. Whatever we want to say about these issues, it is true that some are so desperately poor that to ask them to pay for the effects of their emissions would be wrong, so their emissions form the second part of the no-fault burden.

\footnotetext{
${ }^{50}$ For an argument that future people have no rights to be jeopardised, see Beckerman and Pasek (2001), Chapter 1. For a defence of the idea that climate change violates the rights of future people, see Bell (2011a).
} 


\subsubsection{Ability to Pay}

The no-fault burden is made up of the burden created under ignorance and the burden from the emissions of the very poor. Responsibility for the no-fault burden cannot be attributed by PISPP to any extant party, but this does not mean that it can be ignored. The costs associated with it must either be allocated deliberately or they will fall on the victims of climate change selected by the vagaries of geophysical systems and realpolitik. Caney points out that making the very poor pay for the no-fault burden would be wrong (indeed, part of the no-fault burden is made up of emissions we exempted the current poor from having to pay). The same intuition, according to Caney, should make a laissez-faire attitude to the nofault burden just as repellent. This is because it is again the very poor in the tropics and most especially in vulnerable regions such as Bangladesh, the Nile Delta and small island states, who will be asked to bear the costs of climate change without compensation or adaptation (GHF 2009: 58-66). Requiring stringent duties of mitigation, adaptation and compensation from current polluters in proportion to their current emissions ${ }^{51}$ would prevent the worst off from bearing the entire no-fault burden, but would be unfair on current heavy emitters. For they would now be asked to bear others' burdens, over and above the cost of their own pollution. An ability-based principle provides a way out. No-fault emissions have created a bad situation that requires a remedy, and the creators of the situation cannot be held accountable. Under such circumstances, if our goal is to put a bad situation right, it makes sense to assign responsibility to those most able to put it right (D. Miller 2001: 460-1). To put climate change right is to undertake the climate tasks: to prevent its worst effects, help those who will be stricken by it to prepare, and compensate those who will suffer from it. We should look to who is most able to take up these tasks. This brings us to my initial version of an "ability to pay" principle.

\footnotetext{
${ }^{51}$ As suggested by Singer (2004) and Weijers et al. (2010).
} 
Ability to Pay: Parties should pay for the no-fault burden, because they are able to and in proportion to their ability.

It is hard to find examples of direct criticism of such a principle in the case of climate ethics. ${ }^{52}$ Emphasising the relevance of an alternative principle that can assign responsibilities for the no-fault burden is more common. A popular candidate for such a principle is that those who have benefitted from such emissions should bear the associated burdens (Caney 2010; Das in preparation; Page 2008, 2011a). I postpone objections against the "beneficiary pays" idea until the next chapter.

Ability to Pay is presented abstractly; deep and difficult questions remain about what "ability" is. I can turn to this complex question only briefly.

I suggest the following comparative definition: party A has more ability to pay climate costs than party B if they can do so with a lesser decrease in their relevant goods, where decreases are measured proportionate to A and B's respective goods. This of course raises the question: what are the correct measures of a party's goods? Should they involve subjective measures such as welfare, or objective

\footnotetext{
52Page (2011a) sees ability as an unfair measure by which to distribute proportionate burdens (although he thinks ability should play a role in dividing burden-bearers from non burdenbearers) because states that have developed "responsibly" with low-emissions technologies will be asked to pay as much as similarly able states that have developed irresponsibly. But this objection fails to apply when Ability to Pay is being used only as a secondary principle for allocating burdens from no-fault emissions. The recent emissions history of clean and dirty states will be taken into account by a "polluter pays" principle, and the distant (pre-1970) history should be judged to be morally irrelevant (see sub-sections 4.1.3-4.1.4.) so the cleaner state's complaint is groundless. Stephen Gardiner (2004) questions Martino Traxler's claim that his capacity-based approach is uniquely placed to overcome the prisoner's-dilemma structure of climate change politics (Traxler 2002), a claim I am not making about Ability to Pay. Moellendorf's criticism - that Traxler's approach is too demanding on the poorest (Moellendorf 2009) - can be accommodated by refining of the idea of proportionate burdens (see later in this section).
} 
measures such as wealth, or a nuanced approach which focuses on people's capabilities? Choosing between these measures involves entering the debate about the correct "currency of justice" (Dworkin 2004: 340-41; D. Miller 2008: 147), which I cannot do adequately here.

Things become simpler if we focus on the form that the costs of the climate tasks will take. Under most conceptions of the climate tasks, the costs will be monetary, or at least material. For example, mitigation tasks might lead to increased energy costs and tighter regulations on energy efficiency, compensation and adaptation tasks to an extra demand on government revenue..$^{53}$

Given that the costs of the climate tasks are, in the first instance, material, we can avoid the question of the correct currency of justice by continuing to use the placeholder "relevant goods". For regardless of whether the most important goods are subjective or objective, those with more material wealth seem better able to absorb the costs of climate change with the least long-term losses (proportionate to holdings) in the kinds of things we might care about people having. For this reason, ability to pay should be at least linked to a measure of material wealth, although perhaps in a non-linear way. ${ }^{54}$ The more material wealth a party has, the fewer goods they risk losing through absorbing the costs of climate tasks.

But our "ability to pay" idea is still ambiguous. Our world contains great inequality. Do the wealthiest have all the ability to pay, if they can bear all the

\footnotetext{
${ }^{53}$ It is true that many mitigation tasks, such as home insulation and increased energy efficiency are actually "no-regrets policies" which economically rational actors would get a net benefit from (Pacala and Socolow 2004). But climate change cannot be solved using only no-regrets policies (Miller, 2011: 87-92).

${ }^{54}$ If the relevant benefits were judged to be subjective, the relationship between wealth and ability might take into account, for example, the principle of diminishing marginal utility and empirical data about the limited impact of wealth increases on well-being once a threshold of wealth is reached (Layard et al. 2012: 60-66).
} 
losses without dropping to the level of holdings of the next set? Or should we consider that ability to pay is spread, albeit unevenly, across the range of wealth levels, with every party able to pay to some extent? An example will help.

Let us imagine a simplified world with just three parties. A has 100 wealth units, party B, 30, and party $C, 1$.

Table 1. Differing conceptions of 'ability to pay'

\begin{tabular}{l|l|l|l} 
& $\begin{array}{l}\text { A (100 wealth } \\
\text { units) }\end{array}$ & B (30 wealth units) & C (1 wealth unit) \\
\hline Scaled & Major ability & Medium ability & Minor ability \\
\hline High Threshold & All the ability & No ability & No ability \\
\hline Low Threshold & Major ability & Medium ability & No ability
\end{tabular}

Each conception in the table above seems compatible with what I have said about ability being capacity to bear costs with the least drop in proportionate holdings. But we can rule out Scaled immediately, for it is too harsh on the poorest, C. The conception that requires the poorest countries or individuals to bear any of the climate burden can be ruled out by the same poverty-sensitive consideration that we added to our "polluter pays" principle - allocating the climate tasks should not cause the same harms they are intended to prevent. We need to decide, then, whether we should follow High Threshold, requiring only the richest to pay, or Low Threshold, requiring all parties except the very poorest to bear some burden.

High Threshold considers climate costs in a marginal sense; the cost of contributing one more dollar to a climate fund would constitute a lesser drop in proportionate wealth (and presumably in other goods) for A than it would for B, until A's 
wealth was reduced greatly. Low Threshold tries to share the total costs of climate change among all parties except the very poor, in proportion to their ability to pay. Our intuitions about the desirability of each conception will be influenced by our background commitments to particular theories of political philosophy. But there are reasons against choosing High Threshold that are largely independent of such background commitments. In the case of climate change, this would mean that the wealthiest party, or more plausibly, a highly wealthy group of parties, should bear all the cost of no-fault emissions. The Kyoto Protocol distributes its (inadequate) costs by such a mechanism. ${ }^{55}$ The theoretical objection to this is that the approach represents a kind of climate-specific egalitarianism. Proportions of burdens are given to a top tier only, presumably because parties are asked to move towards (more) equal holdings, and any holdings above the threshold are thus expendable. Some of course may be quite unconvinced by the importance of such a move towards equal holdings. Others may be convinced, but suggest that if such a move should be made, it should be made in general terms, rather than through the specific (blunt) instrument of climate burden allocation (Posner and Weisbach 2010: 86ff).

One pragmatic objection is that using Ability to Pay to separate a minority of burden-bearers from the non burden-bearers risks creating a divisive us-and-them scenario, perhaps one of the reasons climate negotiations have been so slowmoving. Another is that applying ambitious portions of the no-fault burden to the minority of able parties may quickly push them below the threshold of ability, and others may rise above it. The associated political manoeuvring and conflict

\footnotetext{
${ }^{55}$ The Kyoto Protocol distinguishes between Annex I countries that bear burdens and nonAnnex 1 countries that bear no burdens, although the UNFCCC norm of "common but differentiated responsibilities and respective capabilities" suggest that a dual rationale (historic emitting and current capability) rather than simply ability to pay is being used. A high or mid-threshold approach has been suggested by Weijers et al. (2010) (with a three-tier approach) and Page (2010).
} 
involved in the rearrangement of parties around the threshold would further delay needed action on climate change.

The Low Threshold interpretation of the "ability to pay" principle avoids the above objections. It does not represent a narrow climate-specific egalitarianism. Its poverty-sensitive threshold need not be as politically divisive as a high threshold, as graded contributions would ensure that those parties just above the threshold will bear burdens little different from those below the threshold, and should also be receiving benefits of adaption and compensation.

Thus we reach a refined ability-based principle:

Ability to Pay': Parties should pay for the no-fault burden, in proportion to their capacity to absorb their total share of the costs of climate tasks with the least drop in proportionate relevant benefits, unless doing so would seriously threaten their basic needs.

As noted earlier, because the costs of climate tasks are initially material, this ability could be modelled by a measure of wealth, perhaps in a non-linear way, if the relevant benefits are non-material. ${ }^{56}$

\subsection{APPLICATION}

Having explained the two track theory, I will now apply it to two practical issues.$^{57} \mathrm{I}$ first consider and rebut the suggestion that my two-track theory justifies passing costs of climate change tasks on to future generations. I then turn to the question of emissions restrictions and allocation, rejecting schemes of emission

${ }^{56}$ See note 53. 
allocation that involve equal-per-capita allowances and state-centred schemes in favour of a company-centred auction scheme.

\subsubsection{Against Discounting}

The two-track view I have been advocating proposes that the well-off should bear those costs that cannot or should not be borne by the polluters themselves. It is at least plausible that future generations will be better-off than us. ${ }^{58}$ Therefore one might be tempted to make the argument that future generations, according to the two-track view, should pay for the no-fault burden. There is a naive version of this argument that advances from the premise that future generations are expected to be wealthier on average than the current generation to the conclusion that we should leave the costs of climate change to them. ${ }^{59}$ This approach is flawed in that it does not disaggregate within generations (Caney 2009c: 171). Given the deep and pervasive inequality we have today, it is implausible to suggest that, even with a large amount of growth in average incomes, all parties in the future will be better off than those well-off parties who could pay for some mitigation measures today.

A more sophisticated argument could be constructed. One might maintain that parties above a certain threshold of wealth - whether they belong to the present or the future - should bear the cost of the no-fault burden. According to this point of view, it just happens that many more people in the future will be above that

\footnotetext{
${ }^{57}$ Section 4.2 owes much to the recent work of Simon Caney, who has addressed at length the question of how principles of justice similar to those I propose should be applied to global climate policy (Caney 2009b, 2011).

${ }^{58}$ This is assumed by economists focusing on climate change such as Nicholas Stern (2007: 161162) and William Nordhaus (2008:11, 169-175)

${ }^{59}$ This argument seems to be typical of several economists who include such a factor as part of a high discount rate for future costs and benefits for example Nordhaus (2008: 169-175) and Robert Mendelsohn (2006).
} 
threshold, so it happens to be mainly wealthy parties from future generations that should bear the costs of the no-fault burden.

How should we respond to this argument? To begin with we should treat sceptically the empirical claim that future generations will, on average, be much richer than us. It is not at all clear whether we are sure enough of this to justify passing costs on to these currently non-existent parties. One might point to the current economic crisis, deep-seated political instability (Huntington 1992) or limits of natural resources such as oil (Deffeyes 2001) water (Gleick and Palaniappan 2010) and phosphorus (Déry and Anderson 2007) as reasons to doubt future affluence. Alternatively, one might point out that the costs of dealing with climate change will rise if early mitigation is not performed (N. H. Stern 2007: 211ff, 405). If the costs rise faster than future wealth does, wealthy parties in the future should be judged to have less ability to pay due to the higher costs of the deferred climate tasks. We also might doubt whether future generations will be willing to bear the burden of climate change. If they are likely to be unwilling (and why should they bear it if we have not?) we should not attempt to pass the burden on to them. (Caney 2009c; Gardiner 2006).

Most importantly perhaps, we should rely on the general principle that increases in wealth and the transfer of wealth to injured parties cannot fully compensate for harms done, especially when those harms involve rights violations or disturb the fundamental interests of persons (Caney 2009c). So while future individuals may (arguably) be more able to pay in terms of wealth, the task they can meet compensation - is the task of last resort. The tasks that should be borne - mitigation and adaptation - cannot be paid for by future individuals, they must be paid now. 60

${ }^{60}$ This leads John Broome (2010) to recommend borrowing from the future to pay the costs of climate change now. 


\subsubsection{Emissions Allocation - Equal Per Capita?}

Having rejected the claim that mitigation can be put off due to the expected wealth of future generations, it is to the task of mitigation that we now turn. Any discussion of significant mitigation efforts must deal with the question of how entitlements to emit greenhouse gas emissions should be distributed among parties. ${ }^{61} \mathrm{I}$ have already criticised the main case for a moral ground for "grandfathering" emissions rights in Chapter Three. Here I will present important objections to another popular view, that every person has an equal share in the global commons that is the atmosphere's ability to absorb $\mathrm{CO}_{2}$.

The equal-shares view has its supporters among philosophers (Gosseries 2005; Singer 2004) and NGOs (Oxfam International: 24). In the world of environmental policy and activism this view is referred to as "Contract and Converge" (Global Commons Institute 2011: 1ff.). It states that total emissions must contract, and shares of this total must converge towards an equal per capita assignment. These assignments, while theoretically granted to every global citizen, are usually proposed to be allocated to states by multiplying their population by the equal per capita quota. ${ }^{62}$

Simon Caney (2009a, 2011) provides several forceful objections to this view. The first identifies the view above as an example of the political theory of resourcism, which holds that we should be concerned with the distribution of resources income, social goods, or in this case, rights to emit. We can make the general criticism against resourcism, denying the claim that goods are what should be

\footnotetext{
${ }^{61}$ As Caney notes, even if a carbon tax system is applied rather than a cap and trade system, this still concerns energy rights: if parties are judged to have lesser energy rights this might be instantiated by their being subjected to higher taxes. See Caney (2011b) for more on this. ${ }^{62}$ Usually their population fixed at some year in the past, or a fixed future projection, in order to avoid perverse incentives for population growth (Singer 2004).
} 
equalized and point out that quality of life, or capabilities, is what should be equalised. And some individuals, through no fault of their own, have a greater need to emit $\mathrm{CO}_{2}{ }^{63}$ in order to achieve the same quality of life or capabilities as others. Consider the heating requirements of those who live in very cold climates, the elderly and the very young, or the transport requirements of someone isolated in an area of very low population density (the Australian Outback, for example). Assigning an allocation of emissions rights to a person in this situation that is equal to the allocation for a person in a sub-tropical climate with no real need for private transport and artificial heating or cooling seems unjust. People may also differ greatly in their access to clean energy sources. For example, due to the vast energy resources of Brazil's rivers, less than $17 \%$ of the electricity used by Brazilians is generated from fossil fuels, while $93 \%$ of the electricity used by South Africans is generated by burning fossil fuels. ${ }^{64}$ It seems quite odd to grant people in such varying situations strictly equal rights to emit. ${ }^{65}$ Further, even a committed resourcist should be concerned, Caney argues, with bundles of goods, rather than each good taken separately. A doctrine that everyone should hold equal shares of

\footnotetext{
${ }^{63}$ For clarity in the rest of this discussion I will consider allocation of the right to emit $\mathrm{CO}_{2}$. The idea of a general emissions scheme that covered all greenhouse gases (as Kyoto does) has been popular in the past, but some view the aggregation of greenhouse gases to be dealt with by a single policy instrument to be a mistake (e.g. Barrett 2007).

${ }^{64}$ Calculated with data from the UN Statistics Division (2012a;2012b)

${ }^{65} \mathrm{Admittedly} \mathrm{this} \mathrm{is} \mathrm{only} \mathrm{a} \mathrm{limited} \mathrm{objection} \mathrm{to} \mathrm{equal} \mathrm{per} \mathrm{capita} \mathrm{rights.} \mathrm{For} \mathrm{there} \mathrm{is} \mathrm{a} \mathrm{forward-}$ looking reason why we might be content to assign equal per capita emission rights despite the vastly different needs of people in different geo-physical regions. Having one's emissions allowance "go further" because one lives in a populated, subtropical climate, say, could be seen as a reward for living in an area suited for low-carbon human habitation. Equalising emissions rights creates a long-term incentive for migration towards places where low-carbon living is easier. But as Alex Gosseries (2005) points out, in the first instance, many people have no choice or little choice about where they live, and even if they did, asking them to choose between freezing in winter and abandoning their homeland (say) when there is sufficient leeway in the global emissions budget to allow them to remain where they are would be cruel and unjust. Still, there could be a case to be made for a per capita allocation based on need that incrementally shifts, over the years, towards a more equal allocation in order to incentivise migration to areas of low-carbon living. But other forms of carbon emissions allocation than equal-per capita shares could be designed to incorporate similar incentives too.
} 
every natural resource is absurd. Possessing large amounts of other goods should therefore decrease one's claim to a share of the common right to emit $\mathrm{CO}_{2}$. Finally, Caney points out that there are many types of burdens of climate change - the actual harms that will come from it, other costly programs of mitigation, as well as the tasks of adaptation and compensation. If some party is bearing none of these other burdens, it seems unfair that they still be allocated an equal share of $\mathrm{CO}_{2}$ to that of a party who is bearing many.

Could we not develop a pattern of distribution of that begins with equal shares, but is modified by the considerations Caney raises? Such a system seems overly complex. Even if it were possible to use the modified principle, we need a positive reason why it is desirable, rather than some other more parsimonious application of the two-track theory.

\subsubsection{Which Agent?}

Before I point to another way of using the two-track theory to allocate emissions, we should consider what kinds of party should be granted entitlements to emit: individuals, countries, or firms?

One reason why states should not be allocated emission rights by the two track theory is the great differences in the relevant characteristics within states we noted in Chapter Two. For some low-emitting country could still contain a large section of its population with high emissions and high ability to pay, while some high emitting country could contain a significant amount of people whose emissions are very low, and who are very poor, at least relative to their community (Page 2008). Treating states as the relevant rights-holders risks a distribution regime that benefits some rich high-polluters over some poor low-polluters, a benefit granted only by virtue of their state membership. 
There is also an unwelcome political consequence of granting emissions rights to states. To avoid overly restrictive and economically damaging results, it is likely that any scheme of international emissions rights will involve trading (Page 2011b). Some low-emitting countries will not use all their emissions rights and, especially if the government is corrupt and undemocratic, the benefits from the sale of these can flow directly to an already privileged elite. The possibility of this lucrative resource would also provide an incentive (in the form of an extra "resource privilege") ${ }^{66}$ for illegitimate governments to take over control of a country (Caney 2009a; Singer 2004).

Overall, there is a strong case against allocating emission rights to states, but allocating emissions rights to individuals, as been suggested with personal carbon allowances, is also highly problematic. Personal carbon allowance schemes such as those proposed by Mayer Hillman (2004: 126-45) are usually unwieldy and involve transaction costs that are too high to be feasible even at a national level (Defra 2008). Analysts have called personal carbon allowances at a national level a "radical and innovative policy with no experience or evidence base, and therefore... surrounded by debate, uncertainty and doubt" (Seyfang 2007: 365). If it is difficult for already established states to grant permits for and monitor all the emissions that their members make, it must be very much more so for an international institution to do so on a global level. Caney claims that to rely on the possibility of such a global institution would be "highly utopian" (Caney 2011: 87). Others might prefer somewhat less complimentary descriptions of such a regime. Allocating emissions rights to individuals seems far from ideal.

${ }^{66}$ See (Pogge 2005) for an explanation but for an alternative view in this context, (D.Miller 2008). 


\subsubsection{An Alternative Practical Framework}

We might, however, be able to abandon the assumption that it is emissions rights that must be deliberately allocated according to a moral principle (Caney 2009a). Perhaps emissions rights should simply be sold to the highest bidders, and the moral work should take place in determining the just distribution of the proceeds from selling such rights (Caney 2009a; Tickell 2008). Oliver Tickell's Kyoto2 scheme exemplifies such an approach. Shares of the global right to emit greenhouse gases would be auctioned off to the firms that wish to be able to create such emissions (or sell the products which eventually create such emissions) as 'upstream' as possible, for example, when fossil fuels leave the ground. Most of this extra cost to firms, we can assume, will be passed onto consumers of fossilfuels or fossil-fuel intensive products and services, so the "polluter pays" principle would be honoured directly at the level of the corporation but also indirectly at the level of the state and the individual. ${ }^{67}$ To ensure that today's global poor are not disadvantaged further by the scheme, firms in the poorest regions could be exempt, or the distribution of a dividend from the auction could make up for the increased cost of energy for those who need it for survival, addressing the poverty-sensitive aspect of PISPP (Caney 2009a, 2011).

We should recall that PISPP was an appropriate principle for distributing only around half the burden of climate change - the fault burden. Can Kyoto2 also honour the importance of the no-fault burden and the role Ability to Pay' should play in distributing it? In fact, it may not matter. For recall the range of climate tasks that make up the climate burden: tasks of mitigation, adaptation, and

\footnotetext{
${ }^{67}$ There is, of course, the burden of recent historical emissions between the end of ignorance and the present. To truly embody PISPP, Kyoto2 must make those responsible for producing this class of emissions pay somehow. I believe it can, through targeting the distribution of proceeds from the scheme in a similar way to the way Kyoto2 could deal with the no-fault burden (see below).
} 
compensation. The restricting or pricing of emissions is only a sub-task of the mitigation task. Other mitigation tasks such as the imposition of energy standards or other regulations could be applied via Ability to Pay', and burdens of adaptation and compensation, which will plausibly involve large monetary transfers, seem well suited to distribution via the "ability to pay" principle. If Kyoto 2 asks polluters to bear all the burdens of emissions restrictions, the well-off should take up the other burdens.

If this seems unsatisfactory (perhaps because an emissions allocation scheme is the most feasible way to raise funds to undertake the other tasks ${ }^{68}$ ) Kyoto2 could also be modified to incorporate Ability to Pay'. Honouring Ability to Pay' could be done by insisting that those who are in a position to pay increased energy costs should pay more of them - the "extra" amount that is due to the no-fault burden. How could that be done? Consider the very sizeable revenues that the Kyoto2 auction would create. Rough estimates have such a scheme raising \$1 trillion per year (Tickell 2008: 169). Some of this might need to be set aside for adaptation or compensation for the sufferers of climate change and some, we have already seen, must be used to ensure that the development of today's poorest is not hamstrung by higher energy costs. Still, there could be a sizeable amount left to spend on research and development of clean technology and incentives for its use. We could incorporate Ability to Pay' into Kyoto2 by requiring these expenditures to be directed towards increasing access to clean energy for those of low and mid-level wealth. The wealthy would effectively bear both their share of the fault and the no-fault burdens, whereas those who pollute but are less wealthy would have their burden reduced through the application of auction proceeds to the development of clean energy, and so would bear only their share of the fault burden.

\footnotetext{
${ }^{68}$ Adaptation and compensation funds raised directly from states, for example, have not had a strong history. The 100bn Green Climate Fund, agreed to by rich nations in Copenhagen in 2009, is proceeding slowly (Cuming 2011).
} 


\subsection{CONCLUSION}

The two-track theory is sound and practically applicable. It is strict on current and recent polluting, yet does not demand too much from those who have polluted under mitigating circumstances, while still requiring the entire climate burden to be borne justly. If we do not believe that those who have benefitted from emissions under ignorance and emissions from the poor need to pay, then it seems to be the best theory. But I have thus far only dodged the "beneficiary pays" idea, and will address it in the next chapter, finding that it has only minor relevance in climate change ethics. 


\section{5 \\ Beneficiary Pays?}

Didst thou never hear that things ill-got had ever bad success? - William Shakespeare, Henry VI, part III, -- (1964 [1591]: Act ii, Sc. 2)

\subsection{THE “BENEFICIARY PAYS” IDEA}

In this chapter, I will argue against a prominent idea for distributing the costs of climate change: that those who have gained benefits from the acts that caused high greenhouse gas emissions in the past should pay for the harmful effects of those acts. I argue that the idea can take one of two different forms, neither of which succeeds. The first form - beneficiaries of injustice have a special responsibility to the victims of the injustice - is a plausible idea that probably does not apply straightforwardly to climate change. To apply, it requires further theories of distributive justice that either lend a greater support to an "ability to pay" principle, or are highly controversial and unusual. The second form - that beneficiaries of harmful acts have a special responsibility to those harmed - could theoretically apply to the case of climate change, but it is implausible. I conclude that the "beneficiary pays" idea should not play a major role in distributing 
climate burdens. Finally, I consider special circumstances in climate negotiations which might allow some parties to appeal to a rather limited "beneficiary pays" principle.

The "beneficiary pays" idea has been supported by a number of philosophers (Caney 2009a; Das in preparation; Gosseries 2004; Neumayer 2000; Page 2008, 2011a; Shue 1999). It is especially promising as a way of distributing a large part of the climate burden - the burden caused by historical emissions created under ignorance ${ }^{69}$ - to which a "polluter pays" principle should not be applied. ${ }^{70}$ Allocating the burden from past emissions to those who have benefitted could allow us to attribute responsibility to current parties for past emissions from those who have disappeared or were excusably ignorant (like an "ability to pay" principle). Further, it is sensitive to the nature of the past acts that brought about the climate burdens in the first place (like a "polluter pays" principle). Thus, linking responsibility to the benefits from past emissions can combine the advantages of each approach. ${ }^{71}$

\footnotetext{
${ }^{69}$ For ease of expression, I will in the rest of this chapter refer to these emissions simply as "past" or "historical" emissions, despite the fact that some emissions before the present day were not emitted under excusable ignorance. See Chapter Four for more details.

${ }^{70}$ While it potentially can allocate the burden-share from historical emissions, the "beneficiary pays" idea would be hard pressed to guide the distribution of burdens from poverty-related emissions. This is because it is difficult to claim that the benefits from the emissions of the very poor accrue primarily to other parties than the very poor themselves.

${ }^{71}$ It is sometimes suggested that the "beneficiary pays" idea must face the non-identity problem (Caney 2005). I believe that the non-identity problem to be irrelevant in the context of climate change. The problem is meant to be that we cannot meaningfully say that a person can ever be harmed or benefitted by events that happened before her conception. For each of us, our existence as a unique individual is dependent on the fact that a sperm with a particular arrangement of our father's chromosomes out of the millions of candidates managed to fertilise our mother's egg at a particular moment. But such a delicate matter is highly contingent on many other factors. The upshot of this for climate ethics, supposedly, is that it is nonsensical to judge that a particular person has benefitted from the past emissions events that occurred before her conception. Had the course of history been different enough to involve significantly lower emissions, the person in question would not exist at all, and one cannot compare her welfare now with her non-existence. But the "beneficiary pays" idea can survive the non-identity problem. We can couch the "beneficiary pays" principle in a non-
} 


\subsection{WHICH PRINCIPLE?}

There are two quite different versions of the "beneficiary pays" idea in its general form. Here is a principle typical of one version.

Beneficiary of Injustice Pays (BIP) Those holding benefits from unjust acts or practices should bear the burden associated with the original injustice, until the injustice has been fully rectified or the benefits that triggered the duty have been exhausted (adapted from Page 2011a: 422-23).

And a principle typical of the other:

Beneficiary of Harmful Acts Pays (BHP) Those holding benefits from acts or practices that are causing or will cause harms should bear the burden of rectifying those harms, until the harm has been fully rectified or the benefits that triggered the duty have been exhausted.

\subsubsection{BIP - Benefitting from Injustice}

In Section $5.3 \mathrm{I}$ will argue that BHP is not a plausible principle. In the rest of this section I will show that the assumptions needed to ensure BIP applies to climate

person-affecting or "impersonal" form, rather than a "person affecting" form (Page 2011: 424, Caney 2006) as has been done with the principles BIP and BHP (see main text). This involves shifting the focus of the central claim - from the subject who has benefitted, to the benefits simpliciter. Instead of requiring that rectification must come from certain persons who have benefitted from past industrialisation, it can require that the benefits of industrialisation, such as increased wealth, carry with them duties to pay for some of the climate harms that industrialisation has caused. If the particular identity of the agent is unimportant, the nonidentity problem loses its bite. 
change are either implausible or lend even greater support to an "ability to pay" approach.

Beneficiary of Injustice Pays states that because parties enjoy benefits derived from an injustice, they should bear the burdens associated with remedying that injustice.

This principle or similar variants have received much discussion over the years, especially with application to the issue of affirmative action and reparations for slavery (Fullinwider 1975; Thomson 1973). Daniel Butt (2007) argues for it specifically as a way to distribute "remedial responsibility" to prevent what would be unacceptable harms to others. Edward Page supports this conception of the "beneficiary pays" idea in the context of climate change: "existing states are indirectly at fault so long as they continue to enjoy the benefits generated by this injustice without undertaking measures of mitigation, adaptation, or compensation"(Page 2011a: 422). BIP also plays a part in the work of Caney (2009b, 2010) and Neumayer (2000). As a general principle, BIP is defensible. Receiving benefits borne of injustice seems to give one special responsibility to rectify the injustice at least if the perpetrator cannot (or perhaps does not) do so. Imagine that I have received a quality university education, but only because my father (now dead) bribed an official in order for me to gain my place, at the expense of a more worthy candidate. I have not committed an injustice, but I have benefitted from the injustice and should be prepared to make amends, because I have benefitted from it. Or consider an example more closely related to climate change, because it involves the responsibility for rescuing others from unacceptable conditions. Imagine that person A is made destitute and person B rich by some action designed to harm the first person, by an enemy who is now dead. In the absence of the enemy, Butt plausibly claims, B has a special responsibility to use her new riches to rescue A from ruin (Butt 2007). Butt also provides an explanation of why we might want to support BIP; to fulfil the role of 
genuine moral agents, it is not enough that we are unwilling to commit acts of injustice, but we must also "hold a genuine aversion to injustice and its lasting effects" (Butt 2007: 143). To condemn an act as unjust but refuse to relinquish goods caused by that injustice when one could remedy it is to commit a "conceptual error" - it is to misunderstand the nature of moral condemnation (Butt 2007: 143).

\subsubsection{Against BIP in Application to Climate Harms.}

BIP seems plausible, but much work has to be done to show that it is relevant to distributing the historical portion of the climate burden. BIP is a principle specifically for allocating benefits from unjust acts. But the acts that created the historical burden are not obviously unjust acts; emitting greenhouse gases under ignorance seems quite different from the acts of bribery and malicious harm that created the unjust enrichment in the small scale examples above. Rather than unjustly choosing to harm future people, most past heavy emitters could not have even suspected they were doing so, and can be excused because of this. ${ }^{72}$ Without doubt, we might regret that people emitted so much in the past under ignorance of the likely effects. But the acts of past emitting were not clearly unjust.

Perhaps there is a significant counterfactual which renders the developed world's appropriation of the ability of the atmosphere to safely absorb greenhouse gases unjust. Given the snail's pace of emissions reductions among historically high emitters since the effects of greenhouse gases have been realised, one might charge that past emissions constitute an injustice because high emitters would not have adapted their behaviour even had they known the atmosphere was limited in its ability to absorb greenhouse gases (Singer 2004: 34).

\footnotetext{
${ }^{72}$ See Chapter Four for a detailed defence of this point.
} 
This claim is contentious. After knowledge emerged of the limits of the atmosphere to safely absorb greenhouse gases, total emissions from the EU-15 (the 15 EU members in 1995) dropped by more than 12\% between 1990 and 2009 despite the population growing by 8.5\% (European Environment Agency 2011: 6). ${ }^{73}$ Of course many mitigation policies make good sense domestically, so it may have been pure self-interest that led these countries to cut emissions. Nonetheless, this moderate decline in EU emissions after knowledge of climate harms became widespread makes it harder to argue that there would have been an irresponsible disregard of climate harms by all countries had the knowledge appeared earlier. And even if there would have been such disregard, this is not sufficient to show that past emitting was unjust. It is one thing to make the counterfactual claim that actors would have used as much of the atmosphere as they did, had they known of the ill effects, but BIP requires that past emitters actually committed some injustice. A principle which links responsibility to injustice that did not occur, but would have under a certain counterfactual, is more complex and more controversial than BIP and I will not consider it here.

\subsubsection{Bell's Framework}

Derek Bell provides a nuanced attempt to show that past high emissions were unjust. He first draws a distinction between moral judgement from the "timeneutral standpoint" and moral judgement from the "time-relative standpoint" (Bell 2011b: 402). According to this distinction, when we consider whether acts are blameworthy or invite punishment we should take the time-relative standpoint, and consider what information was available to the agent at the time of the act. But judgements about the rightness of actions, Bell believes, should be made with all

\footnotetext{
${ }^{73}$ Some of this recorded decrease is due to displaced emissions from manufacturing that are still serving European consumers, but have been released in Asia over this period. Still a large proportion is an (arguably deliberate) genuine reduction, due to increases in the use of clean energy and energy efficiency, and refinement of industrial processes.
} 
the knowledge we have able to us now. ${ }^{74}$ Thus, while historical acts such as burning large amounts of coal or converting rainforest to cropland were not blameworthy, we should, from the time-neutral standpoint, recognise they were unjust. Being unjust, BIP will apply to them, so those who possess the benefits from the unjust acts should use those benefits to help pay for the burdens that have been created.

However, Bell is aware that this fundamental reliance on the time-neutral standpoint to assess the justness of acts is too crude. For always taking the timeneutral standpoint would mean that some acts that are unfortunate but obviously not unjust would be counted as injustices. He uses the example of a kindly landlord who recognises the plight of some peasants and grants them a plot of land much better than what they have been working on. Soon after, a small meteorite hits the new patch of land, killing all the peasants. From the timeneutral standpoint we see the harm he has caused, and his ignorance about the fate of the land is time-relative, so only protects the landlord from blame for an act that we must still (counter-intuitively) judge as unjust.

To rule out such cases from his analysis, Bell distinguishes between unfortunate errors (like the landlord's) and errors that can genuinely create injustice. Agents make errors that genuinely create injustice when they are mistaken about either a moral fact (Bell calls this a case of "moral ignorance") or an empirical fact that is fundamental enough to concern the "circumstances of justice" (2011a: 406). The second type of error Bell calls "systematic moral error", and includes ignorance about which goods are scarce and which are not. According to Bell, early heavy emitters were committing systematic moral error, for they were unaware that a good (the atmosphere's ability to absorb greenhouse gases) that they were

\footnotetext{
${ }^{74}$ Bell accepts that such a view renders our judgements about justice of particular arrangement as fundamentally uncertain or "provisional" (2011a: 402); as we discover new information, we "may" (2011a: 402) (and, presumably, must when the information is clear enough) revise our assessment of the justness or otherwise of acts.
} 
claiming was actually a scarce good, rather than a limitless one. Thus, the combination of the time-neutral perspective, the supposition of systematic moral error, and an injustice-tracking principle such as BIP would entail that those who hold benefits born of the acts of heavy past emitting should bear the burdens.

I agree that moral ignorance probably should be judged from the time-neutral standpoint. It also could be the case that "systematic moral error" about the circumstances of justice, such as the mistaken belief that everything was limitless or that there were conditions of extreme scarcity, could lead us to condemn acts committed under such conditions. We can rule a spree of looting unjust even if it was committed by someone who mistakenly believed that there had been a devastating nuclear holocaust which, if true, would have justified it. But past emitters were not ignorant of the circumstances of justice in the Humean or Rawlsian sense - they knew "that natural resources are not so abundant that schemes of cooperation become superfluous" (Rawls 1999: 110); they were merely unaware that one resource, which they thought was abundant, was actually quite scarce. So in order for Bell's analysis to render heavy past emissions unjust, the scale of systematic error which can render acts unjust must be permitted to be much smaller.

Mistakes about the scarcity of particular resources, however, do not immediately seem to be profound enough to render acts distributing such resources unjust, even if we take the time-neutral standpoint. Imagine a variation on the past emissions case, where actions were taken under a mistaken belief that a resource was scarce when in fact it was plentiful. Many foodstuffs were rationed during World War II, in a way that does not seem obviously unjust. Now suppose evidence, then unknowable, comes to light that sugar was not in fact scarce: that a plentiful alternative source (say) would certainly have been found if the price had risen high enough. Should we now re-evaluate the past rationing of sugar as being unjust? This seems too drastic; as with the landlord's act in the previous example, 
the act could be described as unfortunate, but not unjust. It is hard to see why we should be more severe in our judgement when a resource that was supposed to be limitless (indeed, hardly even recognisable as a resource) is now found to be scarce.

More importantly, not all misconceptions about the abundance of resources lead to systematic moral error and thus injustice. For instance, no injustice would occur if a resource was mistakenly thought to be limitless but nonetheless was distributed fairly (from a time-neutral standpoint). To return to the case of climate change, if the distribution of the atmospheric sink was not unfair, even from the privileged position of the time-neutral standpoint, then BIP cannot apply to it. In the next sub-section I will argue that not all standards of fair distribution render the distribution of the atmospheric $\sin \mathrm{k}^{75}$ unjust, and the likely standards strong enough to render it so would motivate an "ability to pay" approach over BIP.

\subsubsection{An Unjust Distribution?}

Let us examine what considerations might render the distribution of the atmospheric sink unjust from the time-neutral standpoint. Some claim that heavy users of the atmospheric sink took more than their fair share. Such an idea seems to be behind Simon Caney's description of why a quasi-BIP principle ${ }^{76}$ should apply to current benefits - because most the wealth of today's affluent can be traced back to 'unjustly high emissions' (Caney 2009b: 243 [italics mine]). It is entailed by Eric Neumayer's claim that we should assign "an equal share of the beneficent existence of the absorptive capacity of nature to every individual,

\footnotetext{
75"The atmospheric sink" is the atmosphere's ability to absorb greenhouse gases without causing unacceptable climate change.

${ }^{76}$ I call it a quasi-BP principle because Caney refers to his secondary principle as an "ability to pay principle" (2010: 213), yet it justifies asking the wealthy to pay because they have benefitted from past emissions, and thus incorporates the "beneficiary pays" idea.
} 
independent of his or her place in either space or time"(Neumayer 2000: 188). Page also seems to support the notion that heavy past emitters used more than their share by comparing benefits from past heavy emissions to interest gained on stolen property (Page 2011).

But this notion of a fair share of the atmospheric sink needs closer examination. A fair share, presumably, either would be that shared fairly intra-temporally (between parties across the generations) or inter-temporally (between the parties existing at one time). But neither can easily yield the result that current beneficiaries of past emissions should pay.

Consider the inter-temporal version. This claim could concern aggregated parties, requiring that each generation deserves a fair amount of such goods; or disaggregated parties, requiring that each party, regardless of their position in time or space, deserves a fair share. Under the aggregated sense, the claim falters. Today's generation is poorer than the past in terms of the flows from many of nature's services including forests, fish stocks, wetlands and the atmospheric sink. But it is much richer in terms of information, knowledge, capital and labour. In essence, previous generations have consumed nature and bequeathed us culture, leaving us with a very different bundle of goods, but arguably not worse off in an aggregated sense.

Now consider the disaggregated version, that each party deserves a fair share of resources regardless of when they exist. If this is true, the claim of unjust distribution between particular parties might hold water. Many privileged people, including past heavy emitters, have used up a swathe of natural resources, including the atmospheric sink. Due to climate change mitigation measures, most people in the near future, including those only moderately well-off, will probably face some restrictions on their use of the atmospheric sink, meaning that they will either not be permitted to access the same amount of it as others in history have, 
or must pay for the privilege. This distribution of the atmospheric sink across parties and generations is unequal. Perhaps under some theories of distributive justice, it is therefore unjust. But it is important to see the implications of the theory which would be required to make it so. As I suggested in Chapter Four, rather than demanding that everyone holds the same amount of every good, the most plausible egalitarian theories focus either on the total bundle of resources that each party holds or on the well-being or capabilities that bundles of goods bring. Egalitarianism of every particular resource becomes even less palatable when applied inter-temporally. It would be ludicrous to demand that justice required every party have a particular or equal share of (say) gold, fur, and silicon across different times. Under a disaggregated, inter-temporal egalitarianism, injustice should be judged by the inequalities across a range of goods between people. And if that is the injustice, it is one that undermines the entitlement of today's wealthy, just as much as it rules past high emitting as unjust. Thus it should require the wealthy to give up their wealth, which would justify an "ability to pay" principle over the narrower "beneficiary pays" principle. ${ }^{77}$

The claim that systematic moral error led to an unjust distribution of access to the atmospheric sink inter-temporally is either false or supports an ability-based principle. Now we can turn to the suggestion that past heavy emitters, due to the illusion of limitlessness, took more than their fair share compared to their contemporaries. This is equally problematic. Most theories of distributive justice would not support this. Consider a sufficientarian view - that everyone should have enough of each important good. Given that no-one was prevented from accessing the atmospheric sink in say, 1930, it is hard to see how anyone then could not have had sufficient of this good to meet their needs. A prioritarian theory - that resources should be directed to the least advantaged - would also

\footnotetext{
${ }^{77}$ Perhaps one could say in this case that those who have benefits derived from such injustice have two reasons to surrender their benefits, and that those who are merely able to pay have one. But having more reasons to do something is not the same as having a stronger reason to do it, or a reason to do more of it (Dancy, 2004: 16-25).
} 
deny that intra-temporal injustice occurred. The least advantaged person in 1930, for instance, would not have benefitted from being granted more of the atmospheric sink, if such a grant would have meant anything at all. In the sense that they were prevented from using the atmospheric sink, this was due to their lack of quite different resources. Finally, Rawls' difference principle, that any inequality must raise the position of the least well off (Rawls 1999: 52-65), is not obviously violated by some getting more of the atmospheric sink than their contemporaries. Had past heavy users been restricted from their unequal use, the increased prices of manufactured goods and the reduction in benefits of technological development and cheap energy would have probably led the worst off of the same generation to become more so.

It is true that an egalitarian committed to an equal distribution of goods may see the distribution of the atmospheric sink within past generations as unjust, meaning that BIP could apply. But as was the case when we considered the intertemporal disaggregated version, reasonable egalitarians should have at least as much reason to support an alternative principle, the "ability to pay" principle. For once again it is not that everyone should have the same amount of hemp or toothpaste or atmospheric sink at a particular time, but that people should possess an equal bundle of goods, or reach equal levels of a subjective measure such as capabilities or well-being. This commitment to overall equality would once again be best served by asking the most well-off to pay for the no-fault burden, rather than linking responsibility to the benefits gained from what may have been (by egalitarian lights) a past injustice between contemporaries.

Whether past heavy emissions involved injustice depends on our view of distributive justice and the appropriate parties with which comparisons of holdings can be made. However, I have argued that reasonable versions of such views must either deny that past emissions were unjust, or affirm they were 
unjust but motivate an "ability to pay" principle to allocate responsibility for them, making BIP redundant.

\subsection{BHP - BENEFITTING FROM HARM}

\subsubsection{Against the BHP Principle}

BIP is not the only way in which the "ability to pay" approach could allocate responsibility for the climate change burden. There is room for a quite different approach, which does not rely, as BIP does, on past emissions constituting an injustice. Such an approach only tries to show that the rich today are beneficiaries of acts which are causing or will cause future harm due to climate change. Under this view, we should not demand special duties of the beneficiaries because they benefitted from injustice, but because, and to the extent that, their benefits bear a special relation to these harmful acts (Das in preparation; Gosseries 2004; Page 2008; Shue 1999). Thus we can examine a principle such as the following:

Beneficiary of Harmful Acts Pays (BHP) Those holding benefits from acts or practices that are causing or will cause harm should bear the burden of rectifying the harm, until the harm has been fully rectified or the benefits that triggered the duty have been exhausted.

Unlike BIP, this principle would be clearly applicable to those holding benefits due to past acts producing high emissions. It is obvious that many parties have received benefits from industrial practices that will cause severe harms. The only problem with BHP is that the principle is implausible, because it is too demanding. 
Here is a counterexample. Beth might happily marry Adam, benefitting greatly, but in the process breaking Henry's heart. It seems fair to say that Beth does not owe rectification to Henry for the suffering such an act causes. In another counterexample, Ben goes into business in a market environment, and, through skill and good sense, out-competes Henriette. Again, Ben benefits from entering this market, and Henriette suffers, but Ben does not thus owe reparations to Henriette (examples from D. Miller 2001: 460).

Perhaps we might be tempted to amend BHP to get around these types of examples, judging that BHP only applies where there is an element of voluntariness involved. Perhaps we do not assign special responsibility to Beth and Ben because Henry and Henriette knew the risks they were running by getting into affairs of the heart and business affairs respectively. This might lead to a principle like:

BHP' Those holding benefits from acts or practices that are causing or will cause harm that are suffered by victims who have not at least tacitly consented to bear the risks of such harm should bear the burden of rectifying the harm, until the harm has been fully rectified or the benefits that triggered the duty have been exhausted.

BHP' would allow Beth and Ben in the examples above to escape responsibility for the harm they caused, but would not allow the current beneficiaries of past emissions to escape responsibility for climate change, for those to be harmed by past emissions did not even tacitly consent to the risk of such harms. But the addition of the criterion of non-voluntariness may not be enough to render $\mathrm{BHP}^{\prime}$ plausible. To return to our example, it is not clear that Beth or Ben would have significant responsibility to rectify the situation, even if it turned out that the "victims" in those cases were (say) naïve teenagers without the experience to have made tacit consent to the risks they faced. This is especially the case if Beth and 
Ben were ignorant, as past emitters were, of the especially vulnerable nature of those who will be harmed. Consider also a patient whose life is saved due to a triage decision at the expense of another, while both were unconscious. Although tacit consent was not given by the patient who dies, justice demands nothing extraordinary from the survivor to the family of the deceased. The amendment to $\mathrm{BHP}$ requiring the absence of tacit consent is not enough to render the ensuing principle plausible and so $\mathrm{BHP}^{\prime}$ cannot guide us in allocating the historical portion of the climate change burden.

\subsubsection{Gosseries' Argument and a Reply.}

Axel Gosseries (2004) argues for two separate claims that in combination would, like BHP, judge current beneficiaries of past emissions morally liable for the historical portion of the climate burden. First, Gosseries argues that past emitters, if they were still around, would gain moral liability for the harms they caused, even when they could not have known of these harms. Second, he argues that such liability should be transferred to current parties who have received the benefits from past emitters. The second claim may be plausible, and I will not discuss it here. But the first claim, I will argue, relies on a principle that suffers the same problem as $\mathrm{BHP}$ and $\mathrm{BHP}^{\prime}$ - it is too demanding.

Gosseries admits that past emitting was not unjust: "the past US generation never wronged Bangladesh [through their high emissions]" (2004: 44). After all, past emissions were made under ignorance of their harmful effects. Nonetheless, he believes, while past emitters may not have committed a wrong; if they were still around they would incur moral liability for the harmful consequences of their actions. To defend this claim, Gosseries advocates a principle he calls the “modified excusable ignorance principle (MIEX)" (Gosseries 2004: 40). 
A person should not be held morally responsible for the harmful consequences of her own act if they were unknown to her and could not reasonably have been known at the time of the action. However, she may still be held liable for compensation for such harmful consequences on others if and only if once the latter were or should have been brought to light, she still enjoyed correlative benefits (Gosseries 2004: 40).

MIEX is a specific form of the "ability to pay" idea. It refers to benefits gained by a person's own actions, and specifies that the possession of these benefits is what determines liability for harms undertaken under ignorance. Gosseries eventually wants to extend such liability to the current beneficiaries of others' harmful acts, in particular, past acts of high emissions. But we should not even judge past emitters liable for the harm from their emitting, for MIEX is implausible.

To motivate MIEX, Gosseries presents an example. Roberto happens to find a large sum of money, (which unbeknownst to him is actually counterfeit) and uses it to buy 50 bottles of wine. By the time the wine-seller finds that the notes happen to be counterfeit, Roberto has drunk 10 of the bottles. Gosseries suggests that in this case, we should ask that Roberto return at least the remaining 40 bottles - for these are benefits he still enjoys from the harmful act of passing over the counterfeit notes.

I agree that Roberto should return the 40 bottles of wine, but I think this just illustrates that only some unwittingly harmful acts generate liability for the harms caused, specifically, those acts where the harm is due to an injustice. Although what Roberto did was not unjust, if he keeps the 40 bottles of wine, his benefits can be easily traced to an unjust act: that of the counterfeiter. MIEX is too demanding because it allows harm alone to undermine the claims people have to their holdings. Consider a similar thought experiment, where the notes were not counterfeit, but accidentally defective, so that they were especially susceptible to 
disintegration when exposed to light. They disintegrate while in the wine-seller's possession. Would we then demand that Roberto return the bottles? I think not. He has still benefitted from a harmful act that can be described in a very similar way to the first case - unwittingly buying wine with notes that have no permanent value. But I doubt he is obliged to return anything in this case. The morally relevant difference seems to me to be that in the first case, Roberto's benefits can be traced relatively easily to an act of injustice: the counterfeiter's act of producing fake notes. The association of Roberto's benefits with such an injustice, rather than with the harm itself, is what removes the claim Roberto has to his benefits. ${ }^{78}$

Once again it seems that it is injustice which removes the entitlement of beneficiaries to their holdings. BIP is a plausible principle but BHP and MIEX are not.

\subsection{Postscript: The Limited Responsibility of Beneficiaries}

It may seem that I have been too harsh on the "beneficiary pays" idea, particularly on $\mathrm{BHP}^{\prime}$. Does morality really permit leaving the naïve and unfortunate victim to suffer while one stands by holding goods born from the very act that has caused their suffering? This is an interesting question, but it frames the problem deceptively. It is just for beneficiaries to refrain from assisting victims, when one or other alternative principle already requires support for the victims of harm -

\footnotetext{
${ }^{78}$ Perhaps a supporter of Gosseries' approach might try to find other examples of not unjust harmful acts that still make the beneficiary of such acts liable. For instance, say the notes in the above example had been legal tender taken from a stranger and hidden in Roberto's house by children (this example was suggested to me by Ramon Das). We might be tempted to say that, while there was no injustice here, Roberto should return the bottles. But I believe it is again an injustice which grounds the duty Roberto has to return the bottles in this case. That Roberto consumed property that rightfully belonged to another was an injustice, and so BIP or some similar principle applies. But past emitters, as I have argued in Section 4.2, were not unwittingly using something that belonged to someone else, because they did not take more than their fair share of the atmospheric sink.
} 
either from those who are most able to provide it, or those with special relationships with the victim. Disaster relief tends to come from national funds, not from the pockets of those few who might have benefitted from the disaster; care of the broken-hearted comes from family and friends, not from those who have benefitted from the affair. In some cases it might be noble for those who have reaped extra benefits from a calamity to aid those in strife, but it is not usually required by justice. The "ability to pay" approach (which I have argued is best suited to allocate the no-fault burden) allows victims of severe misfortune to have their needs seen to without relying on the rather accidental connection between the innocent harmer and the victim.

Over the last two chapters, I have argued that an "ability to pay" principle is more appropriate than a "beneficiary pays" principle in most cases of innocent harm. Still, the "beneficiary pays" approach could be appropriate in a certain subset of such innocent-harm situations: when there is little or no hope that those with the ability to pay will actually pay. This may be especially so in the non-consensual cases we considered such as triage, and the naive business-owners. If there is no safety net of minimal support provided by some institution which allows the burden of meeting non-consensual victims' most vital needs to be shared fairly among those with the ability to pay, and no-one with special connections to the victim will provide support then one might think it unjust for the beneficiary of innocent harm to ignore pleas for help from the non-consensual victims.

Does the case of innocent harm caused to climate victims meet these criteria? The answer is somewhat complicated. Parties who do presently have the ability to pay for the climate tasks cannot in good faith demand that, due to the lack of an ability to pay system, parties who have benefitted from past emissions have a duty to take up the associated burden. Although global cooperation on climate change action is presently woefully inadequate, there is still hope that a strong institution based on just principles will develop. What is more, who, if not those with the 
ability to pay, are in a position to allow and encourage such an institution to develop? That being said, victims of climate change or their advocates, frustrated by the lack of such institutions, might plausibly point to the fact that many parties have benefitted as an extra reason why certain parties should take the lead. But this is a case of frustrated parties appealing to a principle of justice that is thirdbest. Those who are wealthy should bear the cost of past emissions, and the reason why they should is because they are wealthy. 


\section{6}

\section{Conclusion}

Human induced climate change presents us collectively with a climate burden, comprising several tasks: to try to reduce the probability that high levels of warming will occur, to enable some potential victims to avoid some of the worst effects, and to compensate those who will be harmed. In this thesis I have defended what I call a two-track approach which separates the burden of climate change into two parts: the "fault" burden and the "no-fault" burden. The fault burden is that which has been created by greenhouse gas emissions since the time it has been reasonable to suppose that such emissions cause harm, not counting the emissions needed to support people's basic needs. The no-fault burden is the rest: the burden caused by emissions before it was reasonable to suppose that such emissions caused harms, and the burden caused by people merely meeting their basic needs.

In Chapter Two I investigated Dale Jamieson's claim that the responsibility to deal with climate change is too far from a paradigm case of moral or political responsibility, and thus requires a revisionary approach to fully explain the urgency and strength of such responsibility (Jamieson 2007, 2010). I argued that, while climate change does possess some unusual features (a long and time-lagged causal chain, a lack of intention to harm, and geographically and temporally dispersed causers of harm) a revisionary approach is unnecessary. Instead, 
principles of burden-sharing can allocate proportionate responsibility to the dispersed emitters. Once such responsibility has been apportioned, the other unusual features of climate change do not significantly threaten the clarity or urgency of the moral responsibility entailed by such principles. Furthermore, the scale of the harm, the forward-looking nature of climate ethics, and the precision that some principles can bring to the allocation of proportionate responsibility to act on climate change render climate ethics more, rather than less, paradigm.

In Chapter Three I turned to the practice of 'grandfathering' emissions rights granting more rights to emit greenhouse gases to those who have emitted more in the past. Luc Bovens (2011) has made a unique attempt at defending such a practice on moral grounds. His is a Lockean approach, that claims that past use of a resource, when enough and as good is left for others and it is not wasted, generates title to that resource. Bovens' version of a Lockean approach faces two major problems. First, it rests on what may be a problematic analogy between the atmosphere's ability to absorb $\mathrm{CO}_{2}$ and other goods once held in common. Second, both the enough-and-as-good condition and the no-waste condition have been thoroughly violated, meaning even a Lockean account should judge that past emitters have lost their title to the atmospheric sink.

In Chapter Four I developed my positive account. I stressed that a key step in apportioning climate burdens fairly is dividing the fault burden from the "nofault burden". It is just to ask those polluting now and who polluted in the recent past to bear the burdens caused by their pollution, unless doing so would cause the very kind of harm to people's livelihoods that the climate tasks are aimed to prevent. Thus the fault burden is that generated from the greenhouse gas emissions produced now and in the recent past, by those not suffering severe poverty. Conversely, the no-fault burden is that generated by past emissions, produced while it was not reasonable to suppose that such emissions could cause 
harm; and the emissions from the very poor. A "polluter pays" principle, I argued, fairly distributes the fault burden.

I considered the objection that past emissions should also be included in the fault burden, but rejected it. The objection, I argued, can take one of two forms, neither of which succeed. The first form claims that parties should bear the burdens of their acts that caused high emissions because they benefitted from those acts. I argued against such a "beneficiary pays" approach in Chapter Five. The second form is that past heavy emitters should bear the burdens of their acts regardless of whether they benefitted, because strict liability should apply in this case. Henry Shue (1999) supports this form of the objection because he believes that allowing major past polluters to pass burdens they created onto others is incompatible with the principle of equal dignity. This view underestimates the value of a just secondary principle that can distribute the no-fault burden. Others support strict liability in the case of climate change by referring to the legal precedent of allocating strict liability to parties for actions taken in ignorance of their harmful effects. But strict liability has been applied in law only in special cases. It would be unusual for us to apply strict liability to an act that was not inherently dangerous or unusual.

Having divided the climate burden into the fault burden and the no-fault burden, I then turned to the question of how the no-fault burden should be distributed. I proposed that, for this burden, parties should bear it in proportion to their ability to do so. What this would mean, I argued in Chapter Four, is that each party should bear a portion of the no-fault burden that constitutes an equal proportionate drop in wealth, perhaps calibrated on a non-linear scale to take into account non-material views of the appropriate currency of justice.

There are many climate tasks of mitigation, adaptation and compensation, but the application of the two-track theory I have advocated to the restriction of emissions 
is especially interesting. First I argued that, despite the "ability to pay" principle, emissions need to be significantly restricted now. Even if we could be sure that many parties in future generations will be much wealthier than us, the "ability to pay" principle does not allow us to transform the task of mitigation into the task of compensation. To do so would be to knowingly let people's vital interests be harmed only because we promise later compensation, which is unacceptable. So we must restrict emissions. When it comes to allocating these restricted emissions, there is no reason why emissions rights must be allocated either to states or to individuals. Such rights could be sold via an auction to the corporations that initiate the processes that end in pollution (mining fossil fuels for example). Costs would filter through to the users of greenhouse-gas-intensive products, meaning the "polluter pays" principle would be respected, while some of the revenue raised through the auction could be spent to ensure that those with less ability to pay bear less of the costs of emissions restriction than those with more ability to pay.

In Chapter Five I examined an alternative secondary principle for distributing the no-fault burden (or at least its historic portion): that those who have benefitted from past emissions should pay. The justification for this "beneficiary pays" principle can take either of two forms. Those who have benefitted from past emissions, it is sometimes said, should pay for the associated burdens because they have benefitted from an injustice. But it is unclear exactly what the injustice of past emissions consists of. Only a strict egalitarian would deem past high emitting unjust, and such a strict egalitarian should support the use of an "ability to pay" principle over a "beneficiary pays" principle regardless. The second form of the "beneficiary pays" idea is that those who have benefitted from past emissions should pay because they have benefitted from a harmful act. But this justification is too demanding. If we have any responsibilities to help those harmed by (not unjust) actions that benefit us, they are responsibilities of last resort, to be called upon only when the institutions that are meant to protect the 
vulnerable are missing. But we have a chance to create just institutions to protect the victims of the no fault burden, and we should do so on the basis of a different principle - that parties should bear burdens in proportion to their ability to do so.

Climate change presents us with a complex, but not impossible task: that of allocating the burden of the climate change. Close analysis of the varied sources of the climate burden, the purpose of bearing it, and the principles that could potentially allocate it will allow us to do so in a fair way. I have argued that we need a two-track approach, with a "polluter pays" principle that is sensitive to both severe poverty and excusable ignorance allocating the fault burden, and an "ability to pay" principle allocating the no-fault burden. The two-track scheme can be practically implemented, most promisingly perhaps by an auction-anddividend scheme. The climate burden can be borne fairly if those of us who have knowingly created burdens (and are not desperately poor) can bear those burdens that we have created, and the remaining burden is divided among us all in proportion to our ability to bear it. 


\section{References}

Allen, M., Frame, D.J., Huntingford C., Jones, C.D, Lowe, J., Meinshausen, M., and Meinshausen, N., (2009) 'Warming caused by cumulative carbon emissions towards the Trillionth Tonne', Nature, 458 (1163-

6). http://dx.doi.org/10.1038/nature08019

Arnold, D.G. (ed.), (2011), The Ethics of Global Climate Change (Cambridge: Cambridge University Press).

Arrhenius, S. (1896), 'On the influence of carbonic acid in the air upon the temperature of the ground', The London, Edinburgh, and Dublin Philosophical Magazine and Journal of Science, 41 (251), 237-76.

Attfield, R. (2009), 'Mediated responsibilities, global warming, and the scope of ethics', Journal of Social Philosophy, 40 (2), 225-36. http://dx.doi.org/10.1111/j.14679833.2009.01448.x

Baer, P., Athanasiou, T., Kartha, S. and Kemp-Benedict, E., (2008), The Greenhouse Development Rights Framework: The Right to Development in a Climate Constrained World, Revised 2nd Edition, (Berlin: Heinrich Böll Foundation).

Barrett, S. (2007), 'How not to repeat the mistakes of the Kyoto Protocol', Yale Global Online, accessed 18 March 2012.

Barry, C. (2005), 'Applying the contribution principle', Metaphilosophy, 36 (1-2), 21027. http://dx.doi.org/10.1111/j.1467-9973.2005.00363.x

BBC News (2003), 'NZ flatulence tax outrages farmers', BBC News, 20 June, 2003 http://news.bbc.co.uk/2/hi/asia-pacific/3005740.stm, accessed 12 March 2012.

Beckerman, W. and Pasek, J. (2001), Justice, Posterity, and the Environment (Oxford University Press). http://dx.doi.org/10.1093/0199245088.001.0001

Bell, D. (2011a), 'Does anthropogenic climate change violate human rights?', Critical Review of International Social and Political Philosophy, 14 (2), 99124. http://dx.doi.org/10.1080/13698230.2011.529703

--- (2011b), 'Global climate justice, historic emissions, and excusable ignorance', The Monist, 94 (3), 391-411. 
Benson, S. (2011), 'Tony Abbott would win an election in a landslide if it were held as voters oppose carbon tax', Daily Telegraph, 17 October 2011

Berners-Lee, M. (2011), How Bad are Bananas?: The Carbon Footprint of Everything (Vancouver: Greystone Books).

Boden, T.A., Marland, G., and Andres, R.J. (2011), 'Global, Regional, and National FossilFuel CO2 Emissions.', http://cdiac.ornl.gov/trends/emis/tre_glob_2008.html, accessed 3 March 2012.

Bovens, L. (2011), 'A Lockean defence of grandfathering emissions rights', in D.G. Arnold (ed.), The Ethics of Global Climate Change (Cambridge: Cambridge University Press). http://dx.doi.org/10.1017/CBO9780511732294.007

Boyle, A.E. (1990), 'State responsibility and international liability for injurious consequences of acts not prohibited by international law: a necessary distinction?', International and Comparative Law Quarterly, 39, 1, 1415. http://dx.doi.org/10.1093/iclqaj/39.1.1

--- (2005), 'Globalising environmental liability: the interplay of national and international law', Journal of Environmental Law, 17 (1), 326. http://dx.doi.org/10.1093/envlaw/eqi001

Brazilian Delegation to the UNFCCC (1997), Proposed Elements of a Protocol to the United Nations Framework Convention on Climate Change, available at http://unfccc.int/cop4/resource/docs/1997/agbm/misc01a3.htm

Report to the Economic and Social Research Council on Research by John Broome and David Ulph (Cambridge: White Horse).

--- (2010), 'The most important thing about climate change', in J. Boston, A. Bradstock, and D. Eng (eds.), Public Policy: Why Ethics Matters http://epress.anu.edu.au?p=80991 (ANU E-Press).

Butt, D. (2007), 'On benefiting from injustice', Canadian Journal of Philosophy, 37 (1), 12952. http://dx.doi.org/10.1353/cjp.2007.0010

Buxton, N. (2009), 'Bolivia responds to US on climate debt: "If you break it, you buy it"', Climate Justice Now. http://www.climate-justice-now.org/bolivia-responds-to-uson-climate-debt-if-you-break-it-you-buy-it/, accessed 31 January 2012.

Caney, S. (2005), 'Cosmopolitan justice, responsibility, and global climate change', Leiden Journal of International Law, 18 (4), 747-

75. http://dx.doi.org/10.1017/S0922156505002992

--- (2006), 'Environmental degradation, reparations, and the moral significance of history', Journal of Social Philosophy, 37 (3), 464-82. http://dx.doi.org/10.1111/j.14679833.2006.00348.x

--- (2009a), 'Justice and the distribution of greenhouse gas emissions', Journal of Global Ethics, 5 (2), 125-46. http://dx.doi.org/10.1080/17449620903110300

--- (2009b), 'Human rights, responsibilities and climate change', in C.R. Beitz (ed.), Global Basic Rights (Oxford: Oxford University Press). 
--- (2009c), 'Climate change and the future: discounting for time, wealth, and risk', Journal of Social Philosophy, 40 (2), 163-86. http://dx.doi.org/10.1111/j.14679833.2009.01445.x

--- (2010), 'Climate change and the duties of the advantaged', Critical Review of International Social and Political Philosophy, 13 (1), 203-

28. http://dx.doi.org/10.1080/13698230903326331

--- (2011), 'Climate change, energy rights and equality', in D.G. Arnold (ed.), Ethics of Global Climate Change (Cambridge: Cambridge University Press).

Caney, S. and Hepburn, C. (2011), 'Carbon trading: unethical, unjust and ineffective?', Royal Institute of Philosophy Supplement, 69, 201-

34. http://dx.doi.org/10.1017/S1358246111000282

Carson, R. (1962), Silent Spring (Greenwich: Fawcett Publications).

Central Intelligence Agency (2010), 'People and Society' The World Factbook, https://www.cia.gov/library/publications/the-world-factbook/geos/xx.html accessed 27 February 2010.

Climate Change Information New Zealand (2011), "About allocation in the ETS", Climate Change Information http://www.climatechange.govt.nz/emissions-tradingscheme/allocations/, accessed 22 February 2012.

Comission on Global Governance (1995), Our Global Neighbourhood (Oxford: Oxford University Press).

Cuming, V. (2011), 'Have Developed Nations Broken their Promise on \$30bn 'Fast-Start' Finance?', Bloomberg New Energy Finance White Paper, 5 September 2011, available online at http://www.newenergyfinance.com/WhitePapers/download/47 accessed 22 March 2012

Das, R. (in preparation), 'Has industrialization benefitted no-one? Climate change and the non-identity problem'.

de Geus, A. (1997), 'The living company', Harvard Business Review, 75 (2), 51-60.

Deffeyes, K.S. (2001), Hubbert's Peak: the Impending World Oil Shortage (Princeton, N.J.: Princeton University Press).

Defra (2008), 'Synthesis Report on the Findings from Defra's Pre-feasibility Study into Personal Carbon Trading', (London: Department for Environment, Food and Rural Affairs).

Dellink, R. and Den Elzen, M. (2009), 'Common but differentiated responsibilities for adaptation financing: an assessment of the contributions of countries', Institute for Environmental Studies (IVM) Working Paper (Amsterdam: Institute for Environmental Studies).

Déry, P. and Anderson, B. (2007), 'Peak phosphorus', Energy Bulletin, (August 13 2007), 113.

Doran, P. and Kendall-Zimmerman, M. (2009), 'Examining the scientific consensus on climate change', Eos, Transactions, American Geophysical Union, 90, 2223. http://dx.doi.org/10.1029/2009EO030002 
Draper, G., T. Vincent, M.E. Kroll, and J. Swanson. (2005), 'Childhood cancer in relation to distance from high voltage power lines in England and Wales: a case-control study', BMJ, 330 (7503), 1290-94. http://dx.doi.org/10.1136/bmj.330.7503.1290

Dworkin, R. (2004), 'Ronald Dworkin replies', in J. Burley (ed.), Dworkin and his Critics (Malden, MA: Blackwell), 337-95. http://dx.doi.org/10.1002/9780470996386.ch18

European Comission (2008), 'Questions and answers on the Commission's proposal to revise the EU Emissions Trading System ',

http://europa.eu/rapid/pressReleasesAction.do?reference=MEMO/08/35\&format= HTML\&aged=0\&language=EN\&guiLanguage=en, accessed 19 December 2011 .

European Environment Agency (2011), 'Annual European Community greenhouse gas inventory 1990-2009 and inventory report 2011 (Final draft) (Copenhagen: European Environmental Agency)', available at: http://www.eea.europa.eu/publications/european-union-greenhouse-gasinventory-2011, European Union (EU) (2004), 'Official directive 2004/35/ce of the European Parliament and of the Council of 21 April 2004 on environmental liability with regard to the prevention and remedying of environmental damage available at: http://eur-

lex.europa.eu/LexUriServ/LexUriServ.do?uri=OJ:L:2004:143:0056:0075:EN:PDF.

Ferguson, J. (2009), 'The Copenhagen summit: Possibly the most important meeting in the history of the world', The Daily Record, 4 December 2009, http://www.dailyrecord.co.uk/news/editors-choice/2009/12/04/the-copenhagensummit-possibly-the-most-important-in-the-history-of-the-world-86908-21872028/, accessed 10 March 2012.

Fullinwider, R.K. (1975), 'Preferential hiring and compensation', Social Theory and Practice, 3 (3), 307-20.

Gardiner, S. (2004), 'Ethics and global climate change', Ethics, 114 (3), 555600. http://dx.doi.org/10.1086/382247

--- (2006), 'A perfect moral storm: climate change, intergenerational ethics and the problem of moral corruption', Environmental Values, 15 (3), 397 413. http://dx.doi.org/10.3197/096327106778226293

--- (2011), 'Is no one responsible for global environmental tragedy? Climate change as a challenge to our ethical concepts', in D.G. Arnold (ed.), The Ethics of Global Climate Change (Cambridge: Cambridge University Press).

Gardiner, S., Caney, Simon, and Jamieson, Dale (eds.) (2010), Climate Ethics: Essential Readings (Oxford: Oxford University Press).

Gilbert, D. (2006), 'If only gay sex caused global warming', Los Angeles Times (2 July 2006) republished at http://www.randomhouse.com/kvpa/gilbert/blog/200607its_the_end_of_the_worl d_as_we.html, accessed 19 April 2012.

Gleick, P.H. and Palaniappan, M. (2010), 'Peak water limits to freshwater withdrawal and use', Proceedings of the National Academy of Sciences, 107 (25), 1115562. http://dx.doi.org/10.1073/pnas.1004812107 
Global Commons Institute (2011), 'The 'Contraction \& Convergence' campaign: a short summary', http://www.gci.org.uk/Documents/Campaign_Summary_.pdf, accessed March 272012.

Global Humanitarian Forum (2009), The Anatomy of a Silent Crisis, Global Impact Report (Geneva: Global Humanitarian Forum).

Gosseries, A. (2004), 'Historical emissions and free-riding', Ethical perspectives, 11 (1), 3660. http://dx.doi.org/10.2143/EP.11.1.504779

--- (2005), 'Cosmopolitan luck egalitarianism and climate change', Canadian Journal of Philosophy, 31 (5), 279-310.

Hansen, J., Sato, M., Kharecha, P. Russell, G. Lea, D.W. and Siddall M., (2007), 'Climate change and trace gases', Philosophical Transactions of the Royal Society A: Mathematical, Physical and Engineering Sciences, 365 (1856), 1925-

54. http://dx.doi.org/10.1098/rsta.2007.2052

Hardell, L., Carlberg, M., and Hansson Mild, K. (2009), 'Epidemiological evidence for an association between use of wireless phones and tumor diseases', Pathophysiology, 16 (2-3), 113-22. http://dx.doi.org/10.1016/j.pathophys.2009.01.003

Hardin, G. (1968), 'The tragedy of the commons', Science, 162 (3859), 124348. http://dx.doi.org/10.1126/science.162.3859.1243

Harding, P (ed.), (2011), 'Quotes Corner', http://www.philharding.net/quotescorner/quotes-corner-1sd.htm, accessed 25 April 2012.

Harrison, P. (2011), 'Europe and US in legal clash over airline emissions', Reuters US, July 12011 http://www.reuters.com/article/2011/07/01/uk-eu-climate-aviationidUSLNE76005120110701 accessed 13 January 2012

Hart, H.L.A. (1968), 'Prolegomenon to the principles of punishment', in Hart, H.L.A., Punishment and Responsibility: Essays in the Philosophy of Law (Oxford University Press), 1-27.

Hiller, A. (2011), 'Climate change and individual responsibility', The Monist, 94 (3), 349 68.

Hillman, M. and Fawcett, T. (2004), How We Can Save the Planet (London: Penguin Books).

Höhne, N., Hare, B., Schaeffer, M., Vieweg-Mersmann, M.,Rocha, M., Chen, C., Rogelj, J., Mengel, M. and Perrette, M., (2011), 'After Durban: Risk of delay In Raising Ambition Lowers Chances For $2^{\circ} \mathrm{C}$, while Heading for $3.5^{\circ} \mathrm{C}^{\prime}$, Climate Action Tracker Update, 11 December 2011, available at: http://climateactiontracker.org/assets/publications/briefing_papers/CAT_Durban_ update_2_20111211.pdf

Holcombe, R.G. (2006), 'Should we have acted thirty years ago to prevent global climate change?', Independent Review - Oakland, 11 (2), 283.

Houghton, R.A. (2008), 'Carbon flux to the atmosphere from land-use changes: 1850-2005', TRENDS: A Compendium of Data on Global Change (Oak Ridge: Carbon Dioxide Information Analysis Center, Oak Ridge National Laboratory, U.S. Department of Energy). 
Huntington, S.P. (1992), 'The clash of civilizations,' Foreign Affairs., 72, 2249. http://dx.doi.org/10.2307/20045621

International Energy Agency (IEA) (2011), 'CO2 Emissions From Fuel Combustion: Highlights', (Paris: International Energy Agency).

Jamieson, D. (2007), 'The moral and political challenges of climate change', in S.C. Moser and L. Dilling (eds.), Creating a Climate for Change (Cambridge: Cambridge University Press). http://dx.doi.org/10.1017/CBO9780511535871.033

--- (2008), Ethics and the Environment: An Introduction (Cambridge: Cambridge University Press).

--- (2010), 'Climate Change, Responsibility, and Justice', Science and Engineering Ethics, 16 (3), 431-45. http://dx.doi.org/10.1007/s11948-009-9174-x

Karoly, D. (2011), Climate futures and choices for society, Conference presentation, Climate Futures Conference, 31 March 2011, Wellington, available at: http://mdsweb.vuw.ac.nz/Mediasite/Viewer/Viewers/Viewer320TL.aspx?mode=D efault\&peid=f9fc576e-b2f4-4362-8af6-e88e29f7aa1e\&pid=bfd8dddf-a353-49af-803198435f4de4c0\&playerType=WM7\#, accessed 19 March 2012.

Ki-moon, B. (2009), 'Remarks at 39th plenary assembly of the World Federation of United Nations Associations', available at: http://www.un.org/apps/news/infocus/sgspeeches/search_full.asp?statID=555

Kingston, E. (2012), 'How much have dead people contributed to global warming? [dataset]', https://docs.google.com/open?id=0Bx6nBRS4AuwERnA2TFVET2NHRTA, accessed 11 April 2012.

Klass, A.B. (2004), 'From reservoirs to remediation: The impact of CERCLA on common law strict liability environmental claims', Wake Forest Law Review, 39, 903-70.

Layard, R., Clark, A., and Senik, C. (2012), "The causes of happiness and misery", in J. Helliwell, R. Layard, and J. Sachs (eds.), World Happiness Report (Columbia: Earth Institute).

Locke, J. (1956[1689]), The Second Treatise on Government (Oxford: Basil Blackwell) Manning, S. (2008), 'Year-by-year population estimates: 10,000 BC to 2007 AD. 12 January 2008', Historian on the Warpath http://www.scottmanning.com/content/year-byyear-world-population-estimates/, accessed 14 December 2011.

Maslanyj, M., Lightfoot, T., Schüz, J., Sienkiewicz, Z. and McKinlay, A., (2010), 'A precautionary public health protection strategy for the possible risk of childhood leukaemia from exposure to power frequency magnetic fields', BMC Public Health, 10 (1), 673-83. http://dx.doi.org/10.1186/1471-2458-10-673

Massachusetts Institute of Technology (MIT) (1970), Inadvertent Climate Modification: Report of the Study of Man's Impact on Climate (Cambridge, MA.: MIT Press).

McMichael, A, D.Campbell-Lendrum, S. Kovats, S. Edwards, P. Wilkinson, T. Wilson, R. Nicholls, S. Hales, F. Tanser, and D. Le Sueur, (2005), 'Global climate change', in M. Ezzati, A. D. Lopez, A. Rodgers and C. J. L. Murray, Comparative quantification of health risks: global and regional burden of diseases attributable to selected major risk factors (Geneva: World Health Organization). 
Meehl, G.A., T. F. Stocker, W. D. Collins, P. Friedlingstein, A. Gaye, J. M. Gregory, A. Kitoh, R. Knutti, J. M. Murphy, A. Noda, S. C. B. Raper, I. G. Watterson, W.A.J. and Z.-C. Zhao (2007), 'Global climate projections.', in Solomon, S., Qin, D., Manning, M., Chen, Z., Marquis, M., Averyt, K.B, Tignor, M. and Miller, H.L., (eds.), Climate Change 2007: The Physical Science Basis.Contribution of Working Group I to the Fourth Assessment Report of the Intergovernmental Panel on Climate Change (Cambridge: Cambridge University Press).

Mendelsohn, R.O. (2006), 'A critique of the Stern Report', Regulation, 29 (4), 42-46.

Miller, D. (2001), 'Distributing responsibilities', Journal of Political Philosophy, 9 (4), 45371. http://dx.doi.org/10.1111/1467-9760.00136

--- (2004), 'Holding nations responsible', Ethics, 114 (2), 24068. http://dx.doi.org/10.1086/379353 \

--- (2008), Global justice and climate change: How should responsibilities be distributed?, The Tanner Lectures on Human Values, available online at: http://www.tannerlectures.utah.edu/lectures/documents/Miller_08.pdf

Miller, R. (2010), Globalizing Justice: The Ethics of Poverty and Power (Oxford: Oxford University Press). http://dx.doi.org/10.1093/acprof:oso/9780199581986.001.0001

Ministerial Conference on Environment and Development (1991), 'Beijing Declaration on Environment and Development ', (UN Document A/CONF.151/PC/85).

Moellendorf, D. (2009), 'Treaty norms and climate change mitigation', Ethics $\mathcal{E}$ International Affairs, 23 (3), 247-65.

Natarajan, J. (2011), 'Speech at President's Informal Plenary COP17, Durban, 10 December 2011', http://unfccc4.metafusion.com/kongresse/cop17/templ/play.php?id_kongresssession=4735\&theme=un fccc. (21:40-29:00)

Neumayer, E. (2000), 'In defence of historical accountability for greenhouse gas emissions', Ecological Economics, 33 (2), 185-92. http://dx.doi.org/10.1016/S09218009(00)00135-X

Nolt, J. (2011), 'Greenhouse gas emissions and the domination of posterity', in D.G. Arnold (ed.), The Ethics of Global Climate Change (Cambridge: Cambridge University Press). http://dx.doi.org/10.1017/CBO9780511732294.004

Nordhaus, W.D. (2008), A Question of Balance: Weighing the Options on Global Warming Policies (New Haven: Yale University Press).

Norton, B.G. (1994), Toward Unity Among Environmentalists (Oxford: Oxford University Press.).

Organisation for Economic Cooperation and Development (OECD) (1974), The Polluter Pays Principle: Definition, Analysis, Implementation (Washington: Organisation for Economic Cooperation and Development).

---(2011), Development Aid Reaches an Historic High in 2010. (Paris: Organisation for Economic Cooperation and Development.) available at: http://www.oecd.org/document/35/0,3746,en_2649_34447_47515235_1_1_1_1,00.ht $\mathrm{ml}$. 
Oxfam International (2007), 'Adapting to Climate Change: What's Needed in Poor Countries and Who Should Pay', Oxfam Briefing Paper 104 (London: Oxfam International).

Pacala, S. and Socolow, R. (2004), 'Stabilization wedges: solving the climate problem for the next 50 years with current technologies', Science, 305 (5686), 968-

72. http://dx.doi.org/10.1126/science.1100103

Page, E. (2008), 'Distributing the burdens of climate change', Environmental Politics, 17

(4), 556-75. http://dx.doi.org/10.1080/09644010802193419

--- (2011a), 'Climatic justice and the fair distribution of atmospheric burdens: A conjunctive account', The Monist, 94 (3), 412-32.

--- (2011b), 'Cashing in on climate change: political theory and global emissions trading', Critical Review of International Social and Political Philosophy, 14 (2), 25979. http://dx.doi.org/10.1080/13698230.2011.529713

Palmer, C. (2011), 'Does nature matter? The place of the nonhuman in the ethics of climate change', in D. Arnold (ed.), The Ethics of Global Climate Change (Cambridge: Cambridge University Press). http://dx.doi.org/10.1017/CBO9780511732294.014

Parfit, D. (1984), Reasons and Persons (Oxford: Clarendon Press).

Parry, M., Canziani, O. Palutikof, J. and Co-authors (2007), 'Technical summary. climate change 2007: impacts, adaptation and vulnerability"', in Parry,M.L., Canziani, O.F., Palutikof, J.P., van der Linden, P.J. and Hanson, C.E., (eds.), Contribution of Working Group II to the Fourth Assessment Report of the Intergovernmental Panel on Climate Change (Cambridge: Cambridge University Press), 23-78.

Peterson, T.C., Connolley, W.M., and Fleck, J. (2008), 'The myth of the 1970s global cooling scientific consensus', Bulletin of the American Meteorological Society, 89 (9), 1325-37. http://dx.doi.org/10.1175/2008BAMS2370.1

Pew Center on Global Climate Change (2005), I, (Alexandria, VA: Pew Center on Global Climate Change).

Pogge, T. (2005), 'Severe poverty as a violation of negative duties', Ethics \& International Affairs, 19 (1), 55-83. http://dx.doi.org/10.1111/j.1747-7093.2005.tb00490.x

Poore, R.Z., Williams Jr, R.S., and Tracey, C. (2000), 'Sea level and climate', US Geological Survey Factsheet, 002-00.

Posner, E.A. and Weisbach, D. (2010), Climate Change Justice (Princeton, NJ: Princeton University Press).

Rawls, J. (1999), A Theory of Justice (Cambridge, MA: Belknap Press).

Seyfang, G. (2007), Personal Carbon Trading: Lessons from Complementary Currencies,

(Norwich: Centre for Social and Economic Research on the Global Environment, University of East Anglia)

Shakespeare, W.(1964 [1591]), Henry VI Part III ed. Cairncross, A.S (London: Methuen). Sherwood, S.C. and Huber, M. (2010), 'An adaptability limit to climate change due to heat stress', Proceedings of the National Academy of Sciences, 107 (21), 9552-

56. http://dx.doi.org/10.1073/pnas.0913352107 
Shue, H. (1993), 'Subsistence emissions and luxury emissions', Law \& Policy, 15, 39-

59. http://dx.doi.org/10.1111/j.1467-9930.1993.tb00093.x

--- (1999), 'Global environment and international inequality', International Affairs, 75 (3), 531-45. http://dx.doi.org/10.1111/1468-2346.00092

--- (2011), 'Human rights, climate change, and the trillionth tonne', in D. Arnold (ed.), The Ethics of Global Climate Change (Cambridge: Cambridge University Press).

Singer, P. (2004), One World: the Ethics of Globalization (New Haven: Yale University Press).

Sinnott-Armstrong, W. (2010), 'It's not my fault: global warming and individual moral obligations', in S. Gardiner, S. Caney, and D. Jamieson (eds.), Climate Ethics: Essential Readings (Oxford: Oxford University Press).

Solomon, S., Qin, D. Manning, M., Chen, Z., Marquis, M. Averyt, K. Tignor, M. and Miller, H. (2007), Contribution of Working Group I to the Fourth Assessment Report of the Intergovernmental Panel on Climate Change (Cambridge: IPCC. Cambridge University Press).

Stern, N.H. (2007), The Economics of Climate Change: the Stern Review (Cambridge: Cambridge University Press).

Stern, T. (2011), 'Durban: an important step forward in combating global climate change', Huffington Post, 16 December 2011, available at http://www.huffingtonpost.com/todd-d-stern/durban-climatetalks_b_1153721.html

Sunstein, C.R. (2005), Laws of Fear: Beyond the Precautionary Principle (Cambridge: Cambridge University Press). http://dx.doi.org/10.1017/CBO9780511790850

The Guardian (2011), 'Canada pulls out of Kyoto Protocol', The Guardian, December 13 2011, http://www.guardian.co.uk/environment/2011/dec/13/canada-pulls-outkyoto-protocol, accessed 24 February 2012.

Thomson, J.J. (1973), 'Preferential hiring', Philosophy \& Public Affairs, 2 (4), 364-84.

Tickell, O. (2008), Kyoto2: How to Manage the Global Greenhouse (London: Zed Books).

Traxler, M. (2002), 'Fair Chore Division for Climate Change', Social Theory and Practice: An International and Interdisciplinary Journal of Social Philosophy, 28 (1), 101-34.

UN Statistics Division (2012a), 'Total electricity', Energy Statistics Database http://data.un.org/Data.aspx?q=electricity+\&d=EDATA\&f=cmID\%3aEL, accessed 18 April 2012.

--- (2012b), 'Thermal electricity', Energy Statistics Database http://data.un.org/Data.aspx?q=electricity+thermal\&d=EDATA\&f=cmID\%3aET, accessed 18 April 2012.

United Nations Environment Program (2011), Bridging the Emissions Gap (Nairobi: United Nations Environment Program).

United Nations Framework Convention on Climate Change (UNFCCC) (1992), United Nations Framework Convention on Climate Change - Full Text. (Rio de Janiero: UNFCCC), available at:

http://unfccc.int/essential_background/convention/background/items/1355.php. 
--- (2009), Draft decision CP.15 Proposal by the President (Copenhagen Accord)

FCCC/CP/2009/L.7 (Copenhagen: UNFCCC), available at:

http://unfccc.int/resource/docs/2009/cop15/eng/107.pdf.

--- (2011), Outcome of the work of the Ad Hoc Working Group on Further Commitments for Annex I Parties under the Kyoto Protocol at its sixteenth session Draft decision /CMP.7 (Durban: UNFCCC)', available at:

http://unfccc.int/files/meetings/durban_nov_2011/decisions/application/pdf/awgk p_outcome.pdf.

--- (2011), Establishment of an Ad Hoc Working Group on the Durban Platform for Enhanced Action. Draft decision -/CP.17' (Durban: UNFCCC), available at: http://unfccc.int/files/meetings/durban_nov_2011/decisions/application/pdf/cop17 _durbanplatform.pdf.

United States Census Bureau (2012), 'International Database: World Population by Age and Sex. ', United States Census Bureau Website http://www.census.gov/population/international/data/idb/worldpop.php, accessed 18 April 2012.

Van Deusen, J.G. (1936), 'The negro in politics', The Journal of Negro History, 21 (3), 25674. http://dx.doi.org/10.2307/2714617

Weart, S. (2011), 'Milestones ', The Discovery of Global Warming http://www.aip.org/history/climate/timeline.htm\#T021, accessed 31 January 2012.

--- (2011), 'Simple Models of Climate Change', The Discovery of Global Warming http://www.aip.org/history/climate/simple.htm, accessed 31 January 2012.

Weijers, D., Das, R., and Eng, D. (2010), 'Sharing the responsibility of dealing with climate change: Interpreting the principle of common but differentiated responsibilities', in J. Boston, A. Bradstock, and D. Eng (eds.), Public Policy: Why Ethics Matters http://epress.anu.edu.au? $\mathrm{p}=80991$ (ANU E Press).

Weitzman, M.L. (2009), 'On modeling and interpreting the economics of catastrophic climate change', The Review of Economics and Statistics, 91 (1), 119. http://dx.doi.org/10.1162/rest.91.1.1

Whitman, W. (1999 [1888]) Leaves of Grass [online text], Project Gutenberg http://www.gutenberg.org/catalog/world/readfile?fk_files=2209237

Wolfram Alpha (2012), ' World Population', Wolfram Alpha knowledgebase, http://www.wolframalpha.com/input/?i=world+population+1947 accessed 18 April 2012.

World Bank (2005), World Development Indicators (Washington, DC: World Bank).

Xie, Z. (2011), 'Speech at President's Informal Plenary COP17, Durban, 10 December 2011', http://unfccc4.metafusion.com/kongresse/cop17/templ/play.php?id_kongresssession=4735\&theme=un fccc, accessed 19 February, 2012. (47:10- 50:30)

Yale Project on Climate Change Communication (2011), Politics and Global Warming: Democrats, Republicans, Independents and the Tea Party, (New Haven: Yale Project on Climate Change Communication). 